\title{
Coating studies and video imaging of the flow patterns of tablets in a semi-circular fluidized bed
}

\author{
Ganeshkumar A. Subramanian \\ West Virginia University
}

Follow this and additional works at: https://researchrepository.wvu.edu/etd

\section{Recommended Citation}

Subramanian, Ganeshkumar A., "Coating studies and video imaging of the flow patterns of tablets in a semi-circular fluidized bed" (2001). Graduate Theses, Dissertations, and Problem Reports. 1175.

https://researchrepository.wvu.edu/etd/1175

This Thesis is protected by copyright and/or related rights. It has been brought to you by the The Research Repository @ WVU with permission from the rights-holder(s). You are free to use this Thesis in any way that is permitted by the copyright and related rights legislation that applies to your use. For other uses you must obtain permission from the rights-holder(s) directly, unless additional rights are indicated by a Creative Commons license in the record and/ or on the work itself. This Thesis has been accepted for inclusion in WVU Graduate Theses, Dissertations, and Problem Reports collection by an authorized administrator of The Research Repository @ WVU. For more information, please contact researchrepository@mail.wvu.edu. 


\title{
Coating Studies and Video Imaging of the Flow Patterns of Tablets in a Semi-Circular Fluidized Bed
}

\author{
Ganeshkumar A. Subramanian \\ THESIS \\ Submitted to the College of Engineering and Mineral Resources \\ at West Virginia University \\ In partial fulfillment of the requirements \\ for the degree of \\ Master of Science \\ in \\ Chemical Engineering
}

\author{
Richard Turton, Ph.D., Chair \\ Eugene V. Cilento, Ph.D. \\ Aubrey L. Miller, Ph.D. \\ Department of Chemical Engineering \\ Morgantown, West Virginia \\ 2001
}

Keywords: Particle Coating, Wurster bed, Fluidization, Velocity and Voidage Profile, Video Imaging, Inserts, Coating Variation. 


\title{
ABSTRACT \\ Coating Studies and Video Imaging of the Flow Patterns of Tablets in a Semi- Circular Fluidized Bed
}

\author{
Ganeshkumar A. Subramanian
}

Particle coating is of increasing interest in the Pharmaceutical Industry, with more and more manufacturers moving towards production of tablets with layers of coating. When a tablet is coated with a drug, the amount of coating that each tablet possesses becomes very critical, as it constitutes the total dosage. The amount and consistency of drug coated on the tablet depends on the dynamics of the tablet in the vicinity of the spray zone.

The objective of this work was to study the dynamics of particle motion (large place bo tabiets, $8 \mathrm{~mm}$ diameter and sphericity factor, $\phi \neq 1$ ) in the vicinity of the spray zone of a semi-circular Wurster bed coater. A novel method of computer based video imaging was used to measure the velocity and voidage profiles in the draft tube region of the semi-circular fluidized bed coater. Continuous and pulse coating runs were performed to study the variation in coating consistency. This variation was explained in-terms of coating-per-pass variation and the cycle time variation. Inserts iwere used to alter the voidage profile around the spray nozzle and the coating runs were used to study their effect on the coating consistency.

The experimental set-up consists of two cameras connected to separate framegrabbing boards that are in turn connected to a computer. Software written in Visual Basic 6.0 controls the triggering of the cameras and retrieving of images from the frame grabber to the computer screen. For velocity measurements, the time lag between the cameras was set to a known value and the relative distance moved by the particle, in both the $\mathrm{x}$ and $\mathrm{y}$ directions, was measured with the help of computer-generated crosshair. Using this technique, the velocity vector was determined, in both the vertical and horizontal plane. For voidage measurements, the number of tablets in the area of focus was determined, and the depth of field obtained from previously calibrated values. By using these values, with the known tablet volume in a given volume of bed, void volume in the bed was calculated. By repeating this process across the bed, the voidage profile was obtained.

Velocity and voidage profiles were found to be consistent with visual observations. The parameters that were investigated included air velocity, gap height ! (height between the draft tube and the distributor), 'idistributor plate design, and the use of guides or inserts to direct particle movement from the annulus into the draft tube. The rationale behind the use of these inserts (deflectors) was to provide a smooth path that 
would guide the radially inward moving particles away from the spray nozzle. This prevents the tablets from flowing directly over the spray nozzle and thus prevents the local wetting of a small portion of the particles. For the coating runs, FD\&C Blue Dye No.1 dissolved in aqueous-based polymeric dispersion was used. After the coating experiment, 100 tablets picked at random were analyzed for their blue dye content and the data analyzed statistically.

The experimental data show that video-imaging techniques can be used to estimate velocity and voidage profiles in a semi-circular fluidized bed. These profiles are presented as maps in the draft tube region. The results showed that the major cause for variation in coating consistency was due to variation in the amount of coating received by tablets during each pass and that by reducing this variation, by reducing the, sheltering phenomena, the overall coating consistency was improved. 


\section{ACKNOWLEDGEMENTS}

I wish to express my sincerest gratitude to my advisor Dr. Richard Turton for his guidance, advice and encouragement during the course of this work. It has been a great pleasure and honor to work with such a gifted researcher and wonderful person.

I would like to express my gratitude to the members of my advisory committee, Dr Eugene V. Cilento and Dr. Aubrey Miller for their useful comments and suggestions on the work. I would like to specially thank Dr. Cilento for spending some of his valuable time helping me with statistical analysis of experimental data. I am also thankful to all the faculty and graduate student in the Department of Chemical Engineering, especially Aashish Bhattia, for his valuable discussions while sharing the same laboratory and some equipment with me. I would also like to make a special mention of Neeraj Pugalia, Balakrishnan. A, Jarod Macormick and Sandeepa Sandadi for their valuable inputs and help.

My sincere thanks to Mr. Jim Hall, without whose help and support this work would not have been possible. He fabricated the fluidized bed and the various modifications/inserts used during this work. I also thank Ms. Linda Rogers and Ms. Bonita Helmick for all the help in handling the paper work and being great friends. I wish to thank Mr. Luke Flemmer of Peltec Inc., for providing the software and also helping me getting started with using the same. 
I wish to thank Merck and Co., Inc for sponsoring this project and extending the financial support to finish the final experimental runs.

I wish to thank my parents Mr. Subramanian and Mrs. Anasuya Subramanian, my brother and sister for their unconditional love and support. Words cannot describe the love, patience, support and encouragement they have give me throughout this work and my life.

I finally like to thank God almighty, and dedicate this work to the people who have had a profound impact on my life, my advisor Dr. Richard Turton, and my parents. 


\section{Table of Contents}

CHAPTER I: INTRODUCTION

1-1 An overview of fluidization technology 1

1-2 Fluidization applied to pharmaceutical coatings 2

1-3 Objective of this work $\quad 5$

CHAPTER II: LITERATURE REVIEW 8

2-1 An overview of spouted fluidized bed 8

2-2 Techniques used to study particle motion within a bed 8

2-3 An overview of draft-tube equipped bed 11

2-4 The hydrodynamics within the spray zone of a fluidized bed $\begin{array}{ll}\text { coating device } & 13\end{array}$

2-5 Application of fluidized bed coating to obtain controlled/sustained and sequential release drugs

$\begin{array}{ll}\text { CHAPTER III: EXPERIMENTAL METHOD } & 18\end{array}$

3-1 Description of the experimental set-up and equipment 18

3-2 Design of Deflectors 29

3-3 Measurement techniques and equipment used 34

3-4 Calibration of video imaging system 38

3-5 Principles of velocity measurement 40

3-6 Principle of voidage measurement 42

3-7 Objective of Coating experiments 47

3-8 Determining the coating formula 48

3-9 Coating experiments 49

3-9.1 Continuous coating Experiments 49 
3-9.3 Pulse coating test

3-9.4 Method of coating for pulse tests

3-10 Analysis of coated tablets

3-10.1 Analysis of continuous coating runs

3-10.2 Analysis for pulse test runs

4-1. Velocity measurement in the draft-tube region

4-1.1 Velocity profiles in the draft-tube

4-1.2 Velocity measurements in the annulus

4-2. Voidage Measurement

4-2.1 Voidage measurement in draft-tube

72

4-2.2 Voidage measurement in the annulus

4-3 Mass balance between solid mass flow rate in the spout and annulus

4.5 Results of the Coating Experimental runs

4-5.1 Continuous coating runs 


\section{APPENDICES}

Appendix I. Orifice plate calibration and flow measurement.

Appendix II. Measurement of annulus voidage.

Appendix III. Calibration of velocity measurement technique using disk rotating at know velocity and strobe.

Appendix IV. Apparent Depth of field calibration (ADOF).

Appendix V. Alignment of cameras and calibration of pixel size.

Appendix VI. Velocity vector and voidage calculation.

Appendix VII Scanning spectra of Blue Dye \# 1 in Water.

Appendix VIII Data for calibration of the Spectrometer and the calibration curve higher concentrations.

Appendix IX Data for calibration of the spectrophotometer and the calibration curve for very low concentrations.

Appendix X Determination of Coating Formula.

Appendix XI Coating efficiency calculation

Appendix XII Calibration of the peristaltic pump used for pumping the coating solution.

Appendix XIII Calculation of amount of blue dye coated during the pulse test.

Appendix XIV Obtaining values for voidage by linear interpolation.

Appendix XV Solids Mass flow calculations in the draft-tube and annulus.

Appendix XVI Photographs of the Fluidized Bed

Appendix XVII Photographs of the Distributor plates 


\section{LIST OF TABLES}

Table

Page

3-1. Experimental matrix for the velocity and voidage profile study.

3-2. Experimental matrix for coating consistency study.

3-3. Operating parameters for the continuous coating runs.

3-4. Operating parameters for the pulse test runs.

4-1. $\quad$ STD, Mean, RSD and \% Efficiency on the amount of coating tablets received with the use of different deflectors.

4-2. $\quad$ STD, Mean and RSD on the amount of coating tablets received per-pass with no deflector and with the optimum deflector.

4-3. Average $\mathrm{RSD}_{\text {per-pass }}$ values of the 10 groups formed form the total sample population of 100 optimum deflector.

4-4. $\quad$ Average $\mathrm{RSD}_{\text {total }}$ values of the 10 groups formed form the total sample population of 100 for optimum deflector.

4-5. Average $\mathrm{RSD}_{\text {per-pass }}$ values of the 10 groups formed form the total sample population of 100 for no deflector.

4-6. Average $\mathrm{RSD}_{\text {per-pass }}$ values of the 10 groups formed form the total sample population of 100 no deflector.

4-7. Consolidated results of coating experiments. 


\section{LIST OF FIGURES}

Figures

Page

1-1. Bottom-spray Wurster coater (Glatt Air Techniques) Mehta etal $1986 . \quad 4$

3-1. Schematic diagram of the semi-circular spouted bed coating device. 21

3-2. Diagram showing the dimensions of the semi-circular column of the bed. 22

3-3. Photograph of the fluidized bed with the two-camera set-up. 23

3-4a,b. Schematic showing the low and high gap height between the $\begin{array}{ll}\text { distributor plate and the draft-tube, respectively. } & 24\end{array}$

3-5. Flow diagram of the experimental setup 26

3-6. Schematic diagram of the fluidized bed video imaging system 27

3-7. Photograph of the tablet used in the study. 28

3-8a. Schematic diagram of deflector 1 . The arrows show the direction of deflection of the tablets. 30

3-8b. Photograph of deflector 1 mounted on distributor plate. 30

3-9a. Schematic diagram of modified deflector 1 . The arrows show the direction of deflection of the tablets.

3-9b. Photograph of modified deflector 1.

3-10. Schematic diagram of modified deflector 2. The arrows show the direction of deflection of the tablets.

3-11. Schematic diagram of modified deflector 3. The arrows show the direction of deflection of the tablets.

3-12a. Schematic diagram of optimum deflector. The arrows show the direction of deflection of the tablets.

3-12b. Photograph of optimum deflector mounted on the distributor plate.

3-12c. Photograph of optimum deflector mounted on the distributor plate. 
3-13. Schematic diagram showing an image/frame formed by two fields taken with a standard RS-170 interlaced video format (time lag of $16.67 \mathrm{~ms}$ ) and spliced together to form the image.

3-14. Schematic diagram showing an image/frame formed by two fields taken with a standard RS-170 interlaced video format (time lag of $16.67 \mathrm{~ms}$ ) being split into two fields odd and even.

3-15. Illustration of Stereoscopic Imaging using Two Identical cameras and Imaging Boards.

3-16. Two cameras set-up on the steep sides of an isosceles triangle.

3-17. Photographs of models made to determine depth of field of the camera.

3-18. Photographs of still images of particles in motion as seen on the computer monitor. The hairlines shows the distance moved by the center of the particle.

3-19. A schematic showing the directions of the velocity vector measured.

3-20. Arrangement of light and cameras for the experimental runs.

3-21. Sequence of events before the particles are picked up for voidage measurement.

4-1. Diagram showing the relative position of the distributor plate, deflector, nozzle and the imaginary grid for the case with deflector 1 and lower gap height $(2.5 \mathrm{~cm})$

4-2a,b. Radial particle velocity profile along the height in the draft-tube with no deflector and gap heights of $2.5 \mathrm{~cm}$ and $6.8 \mathrm{~cm}$, respectively.

4-3a,b. Radial particle velocity profile along the height in the draft-tube with deflector 1 and gap heights of $2.5 \mathrm{~cm}$ and $6.8 \mathrm{~cm}$, respectively.

4-4a,b. Radial particle velocity profile along the height in the draft-tube with deflector 1 and gap heights of $2.5 \mathrm{~cm}$ and $6.8 \mathrm{~cm}$, respectively.

4-5a,b. Radial particle velocity profile along the height in the draft-tube with modified deflector 1 and gap heights of $2.5 \mathrm{~cm}$ and $6.8 \mathrm{~cm}$, respectively. 57

4-6. Particle velocity map in the draft-tube at different axial location for the bed with distributor1, no deflector and gap height $2.5 \mathrm{~cm}$.

4-7. Particle velocity map in the draft-tube at different axial location for the 
bed with distributor1, no deflector and gap height $6.8 \mathrm{~cm}$.

4-8. Particle velocity map in the draft-tube at different axial location for the bed with distributor 1 , deflector 1 and gap height $2.5 \mathrm{~cm}$.

4-9. Particle velocity map in the draft-tube at different axial location for the bed with distributor 1, deflector 1 and gap height $6.8 \mathrm{~cm}$.

4-10. Particle velocity map in the draft-tube at different axial location for the bed with distributor 1 , modified deflector 1 and gap height $2.5 \mathrm{~cm}$.

4-11. Particle velocity map in the draft-tube at different axial location for the bed with distributor 1 , modified deflector 1 and gap height $6.8 \mathrm{~cm}$.

4-12a,b. Radial particle velocity profile along the height in the draft-tube with modified deflector 1and gap heights $2.5 \mathrm{~cm}$ and $6.8 \mathrm{~cm}$ respectively.

4-13a,b. Radial particle velocity profile along the height in the draft-tube with modified deflector 1and gap heights $2.5 \mathrm{~cm}$ and $6.8 \mathrm{~cm}$ respectively.

4-14. Particle velocity map in the draft-tube at different axial location for the bed with distributor 2 , no deflector and gap height $6.8 \mathrm{~cm}$.

4-15. Particle velocity map in the draft-tube at different axial location for the bed with distributor 1, modified deflector 1, gap height $6.8 \mathrm{~cm}$ and high airflow rate.

4-16. Graph showing a plot of annular velocity at different gap heights above distributor plate for the three cases of with/without deflector and modified deflector 1.

4-17a,b. Radial particle voidage profile along the height in the draft-tube with no deflector and gap heights $2.5 \mathrm{~cm}$ and $6.8 \mathrm{~cm}$ respectively.

4-18a,b. Radial particle voidage profile along the height in the draft-tube with deflector 1 and gap heights $2.5 \mathrm{~cm}$ and $6.8 \mathrm{~cm}$ respectively.

4-19a,b. Radial particle voidage profile along the height in the draft-tube with 
deflector 1 and gap heights $2.5 \mathrm{~cm}$ and $6.8 \mathrm{~cm}$ respectively.

4-20a,b. Radial particle voidage profile along the height in the draft-tube with modified deflector 1and gap heights $2.5 \mathrm{~cm}$ and $6.8 \mathrm{~cm}$ respectively.

4-21. Voidage map in the draft-tube at different axial location for the bed with distributor 1, no deflector and gap height $2.5 \mathrm{~cm}$.

4-22. Voidage map in the draft-tube at different axial location for the bed with distributor 1, deflector 1 and gap height $2.5 \mathrm{~cm}$.

4-23. Voidage map in the draft-tube at different axial location for the bed with distributor 1 , modified deflector 1 and gap height $2.5 \mathrm{~cm}$.

4-24. Voidage map in the draft-tube at different axial location for the bed with distributor 1, no deflector and gap height $6.8 \mathrm{~cm}$.

4-25. Voidage map in the draft-tube at different axial location for the bed with distributor 1, deflector 1 and gap height $6.8 \mathrm{~cm}$.

4-26. Voidage map in the draft-tube at different axial location for the bed with distributor 1, modified deflector 1 and gap height $6.8 \mathrm{~cm}$.

4-27. Plot of mass-flux in the annulus vs. mass-flux in the draft-tube for the eight different experimental variations.

4-28. The basic process involved during particle coating in a fluidized bed coater.

4-29. A schematic diagram showing the sheltering effect. The tablet closer to the nozzle blocks the coating solution from reaching the tablets that are away from the nozzle.

4-30. Schematic representation of the sources of variation in a fluidized 
bed coating process and the type of variation obtained for each

individual source.

4-31. Frequency plot of amount of blue dye coated on tablets during the continuous coating runs, with the different deflector designs.

4-32a,b. Frequency plot for the pulse test, with optimum deflector and no deflector, respectively.

4-33. Frequency plot of $\left(\bar{x} / S_{\mathrm{x}}\right)$ for the pulse test, with optimum deflector.

4-34. Frequency plot of $\left(\bar{x} / S_{x}\right)$ for the continuous coating experiments, with optimum deflector.

4-35. Frequency plot of $\left(\bar{x} / S_{\mathrm{x}}\right)$ for the pulse test, with no deflector.

4-36. Frequency plot of $\left(\bar{x} / S_{\mathrm{x}}\right)$ for the continuous coating run, with no deflector. 106

6-1. Diagram showing alterations made to the draft-tube. 


\section{INTRODUCTION}

\section{CHAPTER I}

\section{1-1 An overview of Fluidization Technology}

Fluidization is an operation in which a bed of solid particles is suspended by the fluidizing medium, which may be a gas or liquid, passing through the column containing the particles. These particles begin to fluidize when the weight of the particles are balanced by the drag force of the fluid flowing through them and at this state the bed of solids behaves in some ways like a fluid. Gas-solid systems are more common than liquid-solid systems and are widely used in many commercial processes such as gasification of coal, drying of food grains, mixing of powdery material, granulating fine solids, coating in the pharmaceutical industry.

The first large scale, commercially significant use of fluidized beds was by Fritz Winkler (Kunii and Levenspiel, 1969) for the gasification of powdered coal in 1926. Fluid Catalytic Cracking (FCC) in the 1940's was a major breakthrough in the manufacture of high-octane aviation gasoline, which played a very critical role in World War II (Kunii and Levenspiel, 1969). Since then fluidized bed technology has made vast strides and has been used in a variety of industries from mineral processing to the manufacture of coated tablets in the pharmaceutical industry.

In this work, we have concentrated on the use of fluidized bed coating techniques in the pharmaceutical industry. This technique has been widely used not only for functional coating and drug applications (Wurster, 1959; Singiser and Lowenbthal, 1961; Caldwell and Rosen, 1964; Robinson et al., 1968), but also for granulation (Rankell, et al., 1964; Scott et al., 1964; Davies and Gloor, 1971, 1972) and drying (Scott et al., 1963; and Zoglio et al., 1975). For example, tablets may be coated in a fluidized bed to alter the 
drug release rate (controlled-release dosage forms) or the drug release site (enteric coated tablets) and both these coatings can be applied in a fluidized bed coater.

\section{1-2. Fluidization Applied to Pharmaceutical Coatings}

The coating of tablets is a critical, as well as costly step in the manufacturing process of solid dosage forms. Tablets may be coated for the following reasons:

- $\quad$ to mask any unpleasant taste or objectionable odor of the drug

- to improve pharmaceutical elegance by coating to give special colors or textures

- $\quad$ to control the release rate of drug by coating a layer of polymer on the drug

- to protect the drug through first pass metabolism thus controlling the site of drug release

- to incorporate another drug or excipient in the coating to avoid chemical incompatibility, or provide sequential release of drugs

- $\quad$ to mark for product identification (Lehmann and Dreher, 1981; Cheng, 1993; and Rocha, et al., 1995)

In 1989, more than two-thirds of the \$20-billion annual U.S. drug market consists of orally administered drugs, more than $85 \%$ of which are delivered as solid dosage forms (Rekhi et al.1989). Currently, solid drug dosage forms can be classified into four different forms namely tablets, capsules, pills, lozengers and suppositories. In the case of a capsule, the drug is in the form of small particles that may be individually coated and housed in a capsule of gelatin or similar material. Here the amount of drug coating that a single particle possesses is not very critical, since the dosage will be an integral of the 
amount of drug on all particles. In the case of a single tablet coated with a drug, the amount of coating that each tablet possesses becomes very crucial, as it constitutes the total dosage.

Traditionally, tablets were coated in pan coaters and these rotating devices have been used in the pharmaceutical industry since the mid-1800's. However, this equipment has some inherent problems such as lengthy processing time, the need for skilled operator supervision, and high energy for operation. Moreover, there is considerable variation in product quality because of the inherent dead zones in the pan coater. With the abovementioned disadvantages of pan coating processes, newer processes for coating were developed. Some of the commonly used commercial devices are coacervation tanks, compression coating machines, and fluidized and spouted bed coaters.

Wurster, in 1950, was the first to introduce the process of coating drug formulations using fluidized beds. Since then, there have been significant improvements in this method of dosage form manufacture. The fluidized bed coating method has several advantages over other conventional coating methods. The process provides intimate contact between the fluidizing medium and the fluidized particles, resulting in high rates of heat and mass transfer and reduced processing time. In a Wurster bed coater, shown in Figure 1-1 (Wurster, 1953) a bed of tablets is fluidized by a stream of air, supplied by a blower, passing through a distributor plate at the bottom of the bed. The distributor plate is designed such that the airflow at the center of the bed is much higher than that in the annular region. This design, along with the presence of an insert, causes the particles to flow upwards in the form of a spout in the center of the bed and move down slowly in the annular region. The nozzle is located in the center of the bed, just above the distributor 
plate. The coating solution, sprayed in the form of fine droplets, comes in contact with the fast, upward-moving tablets and is dried by the fluidizing air before the particles complete the cyclic movement and re-enter the spray zone. The intensive motion of the particles ensures a uniform coating distribution and reduces the tendency to agglomerate. Another advantage of fluidized bed coating is that particles of any shape can be coated and the process is highly reproducible and reliable.

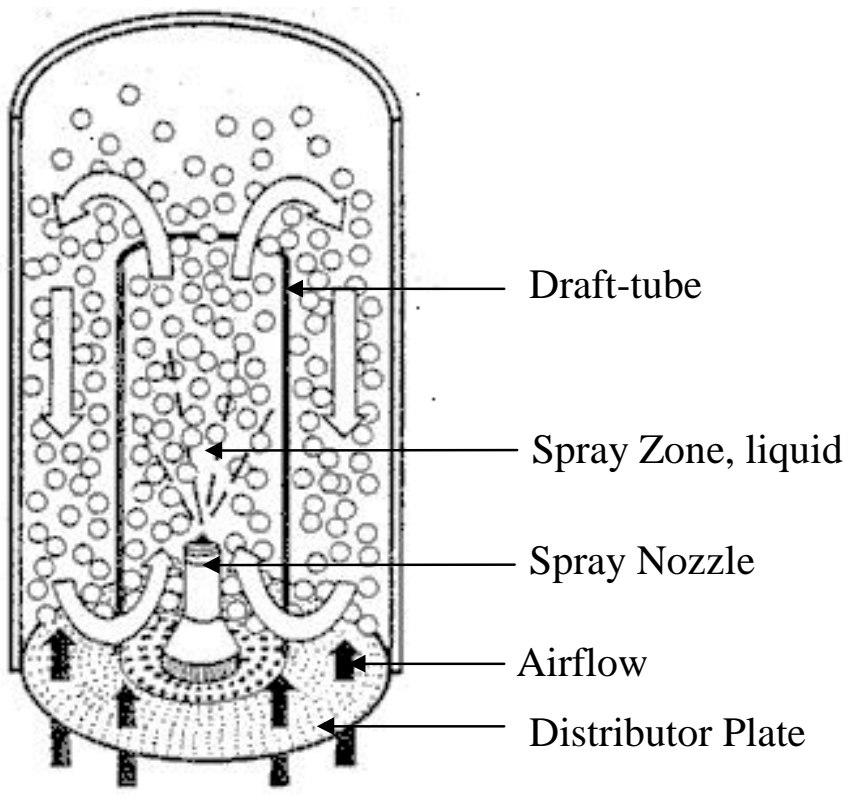

Figure 1-1. Bottom-spray Wurster coater (Glatt Air Techniques) Mehta etal 1986.

Traditionally solvent-based coating systems have been used. However, in the early 80 's aqueous-based coating systems gained popularity over the solvent based systems and have slowly been replacing organic based systems (Chang, et al., 1987; Ghebre-Sellassie, et al., 1988; Rekhi, et al.1989; and Wan and Lai, 1991). There were two main reasons for this change: (1) cost of organic solvents increased dramatically with 
the government introducing new regulations concerning these solvents, and (2) Environmental Protection Agency (EPA) became increasingly stringent on solvent and solvent-vapor discharge to the environment. Aqueous polymeric coating has several advantages over solvent-based coating. Aqueous based coating systems are less expensive, hazard of explosion is negligible, potential for toxicity and problems controlling vapor emissions into the atmosphere is very low. Aqueous based coating systems also have some inherent disadvantages: (1) tablet appearance is usually inferior, (2) selection of coating material is limited to those which are water soluble or water dispersible, (3) water has an adverse effect on many active ingredients and (4) water is less volatile and hence requires more energy to evaporate and dry. However, the advantages out-weigh the disadvantages and many solvent-based coating systems have given way to aqueous polymeric coating systems. With aqueous based systems gaining popularity, fluidized bed coating is the preferred process, as it provides excellent drying efficiency and product uniformity.

\section{1-3. Objective of this work}

Several researchers have worked in the area of fluidized bed coating for pharmaceutical applications. Different techniques have been used to study the hydrodynamics of a semi-circular fluidized bed Wurster coater. Still there has not been much work done addressing the particle velocity and voidage profiles across the entire draft-tube region. Saadevandi and Turton (1996) used video imaging techniques to study the hydrodynamics of particle motion in the spray zone of a fluidized bed and the effect of liquid spray on the voidage and velocity profiles in the spray region. They used smaller 
spherical particles (1mm diameter) with lower bed loadings and were able to measure the velocity and voidage profiles in the draft-tube region of a semi-circular draft-tube equipped fluidized bed coater.

Cheng and Turton (1993) observed that the variation in coating in a Wurster bed coater can be attributed to two factors: (1) coating variation per pass through the spray zone, and (2) variation in the number of times the particle passes through the spray zone. They developed a phenomenological model to determine the variation in the coating received based on the above two factors. Cheng (1993) also talks about the sheltering effect that a particle close to the spray source or nozzle has on a particle further away from the nozzle. Shelukar et al. (2000), conducted experiments to determine the variation in coating-per-pass and variation in total coating received based on the above observation of the sheltering effect and have quantified this variation. The above-mentioned work emphasizes the importance of reducing the variation in per pass coating received and reducing the variation in cycle time distribution. The video imaging technique used also showed that the particles moved close to the nozzle causing the sheltering effect to have a pronounced effect on the coating consistency. The above results and the interest to minimize the variation in the coating consistency is the driving force behind this research. This work can be considered as an extension of the work done by Saadevandi and Turton (1996) and Cheng and Turton (1993).

The objective of this research was to investigate the hydrodynamics of fluidized particles (large placebo tablets, $8 \mathrm{~mm}$ diameter and $5 \mathrm{~mm}$ thick) passing through the spray zone in a semicircular fluidized bed coating device. In addition, the factors that affect the flow pattern, circulation rate, coating consistency and variation were to be evaluated. 
Factors such as distributor design, fluidizing air velocity, gap height (height between distributor and insert), and particle size have been investigated. Since the particles were not spherical, the task of making velocity and voidage measurements was complex as the orientation of the particle was an important factor to be considered. A databank of particle velocity and voidage measurements, for a variety of operating conditions in the bed, was obtained and profiles plotted using custom-written software in Microsoft Visual Basic. Computer based video imaging techniques were used to measure the velocity and voidage profiles in the draft-tube region of the fluidized bed. Some of the parameters investigated were fluidizing air velocity, gap height (height between the draft-tube and the distributor), distributor plate design, and the use of guides or inserts to direct particles from entering the spray zone directly above the nozzle. The use of deflectors was expected to improve the coating consistency, as it would reduce the effect of particle sheltering in the spray zone. The study of the use of guidesldeflectors to alter the voidage in the immediate vicinity of the spray zone and thereby reduce the sheltering effect was the first of its kind.

Actual coating experiments were conducted with and without the use of deflectors to quantify the effect of these devices on coating consistency. Efforts were also made to quantify the variation in coating received by particles in a single pass through the spray zone with the help of pulse tests. 


\section{CHAPTER II}

\section{Literature Review}

\subsection{An Overview of Spouted Fluidized Beds}

Spouted beds have been widely employed in a variety of industrial processes. In these processes, gas is introduced at high velocities into the bottom of the bed and forms a spout of gas and solid particles in the center of the bed. The solid particles move up rapidly in the center, while the particles in the sides form an annular dense bed, which moves downward. The solids are entrained from the annular bed into the spout causing the circulation of particles within the bed. The upward movement of the spout stabilizes the bed. These types of beds are known as conventional spouted beds. Mathur and Gishler (1955) first developed the spouted bed technique and showed the existence of a maximum spoutable bed depth, $\mathrm{H}_{\mathrm{m}}$, and a minimum superficial velocity for spouting, $\mathrm{U}_{\mathrm{s}}$. They also showed that both these quantities were complex functions of fluid properties, particle size and bed geometry.

\subsection{Techniques used to study particle motion within a bed}

Several techniques have been used in the past to study the particle motion and voidage profiles in a fluidized bed. A brief review is given here. High-speed photography can be used to study the particle motion within a bed, though it is restricted to the region near the wall. Toomey and Johnstone (1955) were the first to use this technique to study the particle motion in a metal column fitted with a window. Todd et al. (1957) used the same technique to study the flow dynamics in a two dimensional bed. Massimilla and Westwater (1960) used motion pictures at 2000 frames/sec to measure the movement of 
individual particles and gas bubbles in a fluidized bed. Air was the fluidizing medium and the particles studied were 0.028 in. glass spheres and 200-mesh alumina particles in a 3.75 in. semi-cylindrical glass column. They observed that aggregates were very common and particles and aggregates showed pronounced alternations of fast and slow movement in the upward and downward direction near the wall. They also studied the effect of baffles and observed that baffles increased bed density and reduced particle velocity. Small bubbles rose rapidly with little change while large cavities were slow and tended to collapse and reform elsewhere.

Lefroy and Davidson (1969) measured maximum spoutable bed depth; $\mathrm{H}_{\mathrm{m}}$ and overall pressure drop with bed dimensions ranging from $7.6 \mathrm{~cm}$ to $61 \mathrm{~cm}$ in diameter. They observed that a spouted bed in a half cylinder behaved similarly to a fully cylindrical bed of the same diameter, and they were able to measure the spout diameter $D_{s}$. Van Velzen et al. (1974) investigated solids movement in a spouted bed by means of a radioactively marked particle technique, using a scintillation counter as a detector. Their results showed that the average particle velocity in the spout depended on the gas flow rate, gas inlet geometry, axial elevation, bed height, and column diameter. The solid circulation rate was found to be proportional to the gas flow rate, and further, a function of column and gas inlet geometry, density of fluidizing gas and particle diameter. They gave empirical correlations for both the particle velocities in the spout and the solids circulation rate as a function of axial elevation. Suciu and Maximillan (1977 and 1978), conducted experiments on particle circulation in a spouted bed produced by introducing air in a 100-mm diameter semicircular, conical-bottom column with a transparent front wall. The results they obtained, by using pictures captured using a high-speed camera, 
showed that the average bulk-velocity of particles in the annulus, at a distance of 0.7 $0.8 \mathrm{R}$ ( $\mathrm{R}$ - radius of the cylindrical bed) from the wall, were significantly different from particles which were in contact with the wall.

Boulos and Waldie (1986) used Laser-Doppler Anemometry (LDA) to obtain high-resolution measurements of particle velocities in a spouted bed and were able to find answers to previously unresolved aspects of particle motion, including wall effects in half-section beds. Laser-Doppler Anemometry (LDA) is a non-intrusive technique and is capable of providing particle velocity data of high resolution in the spout and fountain regions. The basic principle of LDA is that the difference in frequency between the incident laser light beam and the light scattered by the moving particles is proportional to the velocity of the particle. By measuring the frequency difference (Doppler shift) and the optical geometry, the velocity was calculated.

He et al. (1994a, 1994b) used fiber optic probes to measure voidage and velocity profiles in the fountain, spout and annulus of semi-circular and circular spouted beds. They observed that the voidage in the annulus was somewhat greater than the voidage in a loosely packed bed and increased with gas flow rate, this was contrary to earlier assumptions. The results also showed that overall voidage profiles were very similar in both the 2-dimensional and 3-dimensional beds. The particle velocity measurement in the spout region showed that although the overall profile for both columns are similar in shape, the local particle velocities in the half column are approximately $30 \%$ lower than the full column, under identical operating conditions. In the half column, particle velocities in the spout adjacent to the front plate were approximately $24 \%$ lower than 
particles a few millimeters away. In the annulus region, the difference between particle velocities adjacent to the column wall and those $2 \mathrm{~mm}$ away was $28 \%$.

Roy et al. (1994) conducted experiments using a 3-D radioactive particle tracking technique in cylindrical beds. This method was used to overcome the distortion caused by the curtain effect associated with a semi-cylindrical bed. A non-invasive $\gamma$-ray emission system, employing eight $\mathrm{NaI}$ detectors was used to follow the motion of a single radioactive particle. The count-rates measured simultaneously by the detectors were converted into tracer coordinates $(\mathrm{x}, \mathrm{y}, \mathrm{z})$ using a pre-established calibration model that accounted for the physical and geometrical aspect involved in the spouting facility. They were able to extract a number of hydrodynamic parameters, which included the complete particle velocity field, the spout shape, the cycle time distribution and the solid exchange distribution at the spout-annulus interface.

\subsection{An overview of Draft-Tube-Equipped beds}

Various modifications have been proposed to improve the operability of spouted beds. One of these is the addition of a tubular insert known as a draft-tube. The draft-tube functions as a partition, separating the bed into two regions, an inner fast-moving leanbed in the upward direction and an annular slow-moving dense-bed region in the downward direction. This design has several advantages over the conventional spouted bed. Notably, for beds with draft-tubes, there are no bed height limitations contrary to conventional spouted beds. The minimum spouting velocity will also be less because the gas does not leak through the spouted core, as in the case in a conventional spouted bed. Also, all types of powders can be spouted easily, while only large particles (Geldart type 
D) can be spouted using conventional beds. The draft-tube forces all the particles to travel through the entire annular section surrounding the draft-tube before reentering the spout, thereby reducing the residence time distribution in the annulus. With independent gas supply to the annulus and central regions, the solid circulation rate can be controlled. A schematic diagram of a draft-tube-equipped spouted bed, with the arrows indicating the direction of solids movement is shown in Figure 1-1.

Draft-tube-equipped spouted beds have found wide application as equipment for chemical reactors, coal devolaitizers, dryers, mixing and blending units, and coating devices. Hattori and Takeda (1978) showed that the side-outlet spouted bed with a drafttube could be used as a chemical reactor. Klaflin et al. (1983) and Khoe et al. (1983) used a draft-tube spouted bed for drying and thermal treatment of grains. Yang and Keairns (1974, 1978 and 1983) successfully demonstrated a single-stage coal devolatilizer for cracking coal in a pilot-scale process development unit. Another important commercial application of this system is the spray coating of pharmaceutical and agricultural products (Wurster, 1957; Wurster et al. 1966; Singiser et al. 1966; Brudney and Toupin, 1961 and Liu and Liter 1993) and as a granulating device for preparing agglomerates (Wurster et al., 1965).

In the past, both 2-dimensional and 3-dimensional columns, with a variety of different designs have been used for the study of hydrodynamics in gas-solid fluidized beds. A 2-dimensional bed can be readily viewed with the aid of good lighting and an image capturing setup and quantitative information on the fluidization characteristics of such a gas-solid system has been reported by Grace and Baeyens (1986). 
Although the 2-dimensional column is useful for qualitative purposes, there are quantitative differences between 2-dimensional and 3-dimensional beds. A column geometry that is intermediate between the 2 and 3-dimensional geometry is the semicylindrical column with a flat transparent surface. The particle dynamics across the diameter can be viewed through the flat face. The semi-cylindrical column has been very popular with many researchers and a number of experiments have been conducted to understand the dynamics of such a bed.

\subsection{The Hydrodynamics within the Spray Zone of a Fluidized Bed Coating Device}

Mann et al. $(1972,1983)$ studied the coating of particles in a fluidized bed with a draft-tube insert. They considered coating to be renewal type process in which a particle receives a random amount of coating material each time it passes through the spray zone. In addition, although the circulation of the particle around the bed is quite regular, the time between successive passes varies, causing additional variation in the total amount of material coated on the particle. Cheng and Turton (1994) used a magnetic tracer technique to address this variation using a phenomenological model of the coating process based on the sheltering effect of particles in the spray zone. However the model was based on the following assumptions: (a) the particles were assumed to pass through the spray zone at a uniform velocity, (b) the voidage in the spray zone was assumed to be constant, (c) the particles were assumed to be distributed evenly throughout the spray from a distance, $r_{0}$, from the centerline of the bed to the inside diameter of the draft-tube insert R, and (d) the shape of the spray was assumed to be a hollow or solid cone. Cheng (1993) performed an analysis of the variance (ANOVA) on the variables involved in the 
coating operation, using a $2^{5}$ factorial design. Spherical particles of approximately $1-\mathrm{mm}$ diameter were used. The results indicated that the spacing between the distributor plate and the draft-tube, as well as the draft-tube diameter, were key factors in controlling the circulation rate.

$\mathrm{Xu}$ (1994) verified these results and concluded that the two gas feed rates, to the inner and outer regions, had a relatively small affect on the circulation rate and that the vertical gap between the distributor and the draft-tube was the dominant factor in determining the solid circulation rate. Recently Saadevandi (1996) used a computerbased video imaging technique to investigate the hydrodynamics of fluidized particles (glass beads, $d_{p}=1.086 \mathrm{~mm}, \rho=2500 \mathrm{~kg} / \mathrm{m}^{3}$, and sphericity $\phi=1$ ) passing through the liquid spray in a semi-circular spouted fluidized bed. He studied the particle velocity and voidage profile in the draft-tube region with dilute and concentrated particle flow conditions. This study showed that the particle velocity decreases and voidage increases with radial distance from the center of the draft-tube and with increasing distance from the distributor, except at the bottom of the bed where the velocities of the particles increase. This was attributed to the inward and upward motion of particles at the bottom of the draft-tube, causing a region of low solid density and velocity at the bottom and center of the draft-tube.

\section{2-5 Application of fluidized bed coating to obtain controlled/sustained and sequential release drugs}

During the past few decades, significant advances have been made in the area of controlled release drugs. By improving the way in which drugs are delivered to the target 
organ, a controlled-release drug delivery system is capable of achieving the following benefits: (1) maintain optimum therapeutic drug concentration in the blood with minimum fluctuation: (2) predictable and reproducible release rates for extended duration (3) enhance activity duration for short half-life drugs (4) eliminate side effects due to toxic levels and frequent dosing (5) reduce drug wastage, and (6) optimize therapy and help better patient compliance (Lee and Robinson, 1987 and Good and Lee, 1987).

The idea of Compression Coated tablets were conceived by P.J Noyes of New Hampshire as early as 1896, but the first compression-coating machines were not available commercially until the 1950s. The Layer-Tablet process was first patented by F.J Stokes in 1917. In this process, the granules of drugs were first compressed separately before the deposition of the next granulated layer and pressed to form the complete tablet. A totally new technique for manufacture of solid dosage forms was started by HoffmannLa Roche Inc., in the 1980s called the web delivery system. In this process, the dosage units are formed by laminating a multitude of layers, some of which are drug coated (Goldberg, H. 1986). Wurster in 1953 was the first to introduce fluidized bed for coating of drug formulations. Since then, several developments have been made in this field and some of this will be reviewed next.

The amount of coating a particle receives in a fluidized bed Wurster coater can be determined by two factors: (1) the amount of coating received by the individual particles during each pass through the spray zone, and (2) the number of times the particle passes the spray zone. A quantitative measure of the variation of these two factors will give the variation in coating consistency of the final product. Mann 1974 and Mann et al., 1984 proposed that the total amount of coating deposited on a single particle depends on the 
number of cycles distribution of particles and the coating amount deposited on particles in each cycle. They derived a theoretical model to determine the total amount of coating based on arbitrary values assigned to the two above-mentioned variables.

Sherony (1981) applied the concept of random surface renewal to describe the exchange of particles between the active feed-zone and the inactive bulk of the bed. He also proposed a model to determine the coated weight distribution on the particle as a function of the coating time and size of the active feed zone. Similar work was done by Wnukowski and Setterwall (1989) for coating mono-sized seed particles in a fluidized bed focusing on the effect of feed supply on the coating mass distribution. They concluded that the coating mass distribution depended on the size of the feed zone, the rate of coating mass supply, and the circulation of the solid in the bed.

Uniformity of the final coated product depended on the fluidizing air and this should be maintained high enough to provide a good solid circulation rate (Chang, et al., 1987). However, this factor is limited by the shape, size and fragility of the particles being coated and the characteristics of the coating material (Mann, 1972). Ragnarsson and Johansson; 1988, observed that regardless of the size of the particles being coated, the coating layer seems to be built up in a similar manner. Choi and Meisen (1996) developed models to describe the operation of shallow spouted beds in which droplets of coating materials (sulfur) were injected coaxially with the spouting gas (air) under steady-state, transient, batch wise and/or continuous condition. The models predict the distribution of the coating material on the bed particles (urea) and the product quality. Weiss and Meisen (1983) identified the principle operating variables affecting the product quality for batch process as the bed temperature, sulfur injection rate, atomizing 
air flow rate through the pneumatic nozzle, bed depth, spouting air flow rate and chemical additives to the sulfur.

Sudsakorn and Turton 1999 conducted experiments to study the effect of particle size on the amount of coating received by the particles in a batch-fluidized bed Wurster coater. They observed that the coating mass $(\mathrm{m})$, received by the particle was related to the particle diameter $\left(d_{p}\right)$ and could be expressed as $m=k d_{p}^{3.40}$, where $\mathrm{k}$ is a constant. Iley 1991, reported a similar correlation between the mass coated and the particle diameter, but reported a lower-order of dependence $\left(m=\mathrm{kd}_{\mathrm{p}}^{2.2}\right)$.

$\mathrm{Li}$ and Peck (1990) found that the processing conditions in an air suspension column were critical in producing controlled release polyethylene glycol-silicone elastomer film coating on tablets. The coating equipment used was shown to play a major role in determining the permeability of the resultant tablet coating. Li and Peck (1990) also discuss in detail the effects of various operating conditions on controlled release film coating applied on tablets, using a fluidized bed. They observed that the temperature of the fluidizing air must be suitably high to evaporate the moisture, but not too high as to cause spray drying of the coating fluid. They also made the following observations about the coated film: (1) coating at a faster spraying rate tended to produce a less compact and more porous coating with fewer film layers and enhanced drug permeability, and (2) coating with high solid-content dispersions provides fewer layers but thicker films with the same coating weight, essentially resulting in more porous films and faster drug release rate. 


\section{CHAPTER III}

\section{EXPERIMENTAL METHOD}

The experimental program in this research can be divided into four main sections, details of the experiments conducted for each section will be explained along with the parameters, the equipment, and the operating techniques as they arise.

As a review, the objective of this research was to obtain the velocity and voidage profiles of tablets in a semicircular fluidized bed coater for various operating conditions. The experimental program involved changing the parameters that affect the flow pattern of the tablets such as distributor plate design, gap height, gas velocity and particle deflectors and study their effect on the hydrodynamics of the bed. Work was also done to determine the variability of the amount of dye coated on batches of tablets with and without the use of the particle deflectors. These deflectors changed the velocity and voidage profiles of the particles near the spray nozzle. Efforts were also made to quantify the variability in amount of coating received by particles after a complete coating run and the percentage of this variation caused by the variability in the amount coated per pass through the spray zone. Table 3-1 and 3-2 give the experimental matrix for the velocity and voidage profile studies and the coating studies, respectively.

\section{3-1 Description of the Experimental Set-Up and Equipment}

A semi-circular, spouted bed with a draft-tube insert was built in house and is shown in Figure 3-1.The dimensions of this bed are shown in Figure 3-2 and a photograph is shown in Figure 3-3. The major portion of the apparatus was made from transparent Plexiglas ${ }^{\circledR}$ (AIN Plastics, Inc., Norfolk, VA) with a transparent glass front 
Table 3-1. Experimental matrix for the velocity and voidage profile study.

\begin{tabular}{|c|c|c|c|c|c|c|}
\hline \multirow{2}{*}{ Experiment } & \multirow{2}{*}{$\begin{array}{c}\text { Distributor } \\
\text { Plate }\end{array}$} & \multirow{2}{*}{$\begin{array}{c}\text { Gas Flow } \\
\left(\mathrm{m}^{3} / \mathrm{s}\right)\end{array}$} & \multirow{2}{*}{$\begin{array}{c}\text { Gap Height } \\
\text { (m) }\end{array}$} & \multicolumn{3}{|c|}{ Deflector Type } \\
\hline & & & & Deflector & $\begin{array}{l}\text { Modified } \\
\text { Deflector }\end{array}$ & No Deflector \\
\hline 1 & A & 0.0649 & 0.027 & $\mathrm{Y}$ & - & - \\
\hline 2 & A & 0.0684 & 0.027 & - & $\mathrm{Y}$ & - \\
\hline 3 & A & 0.0686 & 0.027 & - & - & $\mathrm{Y}$ \\
\hline 4 & A & 0.0695 & 0.074 & $\mathrm{Y}$ & - & - \\
\hline 5 & A & 0.0684 & 0.074 & - & $\mathrm{Y}$ & - \\
\hline 6 & A & 0.0707 & 0.074 & - & - & $\mathrm{Y}$ \\
\hline 7 & B & 0.0684 & 0.074 & - & - & $\mathrm{Y}$ \\
\hline 8 & A & 0.0766 & 0.074 & - & $\mathrm{Y}$ & - \\
\hline
\end{tabular}


Table3-2. Experimental matrix coating consistency study.

\begin{tabular}{|c|c|c|c|c|c|}
\hline Experiment & No Deflector & $\begin{array}{c}\text { Modified } \\
\text { Deflector 1 }\end{array}$ & Deflector 2 & Deflector 3 & Deflector \\
\hline Continuous & $\mathrm{Y}$ & $\mathrm{Y}$ & $\mathrm{Y}$ & $\mathrm{Y}$ & $\mathrm{Y}$ \\
Coating & $\mathrm{Y}$ & $\mathrm{N}$ & $\mathrm{N}$ & $\mathrm{N}$ & $\mathrm{Y}$ \\
\hline Pulse Test & & & & & \\
\hline
\end{tabular}

All the coating runs were carried out with distributor plate 1, gap height $7.4 \mathrm{~cm}$ and with airflow rate $0.0684 \mathrm{~m}^{3} / \mathrm{s}$. 
Column

$(\mathrm{ID}=22.9 \mathrm{~cm})$
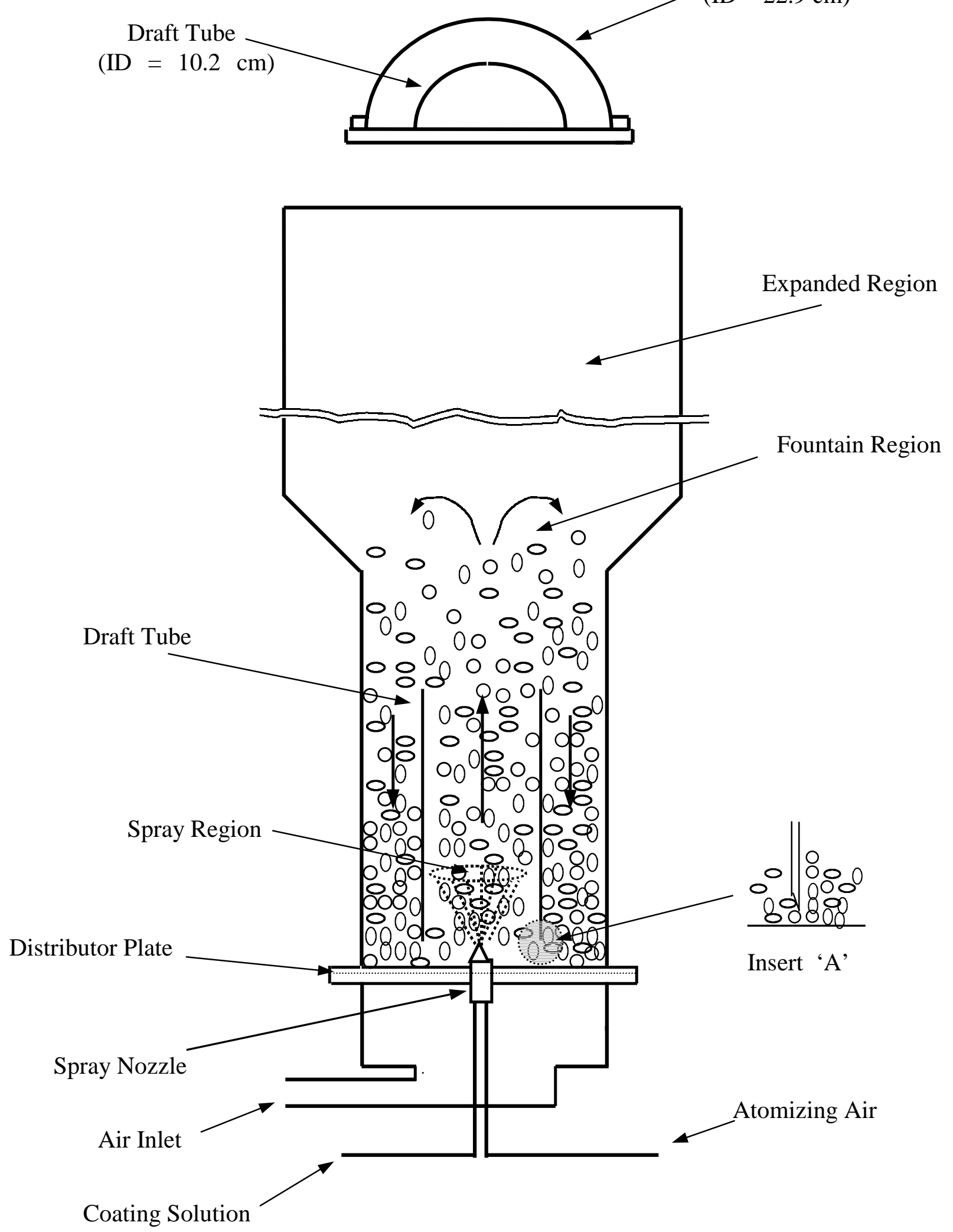

Figure 3-1: Schematic diagram of the semi-circular spouted bed coating device. Arrows indicate direction of solids movement. 


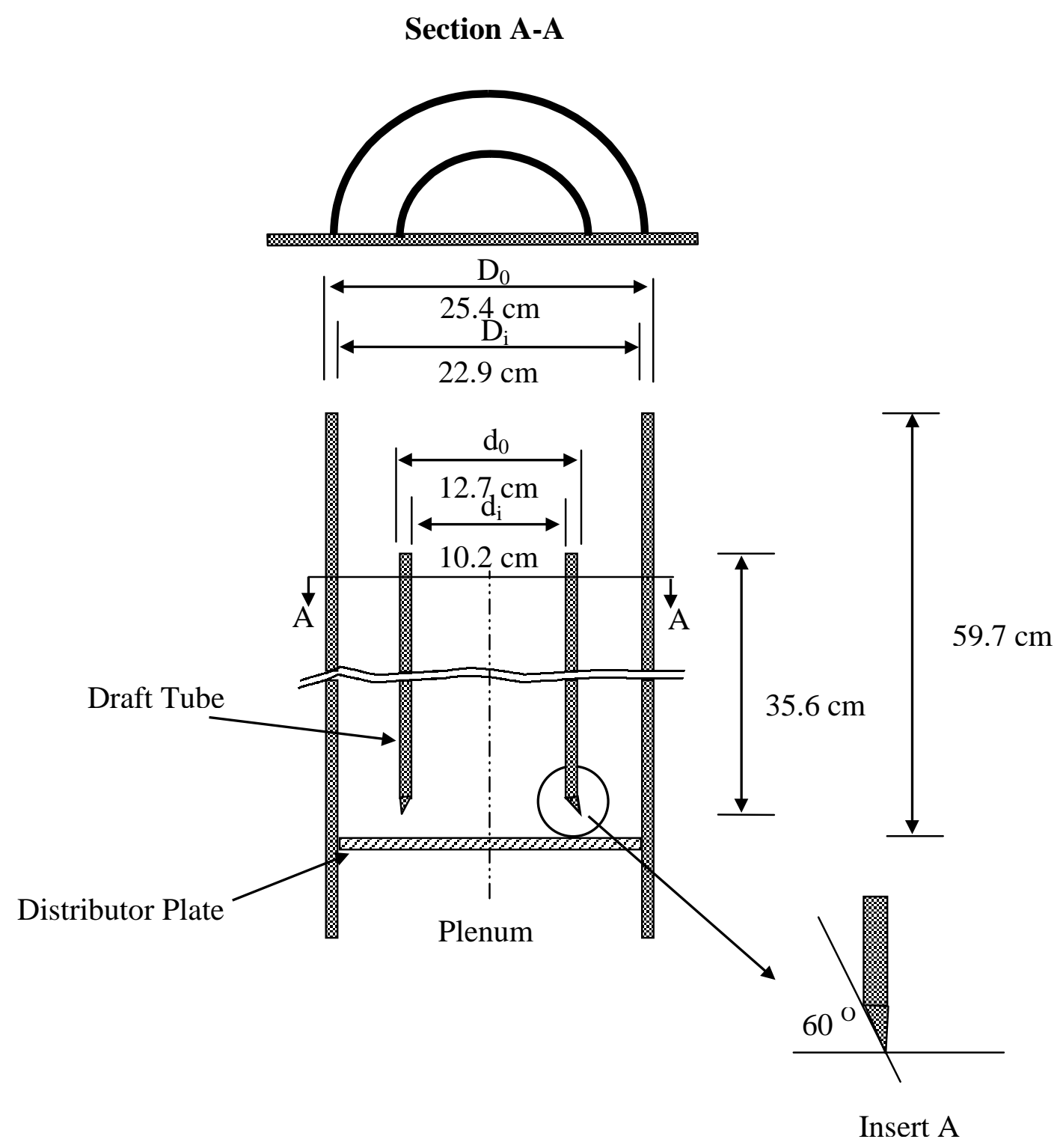

Figure 3-2. Diagram showing the dimensions of the semi-circular column of the bed. 


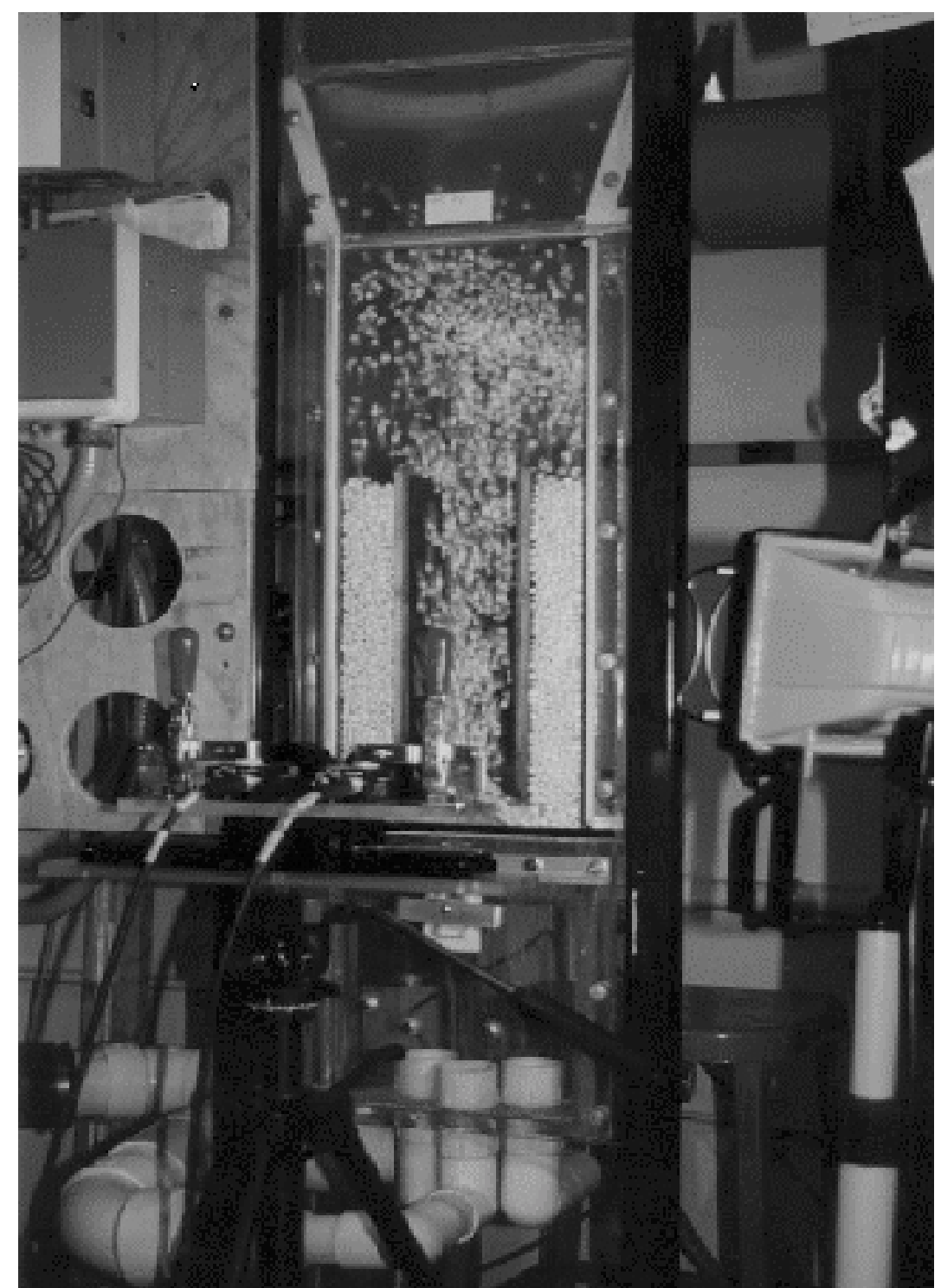

Figure 3-3 Photograph of the fluidized bed with the two-camera set-up. 

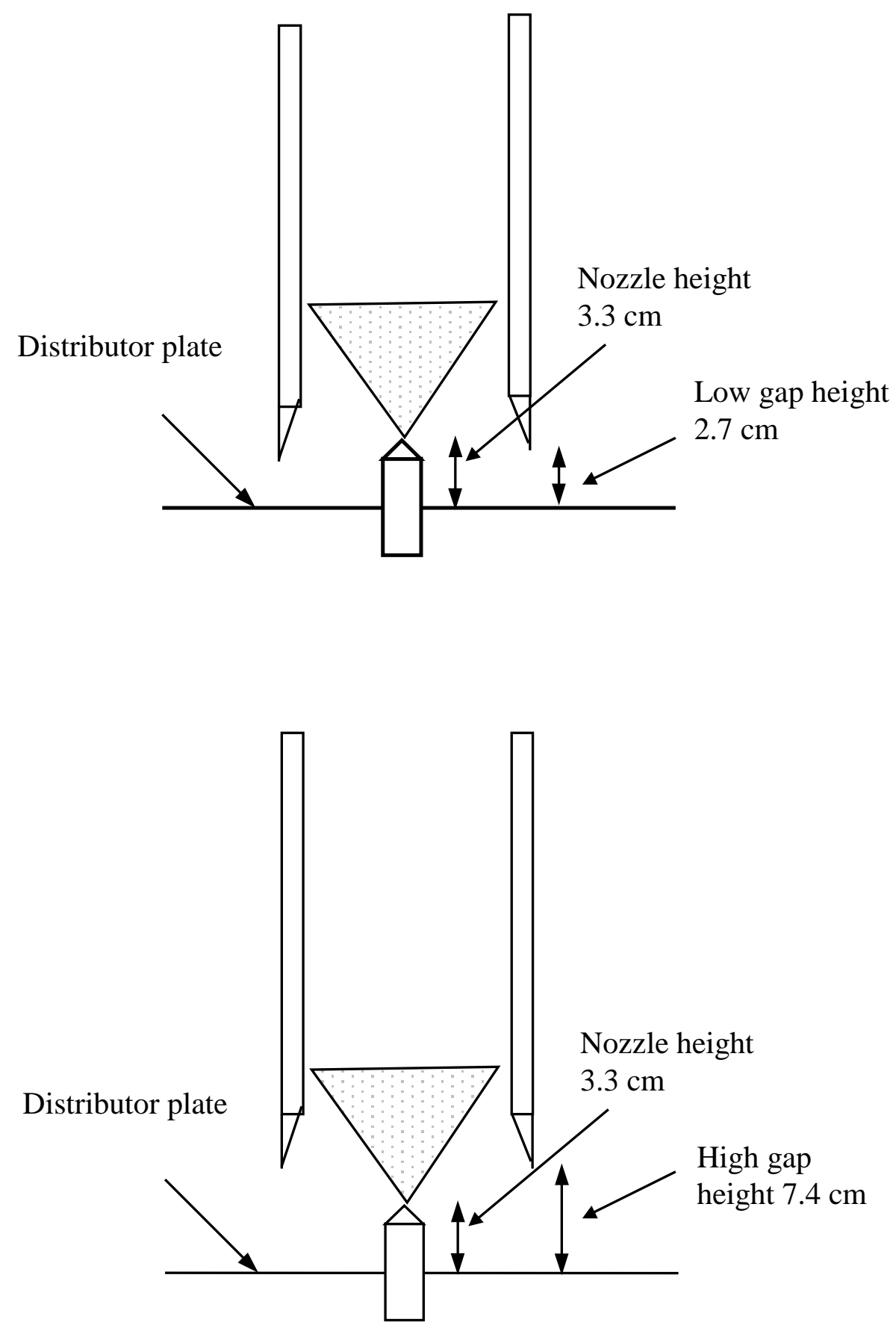

Figure 3-4a, b. Schematic showing the low and high gap height between the distributor plate and the draft-tube. 
face. Through the transparent glass sheet it was possible to observe the flow pattern of the tablets. This enabled the use of a computer-based video imaging system to study the particle dynamics and obtain velocity and voidage data. The bottom of the draft-tube is angled at $60^{\circ}$ from the horizontal as shown in Figure 3-2, insert 'A'. This modification reduces the flow of particles towards the spray nozzle and assists the particle movement upward through the spray zone as shown in Figure 3-1 (the arrows indicate the direction of particle motion). The draft-tube is anchored in the center of the column using two sets of tension bars, springs and o-rings. The draft-tube is pressed against the front transparent glass plate by the springs that seals the draft-tube with the front surface. The o-rings facilitate the upward and downward movement of the draft-tube relative to the distributor plate. The position of the draft-tube relative to the distributor plate can be used to control solids flow from the annular region to the draft-tube region. The higher the position of the draft-tube (bigger gap between the draft-tube and distributor plate) the greater the solids flow, and hence the denser is the bed. Figure 3-4 a, b show the two gap heights investigated and the relative position of the distributor plate and nozzle.

The flow diagram of the experimental system used in this work is shown in Figure 3-5 and the schematic diagram of the video imaging system is shown in Figure 3-6. Air is supplied by a centrifugal blower and is regulated through valves before in enters the plenum chamber located beneath the distributor plate. The airflow rate to the bed is controlled using the valves up-stream of the bed. The airflow rate is inferred from the pressure drop across a calibrated orifice plate upstream of the valves. Calibration details of the orifice plate are given in Appendix I. During the experimental runs to obtain 


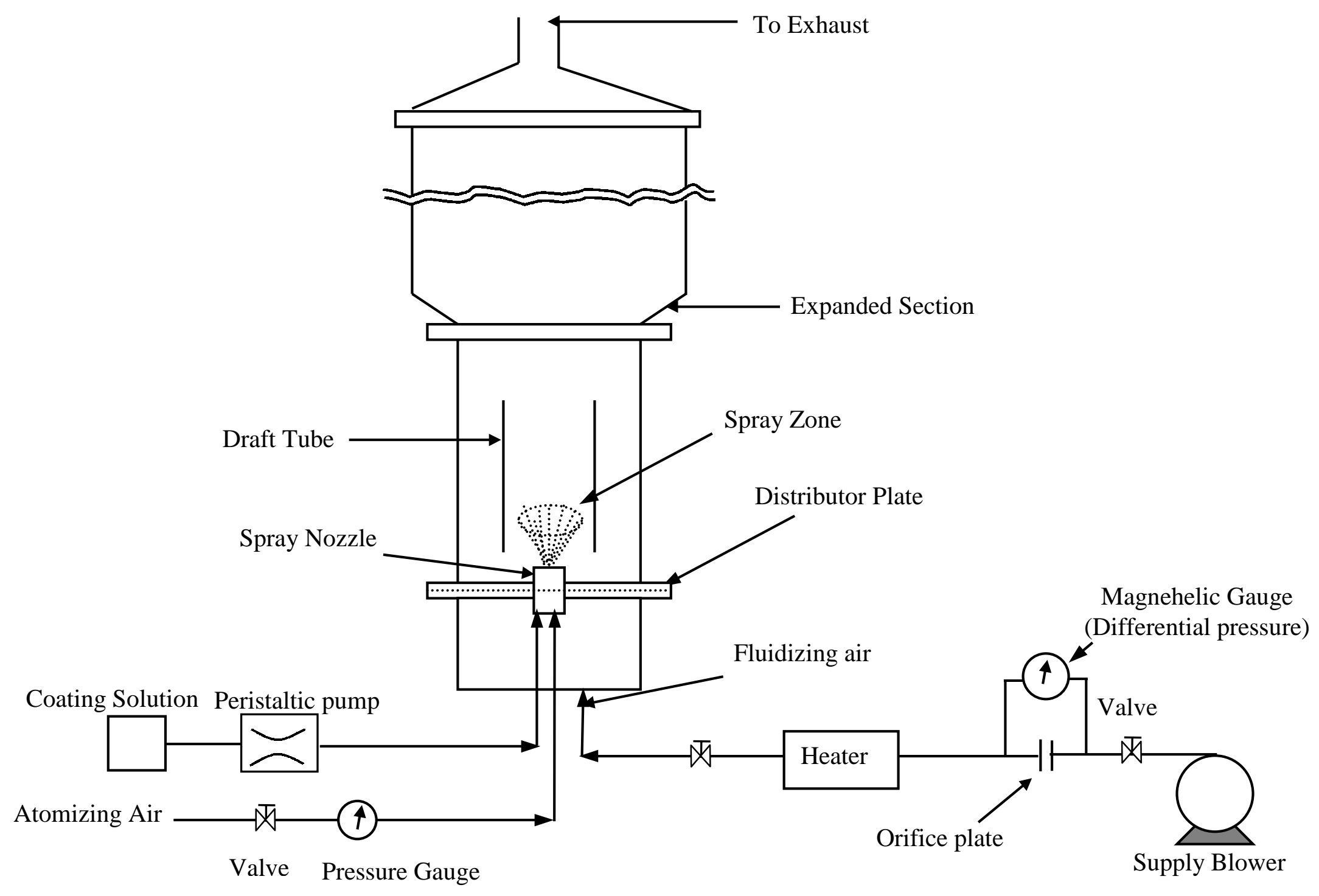

Figure 3-5. Flow diagram of the experimental setup 

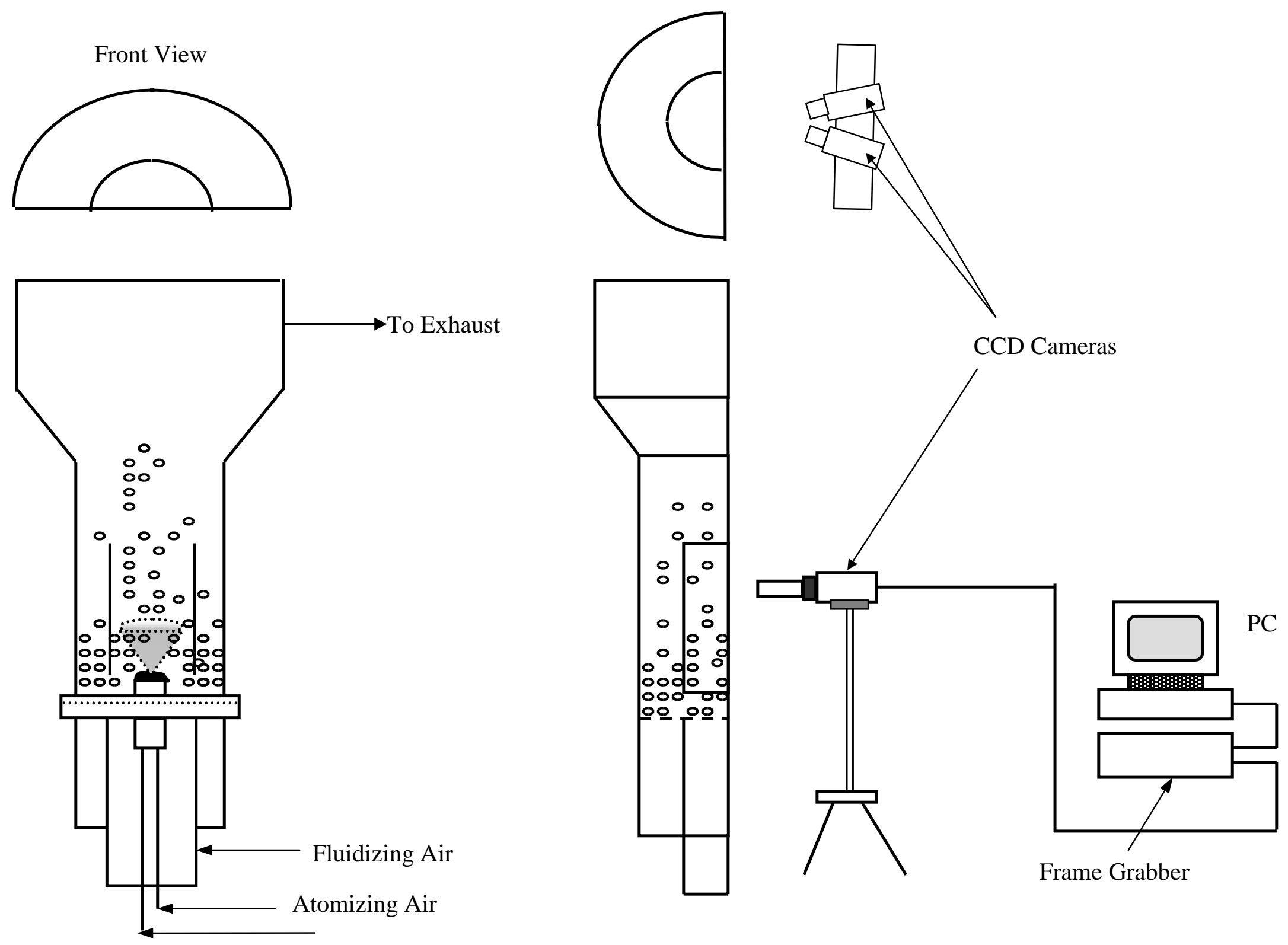

Figure 3-6. Schematic diagram of the fluidized bed video imaging system 
velocity and voidage profiles, the spray nozzle though present was plugged and no air or liquid was allowed to flow through it into the bed.

The particles studied were tablets, $8.05 \mathrm{~mm}$ diameter and $4.2 \mathrm{~mm}$ thick, with an average volume $0.170 \mathrm{~cm}^{3}$ and an average weight of 0.205 grams. These placebo tablets, made by compressing a mixture of Avicel® ${ }^{\circledR}$ PH101 and Magnesium sterate and pan coated with an aqueous solution of Hydroxy Propyl Methyl Cellulose (HPMC) and Hydroxy Propyl Cellulose, were supplied by Merck \& CO., Inc. Figure 3-7 shows a picture of the tablets used in this study. The particle density was calculated using an volume displacement method and was found to be $1.215 \mathrm{~kg} / \mathrm{m}^{3}$ (see Appendix II for details).

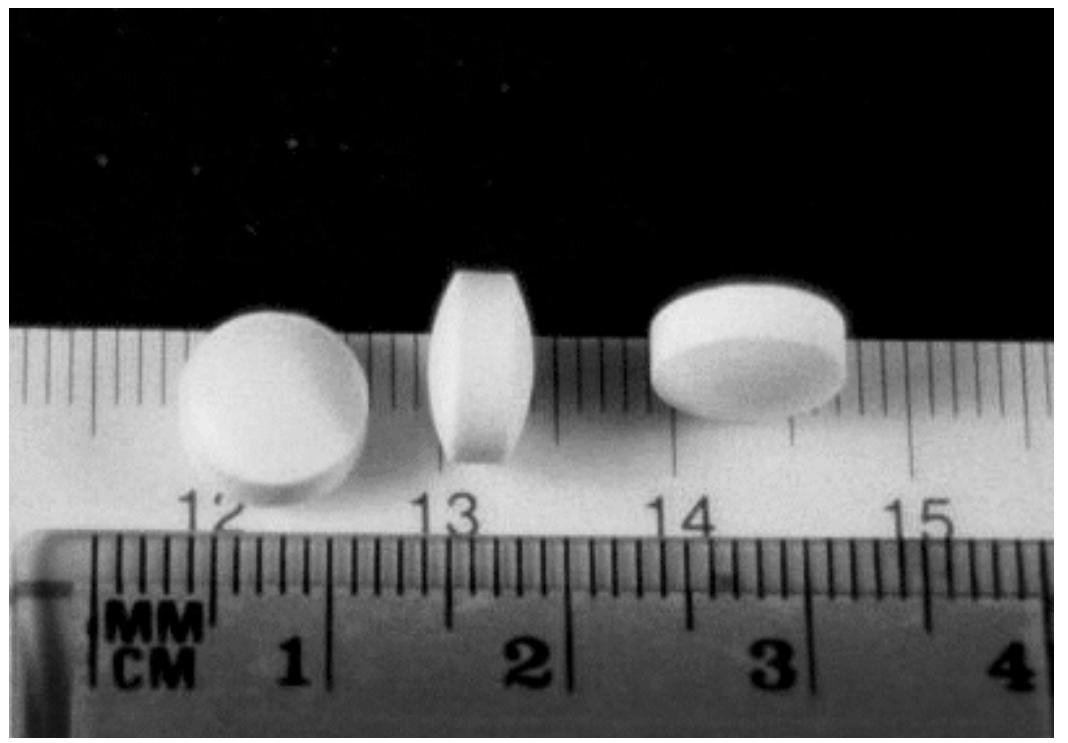

Figure 3-7. Photograph of the tablet used in the study. 


\section{3-2 Design of Deflector}

The work done by Cheng and Turton (1993) and Shelukar et al.(2000) has shown that major cause of the variation in the amount of coating received can be attributed to the variation in the coating-per-pass received by the particles in the spray zone. A major factor for this variation is due to the sheltering effect caused by the particles near the nozzle on particles farther from the spray source, Cheng (1993). This sheltering effect can be reduced by guiding the particles away from the spray source, and this reduces the variation in the coating-per-pass distribution. A more detailed explanation of this phenomena is given in section 4-4. The desired characteristics of the deflector are: (1) to prevent the particles entering the draft-tube from passing close to and directly over the spray nozzle, (2) to give a uniform voidage pattern in the spray zone, (3) does not reduce the particle flow into the draft-tube, and (4) and does not increase the attrition of the tablets. Four different deflector designs were tried before the final optimum deflector was designed.

Figure 3-8a and $\mathrm{b}$ show the first deflector design. Though this deflector was effective in some ways (explained in section 4-2.1), it did not give any substantial improvement in the coating consistency compared to the case without a deflector. The particles still moved close to the spray zone and the desired effect of moving the particles away from the spray nozzle was not obtained. This deflector was further modified by adding a ring around the nozzle as shown in Figure 3-9 a and b. This ring was moved to different positions along the slope of the deflector (Figures 3-10 and Figure 3-11) in an attempt to optimize its effect in deflecting the particles away from the spray nozzle. The use of these deflectors resulted in increased particle attrition. The ring on the deflectors 
caused a sudden change in the direction of flow and increased particle-particle and particle draft-tube collision. However, since the coating runs were carried out over a relatively short period, around 70 minutes, there was no significant attrition on the tablets. However, with Modified deflector 2, where the ring was moved lower on the slope, more attrition was observed. This was because the change in direction is more sudden and this caused increased particle-particle collisions and collisions between the particle and draft-tube.

From the data obtained and the observations made using deflector 1 and modified deflectors 1, 2 and 3, a final deflector (optimum deflector) was designed which is shown in the Figure 3-12 a, b, \& c. This deflector was machined from a single piece of Plexiglas ${ }^{\circledR}$ with higher angle of the slope and a smoother transition to the vertical portion of the deflector.

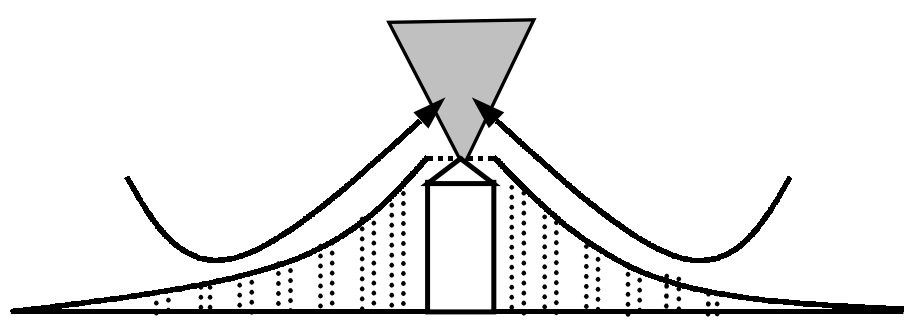

Figure 3-8a. Schematic diagram of deflector 1. The arrows show the direction of deflection of the tablets.

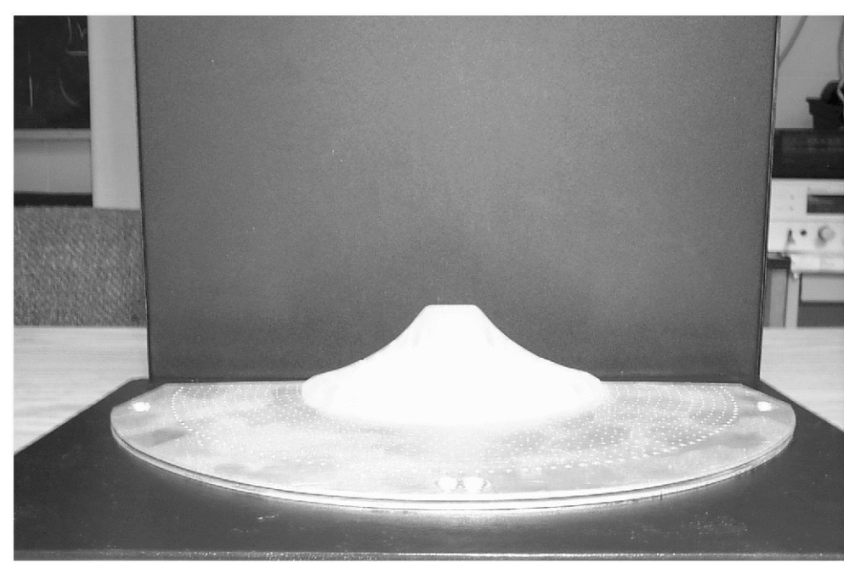

Figure 3-8b. Photograph of deflector 1 mounted on distributor plate 


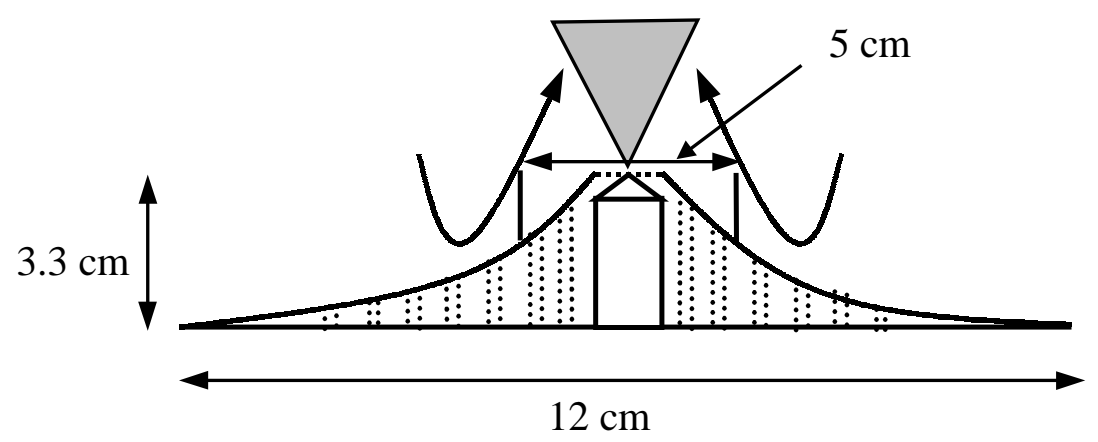

Figure 3-9 a. Schematic diagram of modified deflector 1 . The arrows show the direction of deflection of the tablets.

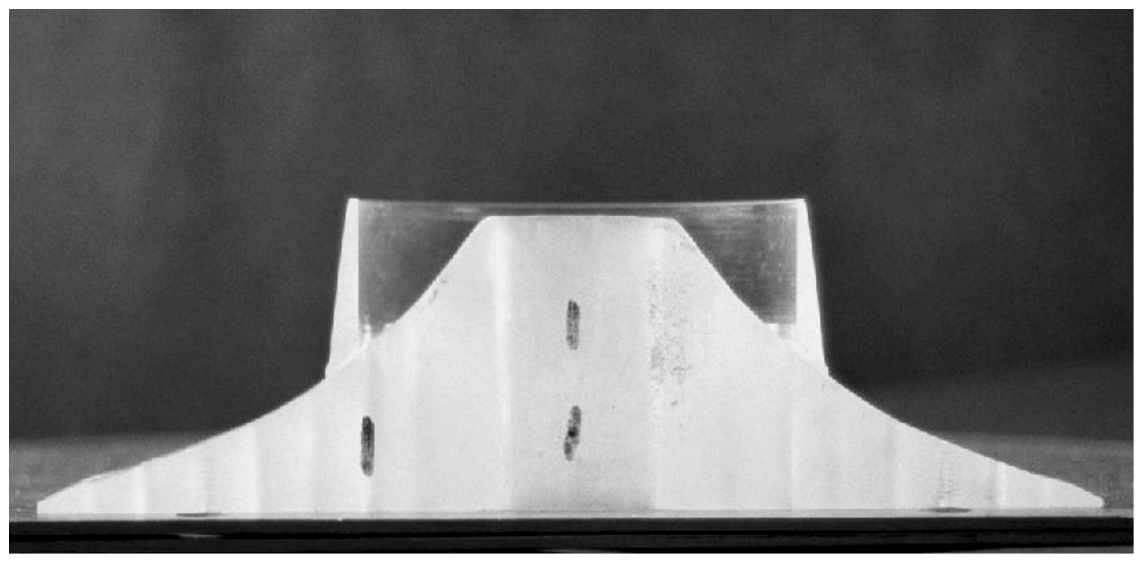

Figure 3-9 b. Photograph of modified deflector 1. 


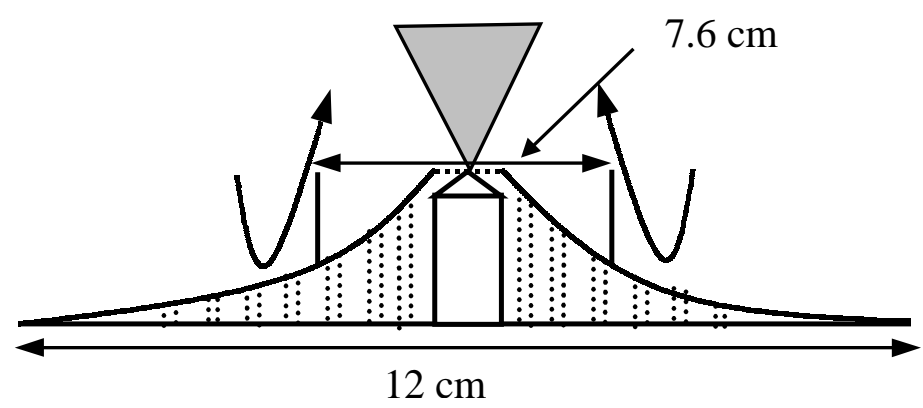

Figure 3-10. Schematic diagram of modified deflector 2. The arrows show the direction of deflection of the tablets.

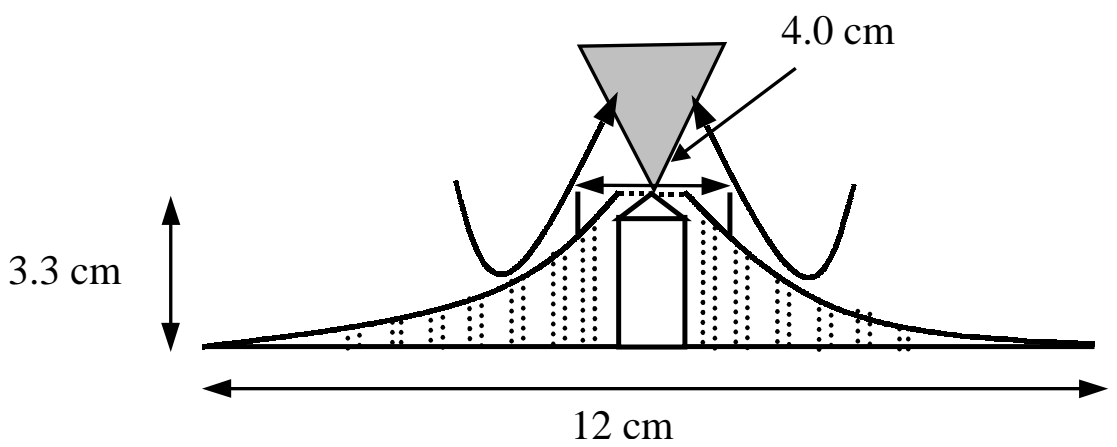

Figure 3-11. Schematic diagram of modified deflector 3. The arrows show the direction of deflection of the tablets.

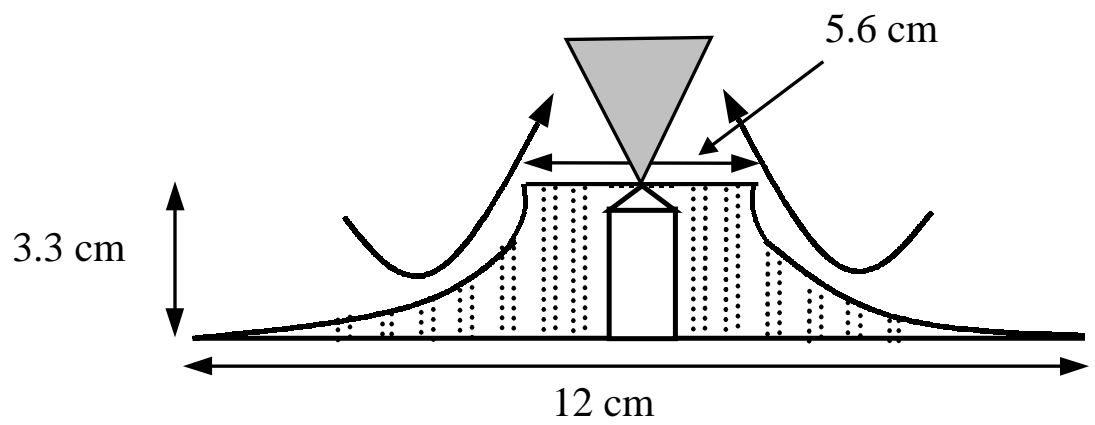

Figure 3-12a. Schematic diagram of optimum deflector. The arrows show the direction of deflection of the tablets. 


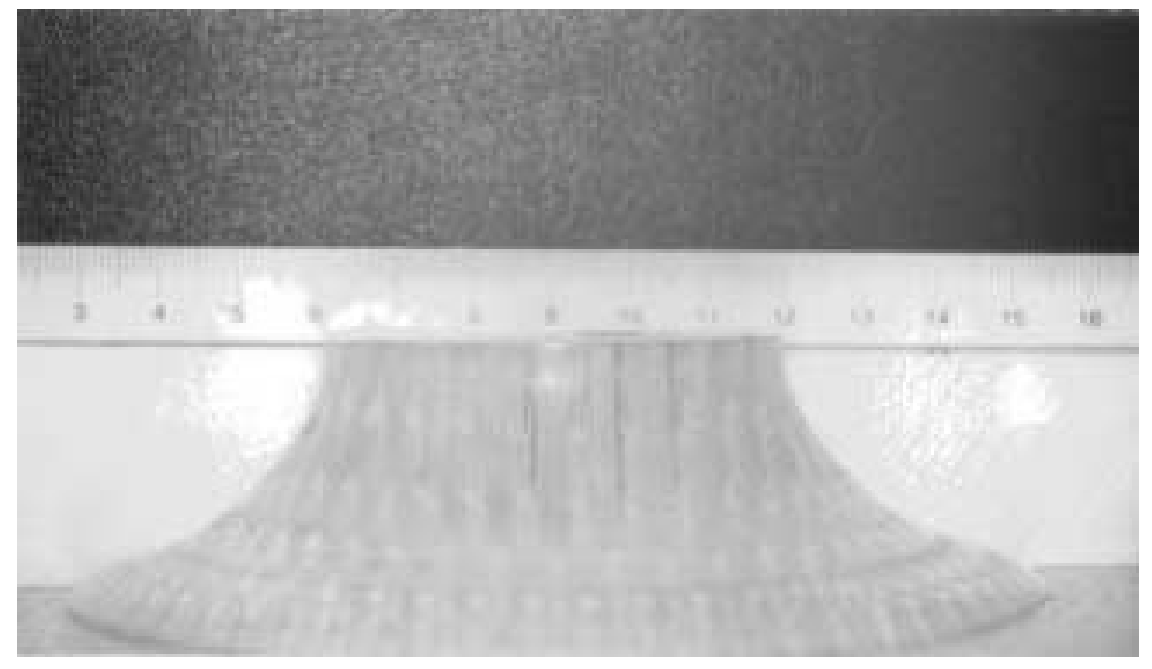

Figure 3-12b. Photograph of optimum deflector mounted on the distributor plate.

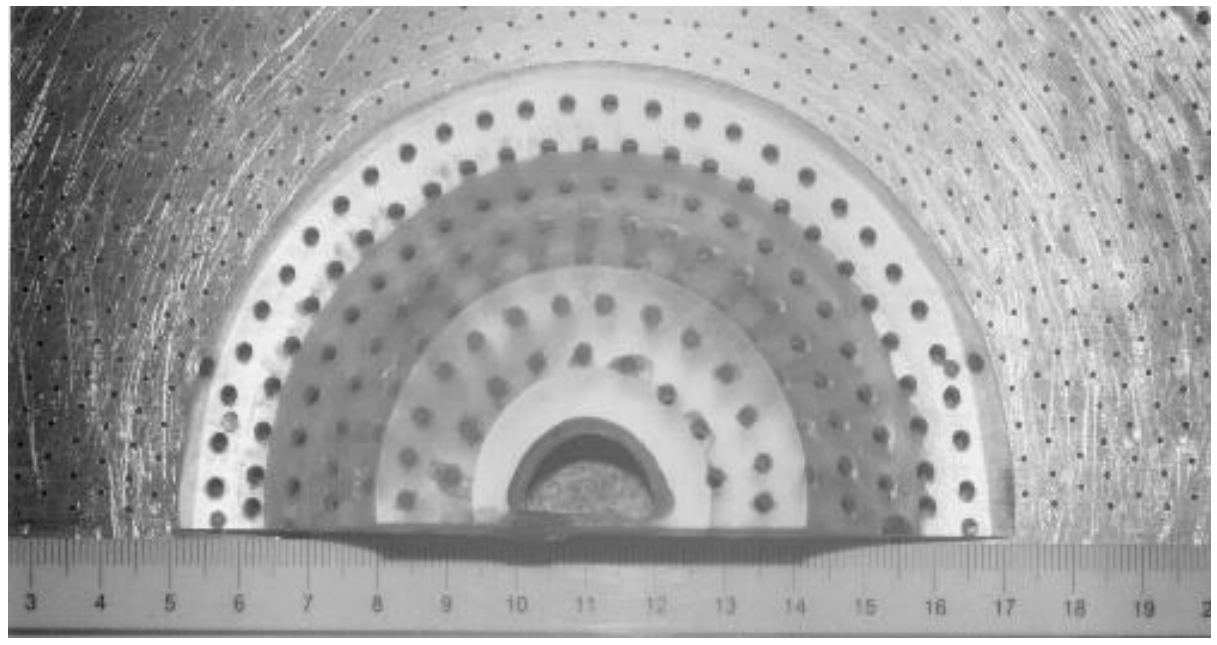

Figure 3-12c. Photograph of optimum deflector mounted on the distributor plate. 


\section{3-3 Measurement Techniques and Equipment Used}

Computer-based video imaging techniques were used with customized imaging software to measure particle velocity and voidage profiles in the semi-circular fluidized bed. The set-up consisted of two CCD cameras (Sony XC - 75 CE CCD, Sony Inc.,), connected to two frame grabbers (PX610 Precision Frame Grabber, Imagenation Corporation, Beaverton, Oregon), which in-turn were connected to a computer (486DX, 33 MHZ, Keydata International Inc., S. Plainfield, NJ). The standard RS-170 interlaced signal (30 frames/sec) from the cameras are captured by the frame grabbers and viewed on the monitor of the computer with the help of custom software written in Microsoft Visual Basic 6.0.

With the RS-170 interlaced video system, each frame or image is formed by two fields, odd and even, taken $16.67 \mathrm{~ms}$ apart and spliced together. This usually has no consequence except when the object being imaged is not stationary. When the object moves before the successive fields are captured by the camera and the fields are spliced together to form a frame/image, we observe a phenomena called inter-line blurring. Figure 3-13 shows the principle of interline blurring. This problem can be overcome by two methods: (1) use very high-speed cameras with variable framing rates, or (2) increase the area of focus or the field of view FOV (explained subsequently). In the first case, the equipment cost is very high and the second solution results in a large number of particles in the field of view, making the identification and matching of particles between fields difficult. 

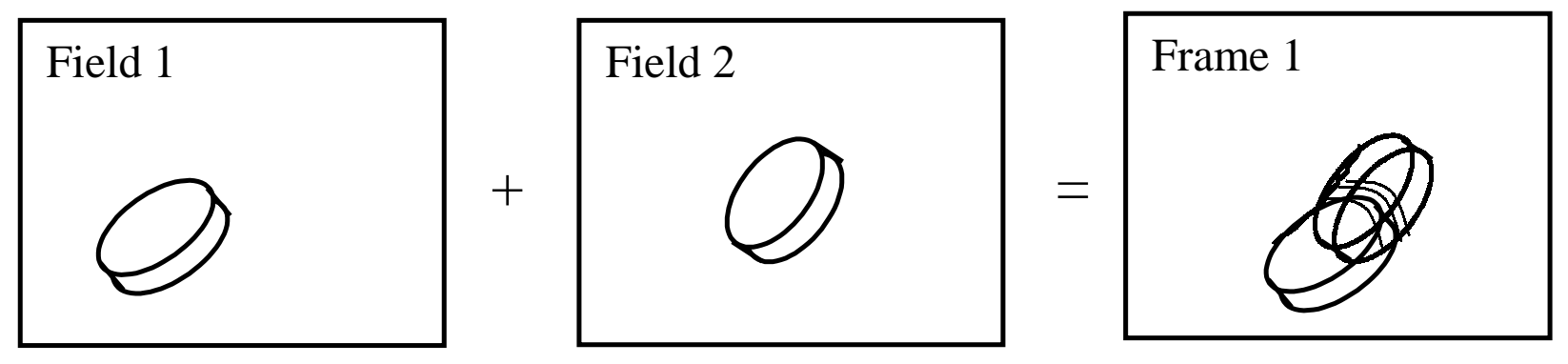

Figure 3-13. Schematic diagram showing an image/frame formed by two fields taken with a standard RS-170 interlaced video format (time lag of $16.67 \mathrm{~ms}$ ) and spliced together to form the image.

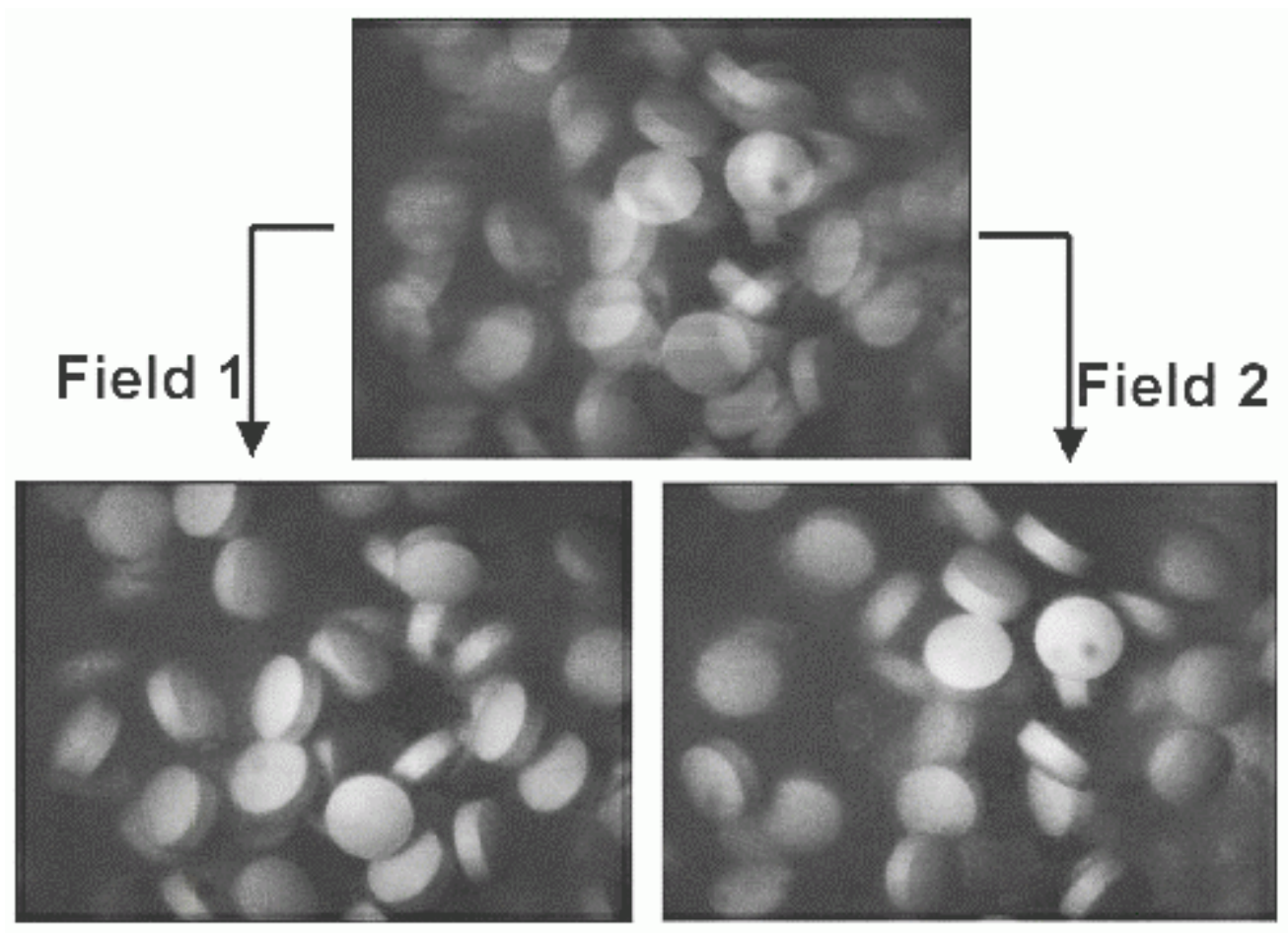

Figure 3-14. Photograph showing an image/frame formed by two fields taken with a standard RS-170 interlaced video format (time lag of $16.67 \mathrm{~ms}$ ) being split into two fields, odd and even. 
In our case, the tablets move with high velocities of 1 to $3 \mathrm{~m} / \mathrm{s}$ and when imaged with a RS-170 format, the particles move a significant distance (16 to $40 \mathrm{~mm}$ ) before the successive fields are captured. Thus, the particles may move out of the field of view and hence cannot be tracked by normal cameras. The solution utilized here is a low cost one that involves the use of two standard (RS-170) CCD video cameras and video cards. The two CCD cameras were focused on the same area and triggered in sequence with a time lag of 1 to $5 \mathrm{~ms}$ controlled by the frame grabber and the custom software. The principle of operation is shown in Figure 3-15.

Step 1: The computer shown in Figure 3-15 triggers both the cameras and the frame grabbers to take images $1-5 \mathrm{~ms}$ apart.

Step 2: By comparring two fields of data from the different cameras (either field 1 from cameras 1 and 2 or field 2 from cameras 1 and 2) images 1-5 ms apart are obtained and we can study the particle location and orientation and estimate the velocity.

The two cameras can be moved from side to side of the fluidized bed to cover the length and breadth of the bed. The two cameras were placed on the sides of a steep isosceles triangle as shown in Figure 3-16, in order to minimize parallax effects. The greater the angle at the apex $\theta$, the greater the difference between the images from the two cameras. Once the cameras where placed and secured, they where focused on a fixed point and the custom software was used to calibrate and minimize the parallax error. In order to check the accuracy of the alignment, the software, and the method used, the setup was first used to determine the velocity of a known moving object and the results were 

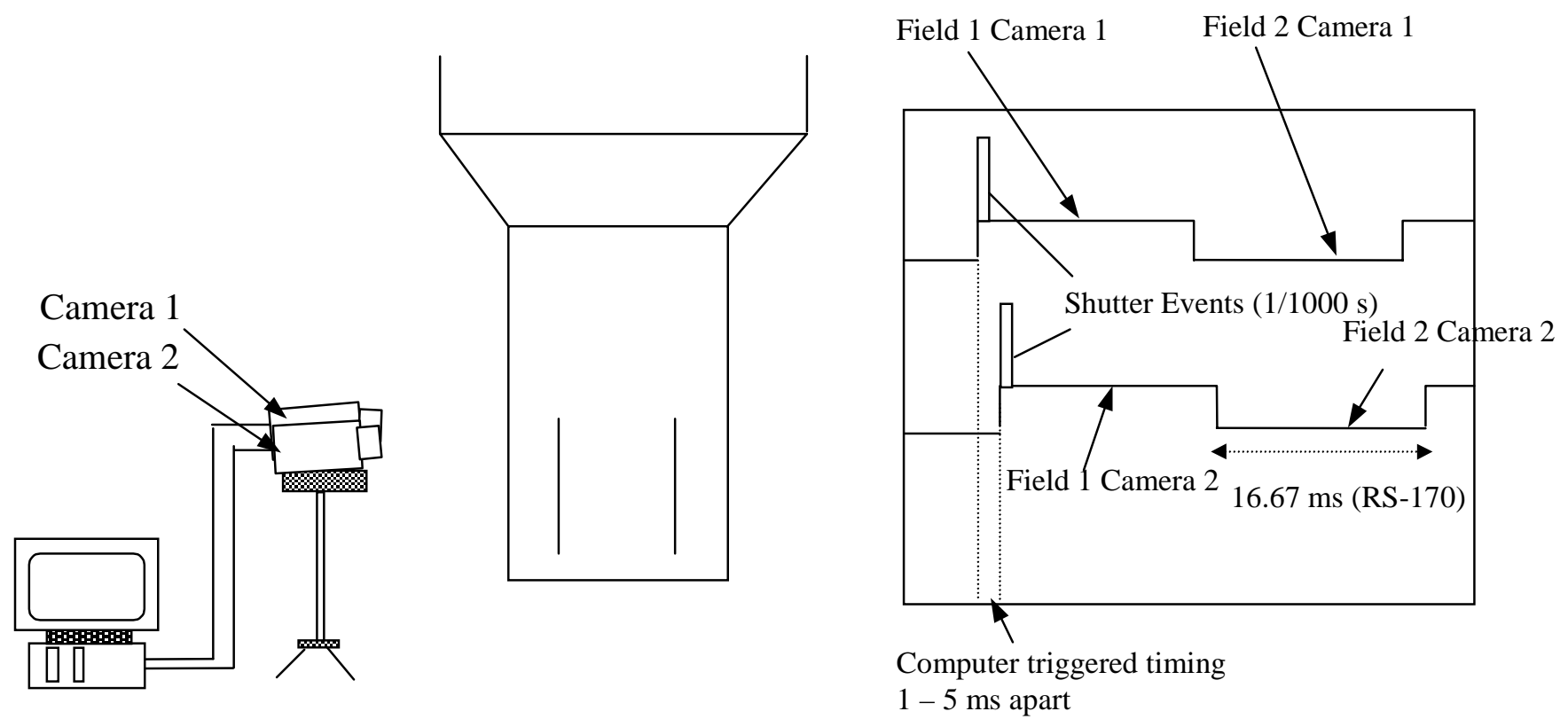

Figure 3-15. Illustration of stereoscopic imaging using two identical cameras and imaging boards.

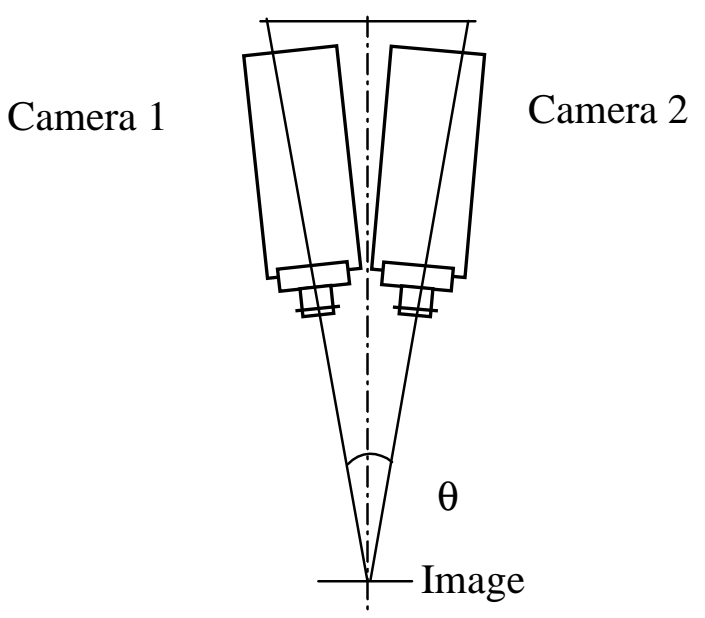

Figure 3-16. Two cameras set-up on the steep sides of an isosceles triangle. 
compared. A hand held drill (DeWalt DW 998, 0 to $650 \mathrm{rpm}$ ) fixed with aflat disk marked with points was used for this purpose. The speed of rotation or the RPM of the disk was measured with a stroboscope (Sticht Nova-strobe® DA Model, Bluefield, VA) and the linear velocity of the point on the disk was calculated using the formula $\quad \mathrm{v}=\mathrm{r} \omega$ (where $\mathrm{r}$ is the distance between the center of the disk and the point in focus and is the angular velocity). The resulting comparison is shown in Appendix III. This check validated the method used and gave an estimation of the accuracy possible.

\section{3-4 Calibration of Video Imaging System}

The draft-tube region where the particle velocities were measured was divided into boxes of dimensions $20 \mathrm{~mm}$ by $20 \mathrm{~mm}$. This size, $20 \times 20 \mathrm{~mm}$, was found to be appropriate, because it was large enough to track a particle within the same box and was not too big to cause confusion with a large number of tablets in the field of view. This square box formed the Field of View (FOV) of the cameras. The positions of the cameras were adjusted and extension rings $(7.5 \mathrm{~mm})$ were used to obtain a clear, focused image.

The depth from the front transparent glass sheet into the bed, over which the camera could pick up clear image of tablets, is the Apparent Depth of Field (ADOF). To determine the ADOF the following procedure was used. Models shown in Figure 3-17 were made. The tablets were mounted on pins, held on a sheet of Plexiglas to give the effect of being suspended in air, as shown in the picture. These models where then placed in the empty fluidized bed with the tablets on the front face just touching the front glass sheet of the bed. The camera was then focused on the inner surface of the glass sheet or the permanent marks made in the draft-tube, so as to get a clear image of the models on 

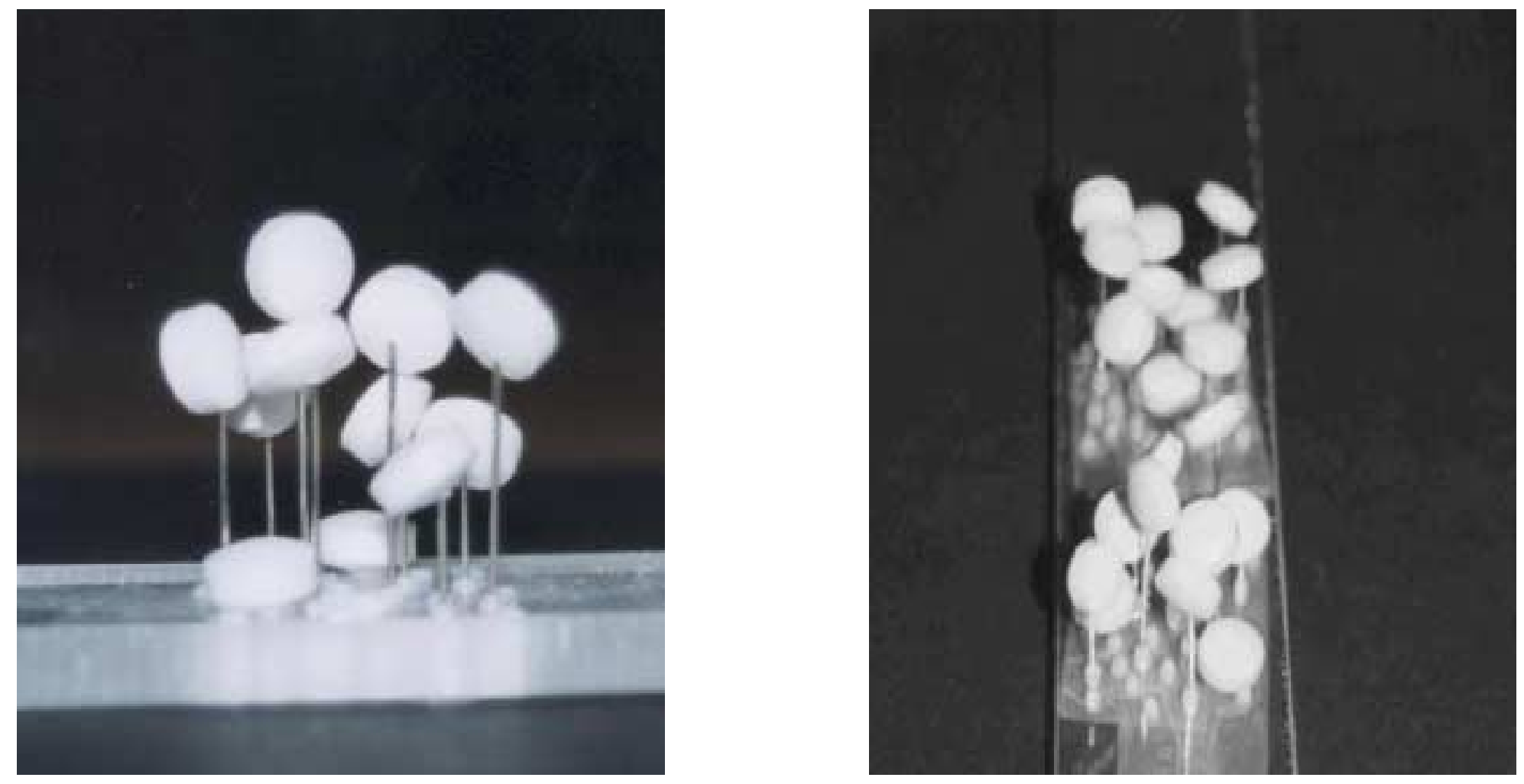

Figure 3-17. Photographs of models made to determine depth of field of the camera. 
the monitor of the computer. The software then runs a set of routines on the acquired image, explained in the voidage measurement section, and returns a numerical value for the number of tablets identified in the field of view (FOV). The software returns the number of tablets in the model, which is compared, to the actual number. We can now identify the tablets in the model picked up by the software and the ones that were not recognized. We know the individual distances of each tablet in the model from the front glass sheet and by identifying the tablets not picked by the software; we can determine the depth to which the camera can identify the tablets. By repeating this procedure several times with different models and with exactly the same lighting effects, the apparent depth of field was determined. The ADOF was determined to be $1.5 \mathrm{~cm}$ and the data for this calibration is given in Appendix IV.

\section{3-5 Principles of Velocity Measurement}

After the initial processes of focusing the cameras, aligning them and calibrating for pixel size (explained in Appendix V) are completed, the supply blower is switched on and the bed is fluidized. When the bed is running, a "grab" event is initiated that causes both cameras to obtain images at the pre-selected time lag. Figure 3-18 shows a still image of the particles in motion as seen on the computer screen. The center of each particle is then located using a computer generated crosshair and the horizontal and vertical distances between the successive images are computed and recorded. The software returns the velocities in both the vertical $\left(\mathrm{u}_{\mathrm{y}}\right)$ and horizontal $\left(\mathrm{u}_{\mathrm{x}}\right)$ 
Field 1 Camera 1

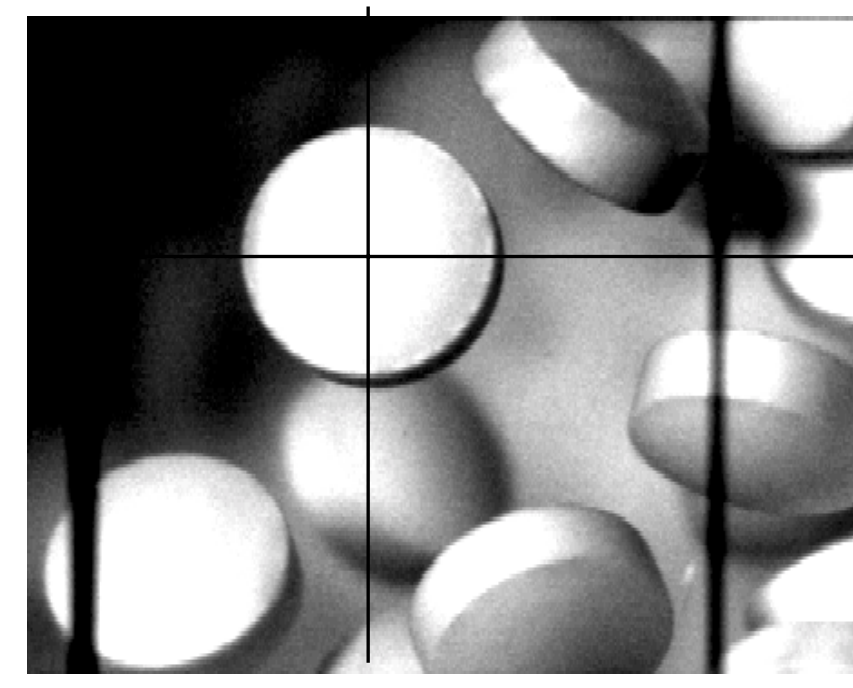

Field 1 Camera 2

Movement of particle defined by

distance between centers and

time gap between the fields

Figure 3-18. Photograph of still images of particles in motion as seen on the computer monitor. The hairlines shows the distance moved by the center of the particle.

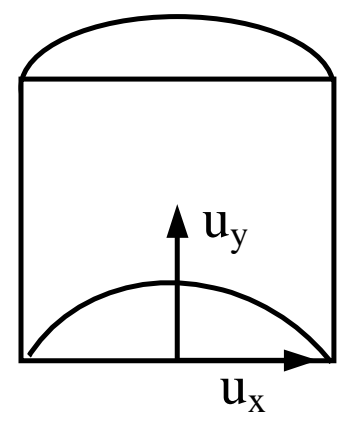

Figure 3-19. A schematic showing the directions of the velocity vector measured. 
direction in meters/second (Figure 3-19). The magnitude and angle of the velocity vector can be calculated as shown in Appendix VI.

The process of obtaining velocities in the horizontal and vertical direction is repeated nearly 80 times for each box/FOV. The cameras are then moved on the sliding stand to focus on the next box. This process is repeated across the entire width and height of the draft-tube so as to obtain the velocity profile of the moving particles across the draft-tube region. The 70 to 100 velocity measurements obtained for each of the boxes are then averaged to get an average velocity vector for the respective boxes.

\section{3-6 Principle of Voidage Measurement}

For the voidage measurement, only one of the cameras was used. The amount of light on the bed during the voidage measurement was very critical. A variation in light intensity changes the depth of field resulting in variation in the number of particles identified by the software. Several trials were done with different light positions, intensities, and tablet models, until the software returned consistent values for voidage for the same model. The final position of the light and its intensity were maintained constant for the entire experimental run. Figure 3-20 shows the final positions of the lights. In order to fine-tune the software, several standard samples of known voidage where made from the same tablets used in the runs. The voidage values from the software, were compared to the actual voidage.

After a field is acquired using the camera for voidage measurement, the software carries out the following tests and operation on the image to obtain a value for the 


\section{Fluidized Bed}

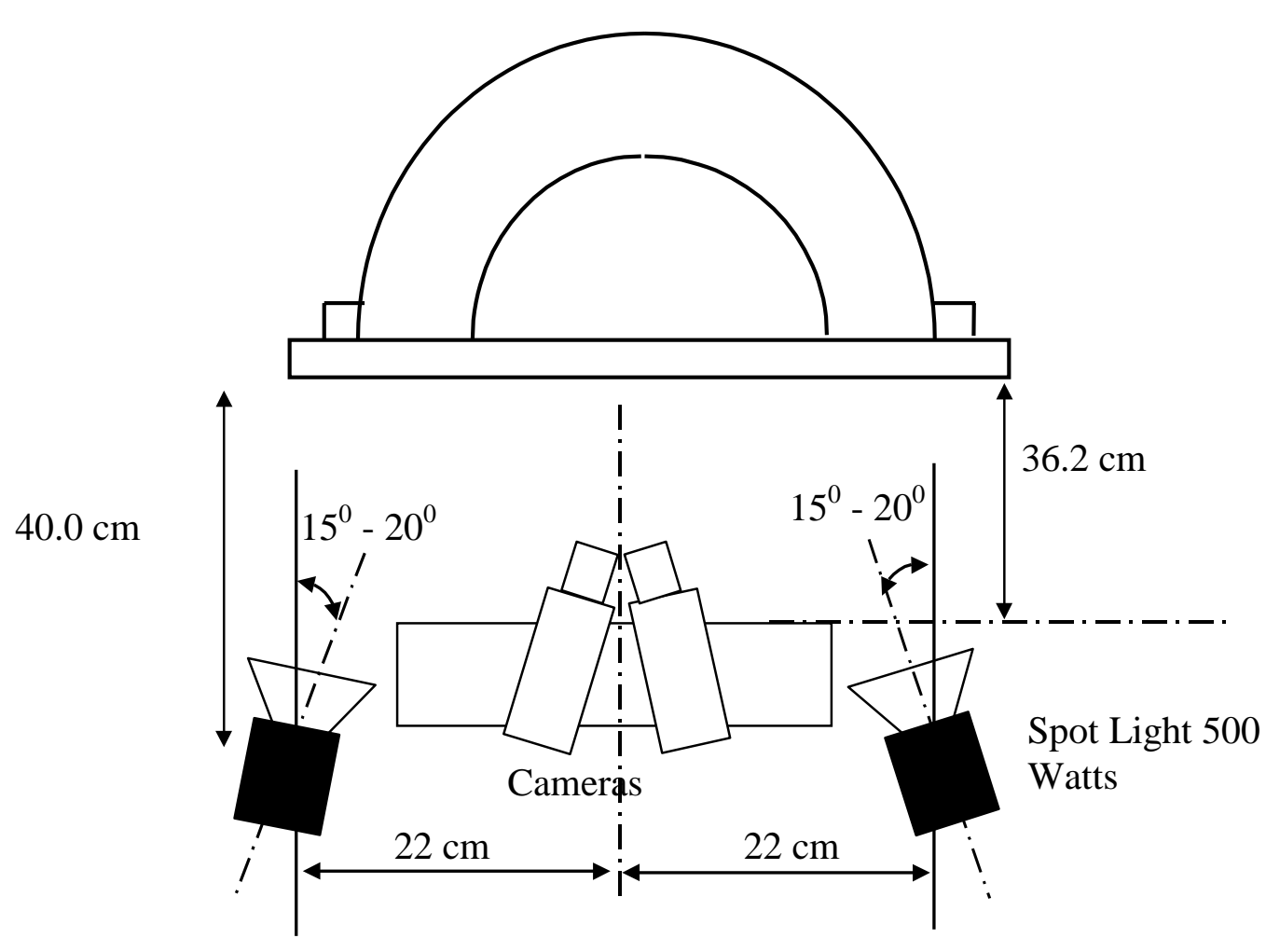

Figure 3-20. Arrangement of light and cameras for the experimental runs. 
voidage in that field. First, the software enhances the acquired image (increases the contrast between the bright and dark areas of the image). Then the software binarized the image into two groups, one as an area that is above the set gray scale value and the other below the set gray scale value. The software allows the user to set the value of the gray scale used in the program. Since the tablets overlap, this binarized image is a contiguous image of a single tablet or a group of tablets. The software then determines the number of tablets in each contiguous area using the algorithm explained below.

The software first calculates the contiguous area of the image above the threshold gray scale value. Two values are set initially, the minimum and maximum area a tablet can occupy. Since the tablets are not spherical and can take any orientation, these values were determined by trial and error. When the software scans a binarized image, it checks each contiguous area and compares it with the pre-set values. If the area is less than the minimum area, then it is rejected and the software jumps to the next contiguous area. If the area is above the maximum area a tablet can occupy, then the software subtracts the area in question with the value of the pre-set maximum area for a tablet and continues to repeat this process with the area left, until the area left is less than the minimum pre-set value. Each time a tablet area is subtracted from a contiguous area, the tablet count is increased by one and the software gives the final number of tablets obtained in that frame. Figure 3-21 shows the sequence of the camera grabbing an image, enhancing it, then binarizing it into two areas (shaded area is above the pre-set value, the remainder is below the pre-set value) and finally the number of tablets are counted based on the algorithm written in the program. Each small black circle in the image represents a particle. 
The number of fields over which the average value is to be determined can be set and this whole process is automated. Hence, when the user gives the number of fields over which he wants to determine the average number of particles in the area of focus, the software captures the number of fields given and determines the number of tablets in each field and returns an average value of the number of tablets in that area of focus or field of view (FOV) for the given number of fields.

To measure the dynamic bed voidage, the process explained above was carried out with the dynamic bed for the various conditions in the experimental matrix. The number of fields over which the voidage value was averaged was fixed at 50. By increasing the number of fields that are analyzed, the error is reduced. However, it was observed that there was no significant difference between the voidage values obtained by averaging over 50 fields and those using 75 fields. Hence, the number of frames for the voidage determination was set to be 50 . 
Raw Image
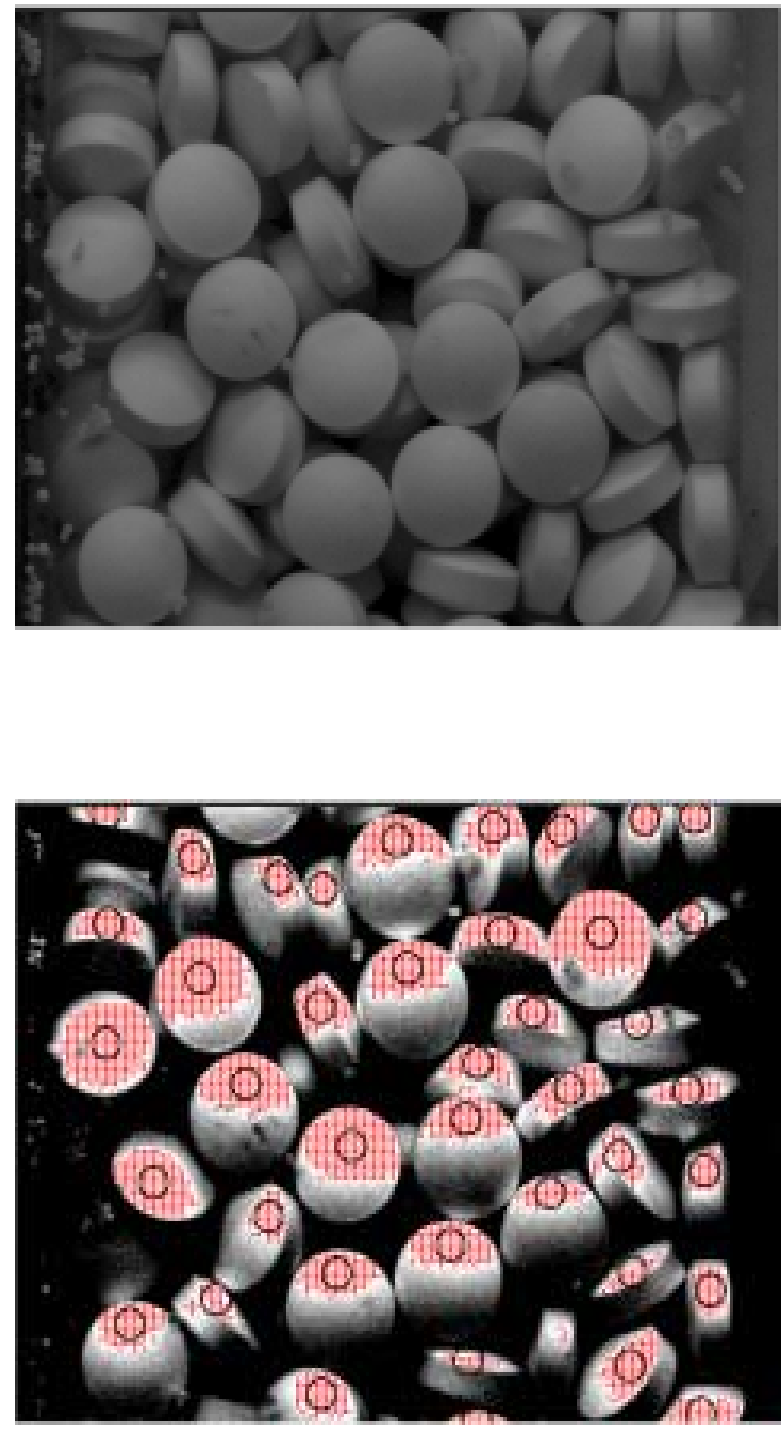

Sorted Image
Enhanced Image
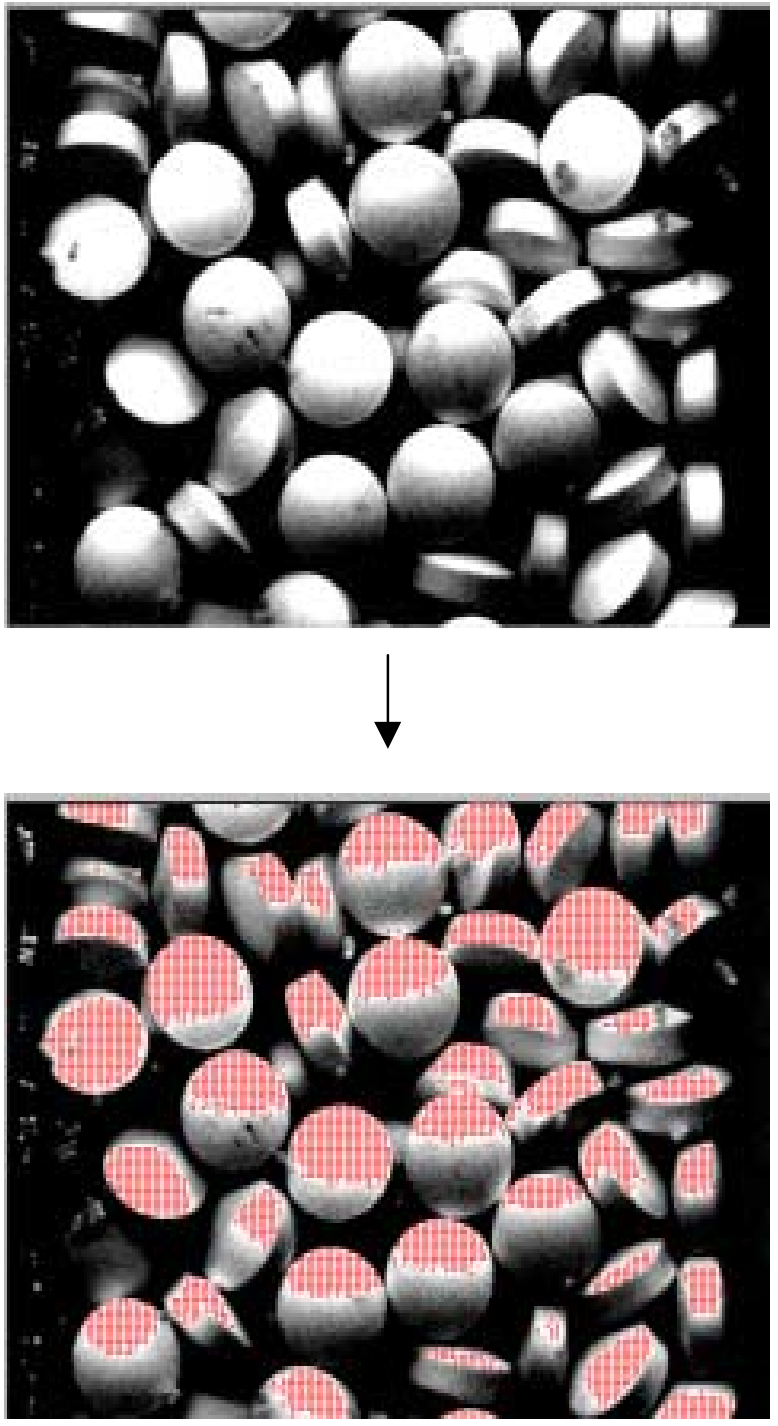

Binarized Image

Figure 3-21. Sequence of events that the software used to identify the number of particles in a field/image. 


\section{3-7 Objective of Coating Experiments}

The objective of these runs was to determine the effect of the use of deflectors to improve coating consistency by preventing the tablets from passing directly over the spray nozzle, thus reducing the sheltering effect explained isection 4-4.'The coating experiments can be divided into two main categories, the continuous coating runs and the pulse tests, each of these runs will be discussed in detail along with the conditions and the parameters used. Work done previously by Cheng and Turton (1993), and Shelukar et al. (2000), have shown that the uniformity in a Wurster bed coating process is primarily determined by two factors - the coating-per-pass distribution and the circulation-time distribution. Both of the above authors concluded that the coating-per-pass distribution contributes more significantly (> 75\%) to the total-coating uniformity. Mann (1972) derived an expression to express the variation in the coating process, in terms of the variation in the amount of coating received per pass, and the variation in the circulation time distribution for tablet movement through the spray zone.

$$
\frac{\sigma_{t o t}}{\mu_{t o t}}=\sqrt{\left(\frac{\sigma_{c t}}{\mu_{c t}}\right)^{2}\left[\frac{\mu_{c t}}{T_{c o a t}}\right]+\left(\frac{\sigma_{x}}{\mu_{x}}\right)^{2}\left[\frac{\mu_{c t}}{T_{c o a t}}\right]}
$$

where $\sigma_{\text {total }}$ is the variance of the coating distribution, $\mu_{\text {total }}$ is the mean of the coating distribution, $\sigma_{\mathrm{ct}}$ and $\mu_{\mathrm{ct}}$ are the standard deviation and mean of the cycle time distribution respectively, $\mathrm{T}_{\text {coat }}$ is the total coating time. $\sigma_{\mathrm{x}}$ the variance of the coating mass per particle per pass, and $\mu_{\mathrm{x}}$ the mean coating mass per particle per pass. $\sigma / \mu$ is called the Relative Standard Deviation (RSD) and is a good measure of the variation in coating consistency. 
The first term on the right hand side of equation (3-1) is the variation caused by the non-uniformity of particle circulation, while the second term represents the variation due to different amounts of coating being received by a particle per pass through the spray zone. It is the second source of variance that is the more important one for coating operations over reasonably long (>20 minutes) coating runs. The coating experiments were designed to investigate quantitatively the effect of deflectors in reducing the variance caused by the second term and hence its effect on the coating quality.

\section{3-8 Determining the coating formulation}

The total amount of coating material used was determined by the time of the coating run and the rate at which the coating material was sprayed. A mixture of Aquacoat@ (Ethyl cellulose aqueous dispersion with 30\% solids, supplied by FMC Corp., Newark, DE) and water with blue dye (FD\&C approved blue dye \# 1, supplied by Warner-Jenkinson Company, St. Louis, MO) was used as the coating mixture. The coating mixture distributes evenly on the tablet surface indicating that this mixture is representative of the actual coating process. The coating solution spreads evenly on the tablet surface indicating that the blue dye is representative of the actual coating process. The coating for the continuous coating runs was formulated such that the amount of blue dye coated on each tablet, at the end of a run, would be high enough to be analyzed by the spectrophotometer. The amount of blue dye used was estimated by back-calculating the amount of blue dye that would be coated if all the coating material pumped were to deposit on the tablets. The weight of the tablets to be coated was very large compared to the amount of coating material and hence the increase in the weight of 
individual tablets was insignificant. The details of calculations for determining the coating formulation are given in Appendix X.

\subsection{Coating Experiments}

\section{3-9.1 Continuous coating Experiments}

The objective of these runs was to determine the overall coating consistency after a complete coating run and hence obtain a value for $\sigma_{\text {total }} / \mu_{\text {total }}\left(\operatorname{RSD}_{\text {total }}\right)$, the LHS of equation 3-1. The operating parameters for the coating runs are given in Table 3-3.

Table 3-3 Operating parameters for the continuous coating runs

\begin{tabular}{|l|l|}
\hline Air Flow Rate & $0.066 \mathrm{~m}^{3} / \mathrm{s}$ \\
\hline Coating liquid flow rate & $10 \mathrm{ml} / \mathrm{min}$ \\
\hline Volume of Coating liquid & $600 \mathrm{ml}$ \\
\hline Temperature of Air & $115 \mathrm{~F}$ or $45 \mathrm{C}$ \\
\hline Time of Coating & $70 \mathrm{~min}$ \\
\hline Weight of Bed Material & $3.675 \mathrm{~kg}$ \\
\hline Weight of Blue Dye used & $2.7 \mathrm{gm}$ \\
\hline Bed air temperature & $114 \mathrm{~F}$ \\
\hline Liquid spray air pressure & $35 \mathrm{psi}$ \\
\hline
\end{tabular}

These coating runs were repeated for the different deflector designs, keeping all the parameters constant except the design of the deflector. After each coating run, 100 tablets were picked randomly and were analyzed for blue dye content. A histogram plot of blue dye concentration per tablet vs. frequency shows the spread of the amount of 
coating each tablet receives. The change in the spread or variance with the use of different deflectors was then studied.

\section{3-9.2 Method of coating for continuous tests}

The fluidized bed is first cleaned and assembled. A pre-weighed quantity (3.675 $\mathrm{kg}$ ) of tablets is then charged into the equipment through the charge point at the top of the bed. The supply blower is then started and the valves adjusted to obtain the desired airflow rate. The coil heater for heating the supply air is then switched on and the temperature set to the desired value. The spray nozzle airflow is adjusted to the desired value, the peristaltic spray pump is switched on, and the flow rate set to $10 \mathrm{ml} / \mathrm{min}$. Calibration details of the peristaltic pump are given in Appendix XII. A detailed flow diagram of the experimental setup is shown in the Figure 3-5.

The fluidized bed is run under these conditions for 70 minutes, and all the coating solution is pumped into the bed over this period. The peristaltic pump and the heater are then turned off and the bed is run for 10 minutes to dry any moisture remaining on the tablets. The supply air is then lowered and the coated tablets are collected through the discharge port at the bottom of the bed above the distributor plate. Finally, the air supply to the spray nozzle is shut-off.

The coating solution is made just before the run by adding blue dye to Aquacoat ${ }$ in a beaker and stirred by a Magnetic stirrer. The solubility of the blue dye in Aquacoat ${ }^{\circledR}$ is excellent and the concentration of blue dye $(0.5 \%)$ was far less than the saturation concentration of $10 \%$. 


\section{3-9.3 Pulse coating test}

The pulse tests were conducted to determine the variation in coating quality due to the variation in the amounts of coating received by a particle-per-pass through the spray zone. This will quantify the second term $\left(\sigma_{\mathrm{x}} / \mu_{\mathrm{x}}\right)$ on the RHS of Equation (3-1).

\section{3-9.4 Method of coating for Pulse tests}

The coating process for the pulse test is similar to that of the continuous coating runs. The parameters are given in Table 3-4 below. After the bed is cleaned and the bed charged with the measured quantity of tablets, the supply blower is switched on and the bed is fluidized with the same conditions as that of the continuous run, except that the coating material does not contain blue dye. After the supply-air has reached the required temperature (usually a couple of minutes), a pulse of highly concentrated blue dye is injected into the coating fluid line close to the spray nozzle. The pulse of blue dye is sprayed over a period of 8 to 10 seconds, which is equal to one circulation time. The fluidized bed is stopped and emptied as in the case of continuous coating runs.

Table 3-4 Operating parameters for the pulse test runs

\begin{tabular}{|l|l|}
\hline Air Flow Rate & $0.066 \mathrm{~m}^{3} / \mathrm{s}$ \\
\hline Coating liquid flow rate & $10 \mathrm{ml} / \mathrm{min}$ \\
\hline Volume of Coating liquid & $100 \mathrm{ml}$ \\
\hline Temperature of Air & $115 \mathrm{~F}$ or $45 \mathrm{C}$ \\
\hline Time of Coating & 25 minutes \\
\hline Weight of Bed Material & $3.675 \mathrm{~kg}$ \\
\hline Weight of Blue Dye used & $2.7 \mathrm{gm}$ \\
\hline
\end{tabular}




\begin{tabular}{|l|l|}
\hline Liquid spray air pressure & $35 \mathrm{psi}$ \\
\hline Bed air temperature & $114 \mathrm{~F}$ \\
\hline Volume of Pulse & $1 \mathrm{ml}$ \\
\hline Number of Pulse & 1 \\
\hline Time of Pulse & $8-10 \mathrm{sec}$ \\
\hline
\end{tabular}

\section{3-10 Analysis of coated tablets}

A Lambda 2 UV/VIS Spectrophotometer (Perkin-Elmer corp., Norwalk, CT) with data acquisition software package PECSS version 4.0 was used for the assay of blue dye. The characteristic wavelength of blue dye \# 1 was found by scanning wavelengths in the range of 300 to $800 \mathrm{~nm}$. The scanning spectrum of blue dye is given Appendix VII. The peak absorbance occurs at a wavelength of $629 \mathrm{~nm}$. The spectrophotometer calibration details for normal concentration are given in Appendix VIII.

\section{3-10.1 Analysis of continuous coating runs}

After the run is completed, the tablets from the bed are discharged into a cardboard box. From the box, samples were picked at random (100 samples). Each of the randomly picked tablets was first dissolved in $10 \mathrm{ml}$ water and shaken well to ensure all the blue dye on the tablet was dissolved in the water. The tablets are highly soluble in water and they disintegrate within a couple of minutes, releasing the blue dye into the water. The mixture was then filtered with filter paper (Fisher Q5, Porosity: Medium, Flow rate: Medium) using vacuum to speed-up the process. The filter paper was then washed with $5 \mathrm{ml}$ of water to remove any dye on the paper. The clear blue water was then 
analyzed for blue dye content using the spectrophotometer. This gives the blue dye content per tablet. The process was repeated for 100 tablets to get an average blue dye content, spread, and variation for each batch. Similarly, samples were analyzed for the other coating runs with the deflector, modified deflector 1 , modified deflector2, modified deflector3 and optimum deflector.

\section{3-10.2 Analysis for Pulse test runs}

The analysis of blue dye content for the pulse test runs was similar to that of the continuous runs. However, for the pulse test, a tablet was dissolved in $2 \mathrm{ml}$ water and then washed with $1 \mathrm{ml}$ water. The amount of blue dye received by tablets during a pulse test was very low and hence the amount of water used to dissolve the tablet was kept as low as possible, so that the blue dye concentration can be deduced by the spectrometer. The blue dye content fell in the lower part of the detectable range of the spectrophotometer and a low concentration calibration curve shown in Appendix IX was used. The software, PECSS version 4.0, used with the spectrometer could calculate values only up to the fourth decimal place and hence when values less than that were calculated, they were rounded off to 0 . Hence, even though the spectrometer detected different values of absorbance for the samples, the software sometimes gave the same concentration values. Therefore, for the pulse tests the value of blue dye concentration was calculated by substituting the value of absorbance into a linear equation that related absorbance to blue dye concentration shown in Appendix XIII, rather than using the results from the PECCS software. 


\section{CHAPTER IV}

\section{RESULTS AND DISCUSSION}

\section{4-1. Velocity Measurement in the Draft-tube region}

\section{4-1.1 Velocity Profiles in the draft-tube}

The draft-tube region in the semi-circular bed was divided into an imaginary grid of square boxes with sides equal to $2.0 \mathrm{~cm}$. The draft-tube, $10.2 \mathrm{~cm}$ wide and $35.2 \mathrm{~cm}$ in height, was divided into five boxes in the horizontal direction and 17 boxes in the vertical direction. Velocity and voidage measurements were taken up to the $13^{\text {th }}$ box in the vertical direction. It was observed that the particles at this point already showed a steady profile, and were out of the spray zone and hence the reminder of the velocity data in the draft-tube was of less significance. The first row of the imaginary boxes was directly above the nozzle, where the particles entered the spray zone. The imaginary grid is illustrated in Figure 4-1.

The particle velocity profiles in the draft-tube were measured for a variety of operating conditions shown in the experimental matrix in Table 3-1. For each operating condition, the velocity profile has been mapped and is pictorially represented using a software program written in Microsoft Visual Basic 6.0. The grid corresponds to that shown in Figure 4-1 and the lines inside these boxes represent the magnitude and direction of the average velocity vector of the particle motion in that region of the drafttube. The velocities shown in these figures were the average value of between 70 to 100 sets of velocity data obtained at each position in the bed.

The major variations in the operating conditions were the gap height between the distributor plate and draft-tube and the presence or absence of different types of 
deflectors. Figure 4-2 and Figure 4-3 show a comparison of the radial velocity profiles of particles at different axial heights in the draft-tube for two gap heights, $2.7 \mathrm{~cm}$ and 7.4 $\mathrm{cm}$, for the cases with and without a deflector.

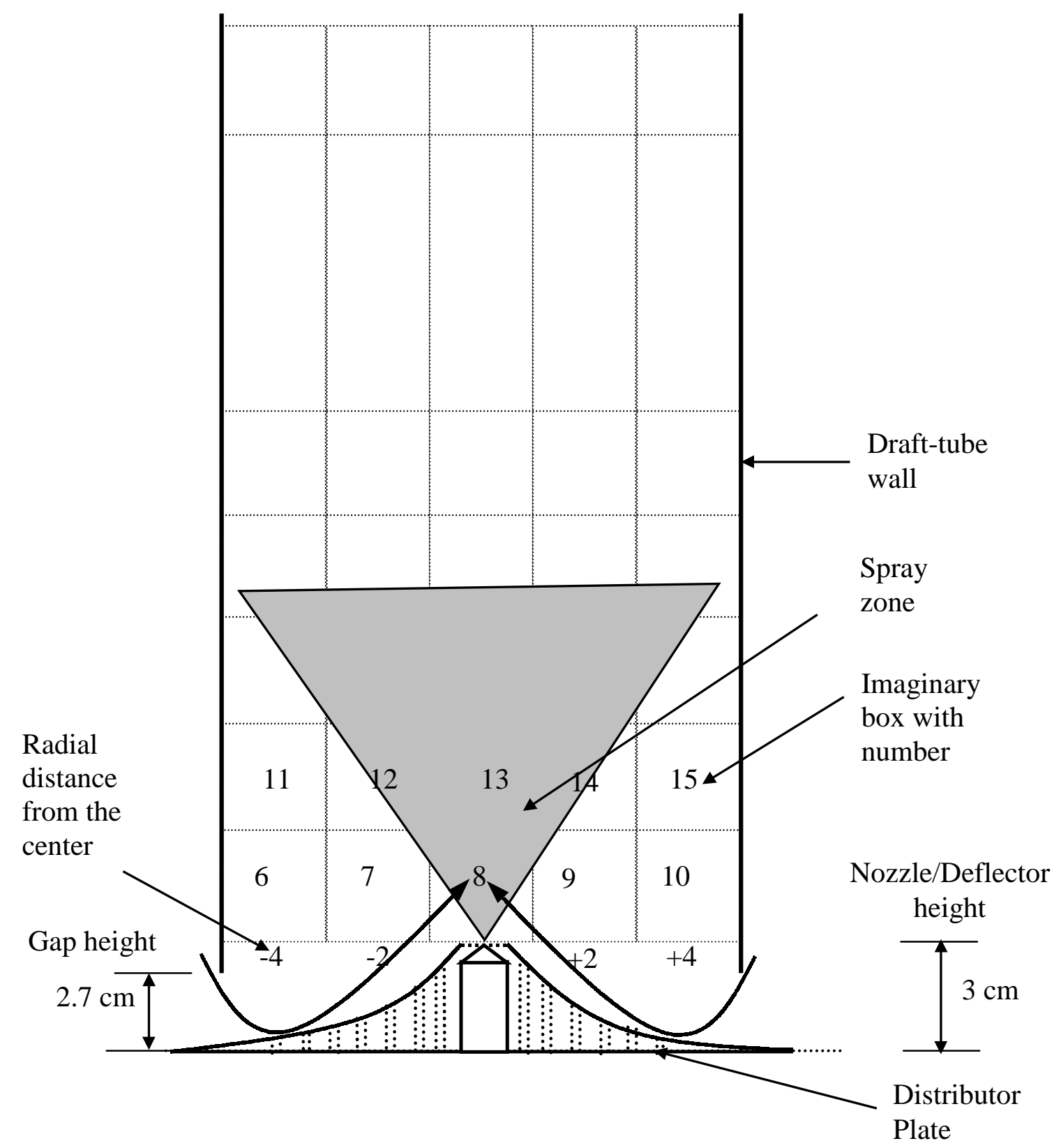

Figure 4-1. Diagram showing the relative position of the distributor plate, deflector, nozzle and the imaginary grid for the case with deflector 1 and lower gap height $(2.7 \mathrm{~cm})$ 

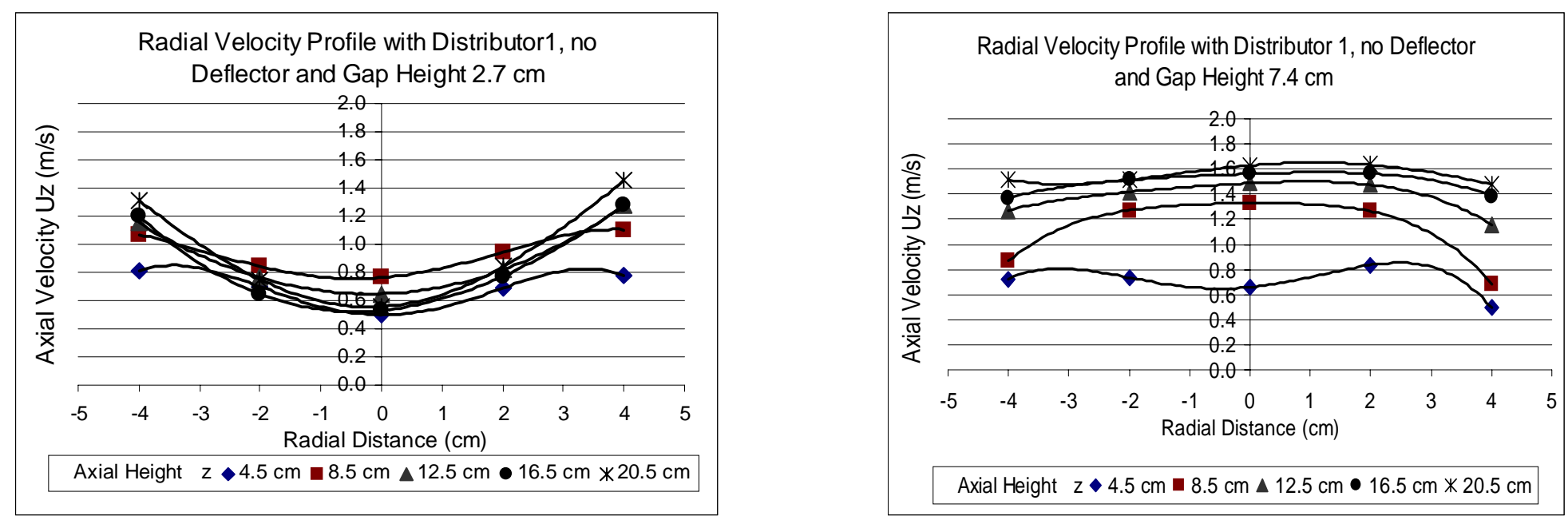

Figure 4-2 a, b. Radial particle velocity profile with height in the draft-tube with no deflector and gap heights of $2.7 \mathrm{~cm}$ and $7.4 \mathrm{~cm}$, respectively.
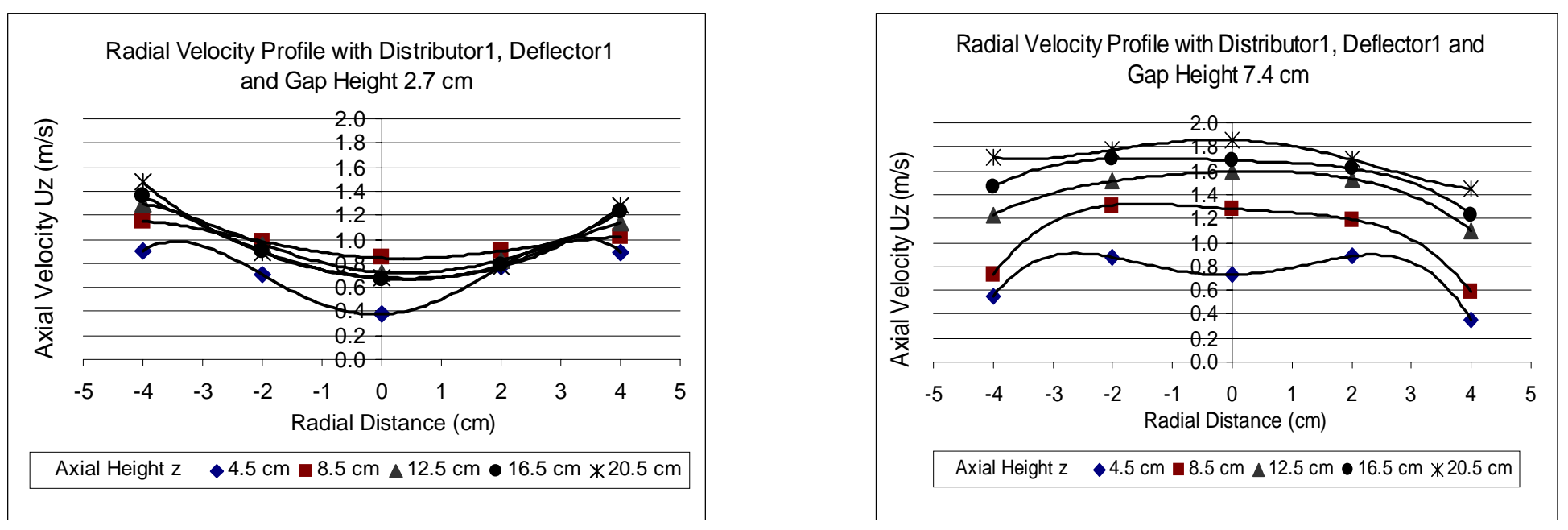

Figure 4-3 a, b. Radial particle velocity profile with height in the draft-tube with deflector 1 and gap heights of $2.7 \mathrm{~cm}$ and $7.4 \mathrm{~cm}$, respectively. 

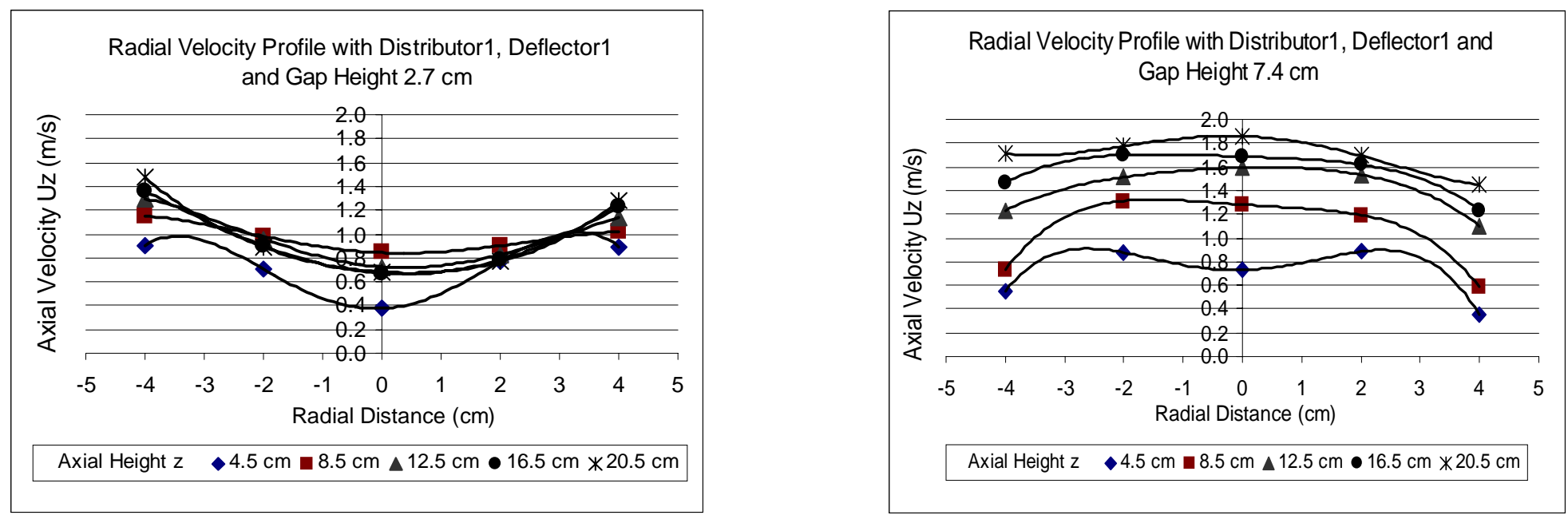

Figure 4-4 a, b. Radial particle velocity profile with height in the draft-tube with deflector 1 and gap heights of $2.7 \mathrm{~cm}$ and $7.4 \mathrm{~cm}$, respectively.
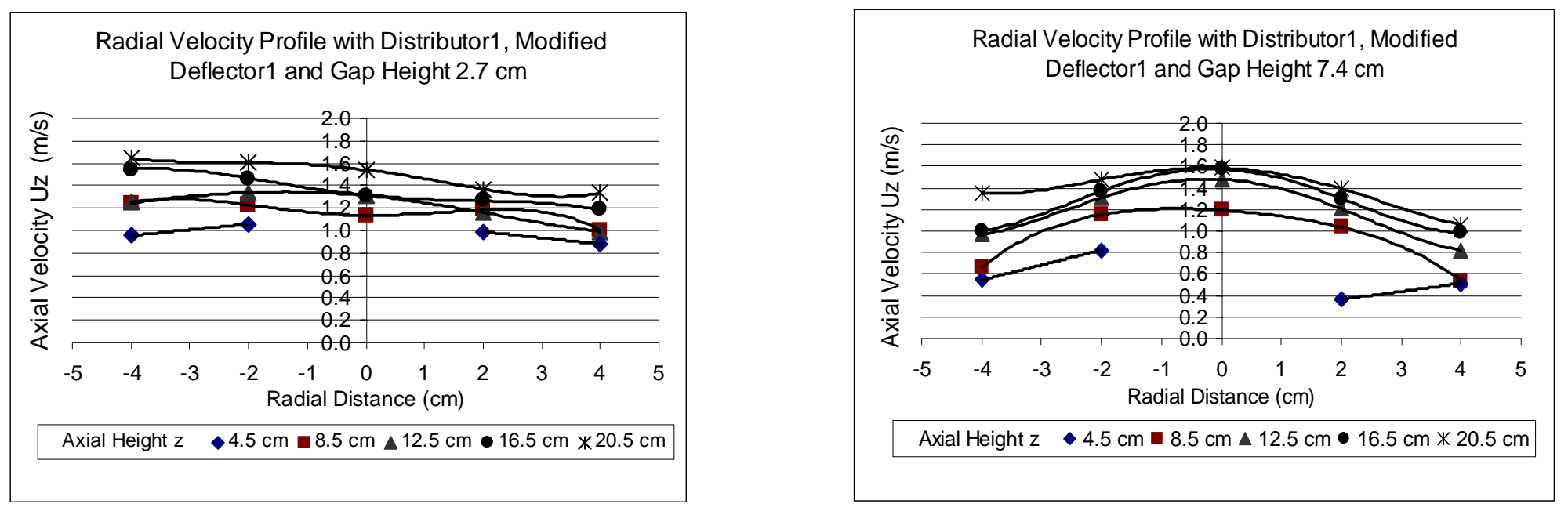

Figure 4-5 a, b. Radial particle velocity profile with height in the draft-tube with modified deflector 1 and gap heights of $2.7 \mathrm{~cm}$ and 7.4 $\mathrm{cm}$, respectively. 
From Figure 4-2, it can be observed that the velocities at the center of the drafttube for the case without the deflector, at the lower gap height $(2.7 \mathrm{~cm})$, are lower than the velocities closer to the wall of the draft-tube. However for the case with deflector 1 , the profile is flatter and the difference in velocities at the center to that close to the wall is small or close to zero. The following explanations are based on the visual observations made during the experiment. In the case of no deflector, the particles that enter through the gap accelerate in the horizontal direction resulting in particle-particle collision at the center of the bed. Thus, the particles lose their momentum and redistribute themselves across the radius of the draft-tube. In the presence of a deflector, the particles are guided away from the center as shown in Figures 3-9a, and hence the velocities at the center are higher than those towards the wall of the draft-tube.

This phenomenon is seen more prominently in the presence of the modified deflector 1 , where the velocities at the center are higher than the velocities closer to the walls of the draft-tube by almost a factor of two. The inclusion of the ring around deflector 1 (resulting in the modified deflector 1) deflects the tablets further away from the center, thus reducing the particle-particle collision in the center. These deflected particles now collide with the particles moving up closer to the draft-tube wall, reducing their velocities. The velocity at the center $(\mathrm{r}=0)$ and axial height $\mathrm{z}=4.5 \mathrm{~cm}$ could not be measured as the modified deflector 1 deflected the particles out of the depth of field causing a region of high voidage, with virtually no tablets, at the bottom and center of the bed. However, the presence of deflectors reduces the effective gap through which the tablets enter into the draft-tube, and thus reduces the particle mass-flux into the drafttube. 
With the higher gap heights $(7.4 \mathrm{~cm})$, these velocity profiles become more symmetric and the particles have a tendency to accelerate as they reach higher axial locations. At the higher gap height, the bottom of the draft-tube is almost at the same height as the top of the deflector and hence the restriction due to the deflector, caused in the case of the lower gap height, is markedly reduced. This results in increased mass-flux through the draft-tube. For this case, the tablets are no longer forced to enter the drafttube region in a horizontal direction; instead, the particles move vertically upward along the draft-tube walls. This movement was further facilitated by the design of the draft-tube with an inner angle of $60^{\circ}$ from the vertical at the bottom as shown in insert A of Figure 3-2.

For the case without the deflector, the velocities at the center were not much different from those at the walls of the draft-tube, but in the presence of a deflector, the velocities at the center were much higher than those at the walls, similar to the case with the lower gap height. The particles that are deflected away from the center move towards the walls of the draft-tube and this causes particle-particle collision near the walls and particle-wall collision resulting in lower particle velocities. This movement of particles away from the center can further be confirmed with the voidage profiles discussed later.

Another phenomenon observed in the case of the higher gap height, for both cases with and without a deflector, was that the particles tend to enter the bed at low velocities and are accelerated rapidly unlike the case of the lower gap heights where the acceleration is less rapid. This phenomenon was more pronounced in the presence of the deflector. The velocity at the center and top of the draft-tube $(\mathrm{r}=0$ and $\mathrm{z}=20.5 \mathrm{~cm})$ is higher in the presence of deflector 1 than in case of no deflector. This is because 
deflector 1 channels or guides the tablets entering into the draft-tube region, resulting in a smooth transition and change in the direction of the tablets. This can be observed by comparing the radial velocity profiles in Figures 4-2 with Figure 4-3, and Figures 4-4 with Figure 4-5. The velocity profile maps for the above cases are shown in Figure 4-6, 4-7 and 4-8. The low velocities in the bottom of the draft-tube can be attributed to the fact that when the gap height is high, more particles enter the draft-tube causing very high particle-particle interaction. With this large number of tablets entering the draft-tube region, the particles behave as one big mass of tablets offering more resistance to the airflow. Krzwanski (1992) also predicted a denser zone of particles in the center of the bed, for some conditions.

The box in the center exactly above the nozzle is left empty for the cases with the modified deflector 1. In the presence of this deflector, the particles are deflected away from the nozzle, thus in the space right above the nozzle no particles were recorded by the camera in the DOF of $1.5 \mathrm{~cm}$ from the inner glass wall. Hence in Figure $4-5 \mathrm{a} \& \mathrm{~b}$ the velocity value at $\mathrm{z}=4.5$ and $\mathrm{r}=0$ is not plotted and in Figure 4-10 and 4-11, the box at $z=4.5$ and $r=0$ is left empty.

Figure 4-12 shows a comparison between the particle velocity profile in the bed for the case with no deflector and a gap height of $7.4 \mathrm{~cm}$ with two different distributor plates. The ratio of inner to outer area in case of distributor plate 1 was 0.83 and in case of distributor plate 2, it was 0.92 (see Appendix XVI for photographs). As observed from the graphs, there is very little difference between the radial velocity profiles at different axial locations for the two cases. In fact, these profiles are both symmetric and. 


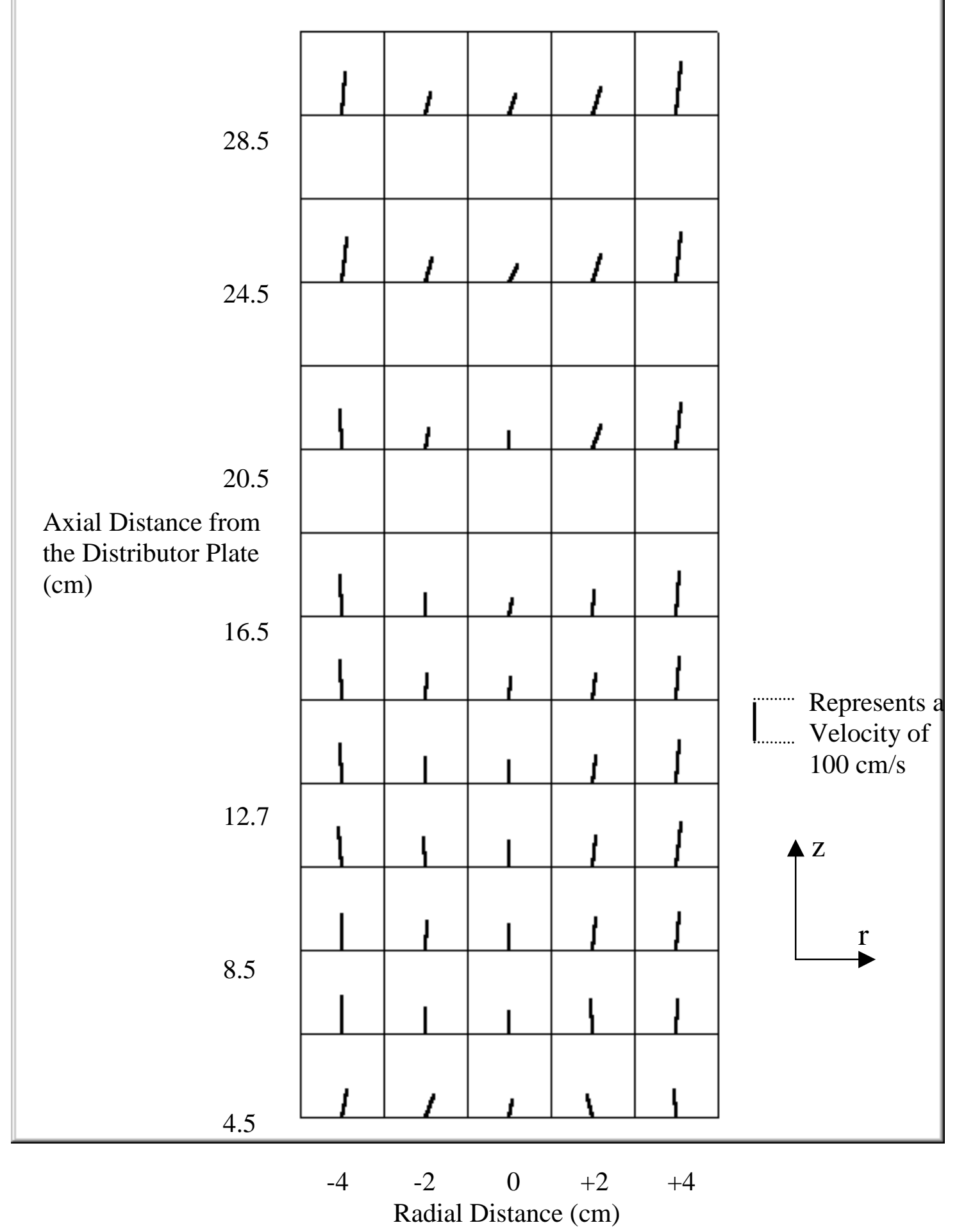

Figure 4-6. Particle velocity map in the draft-tube at different axial locations in the bed with distributor1, no deflector and gap height $2.7 \mathrm{~cm}$. 


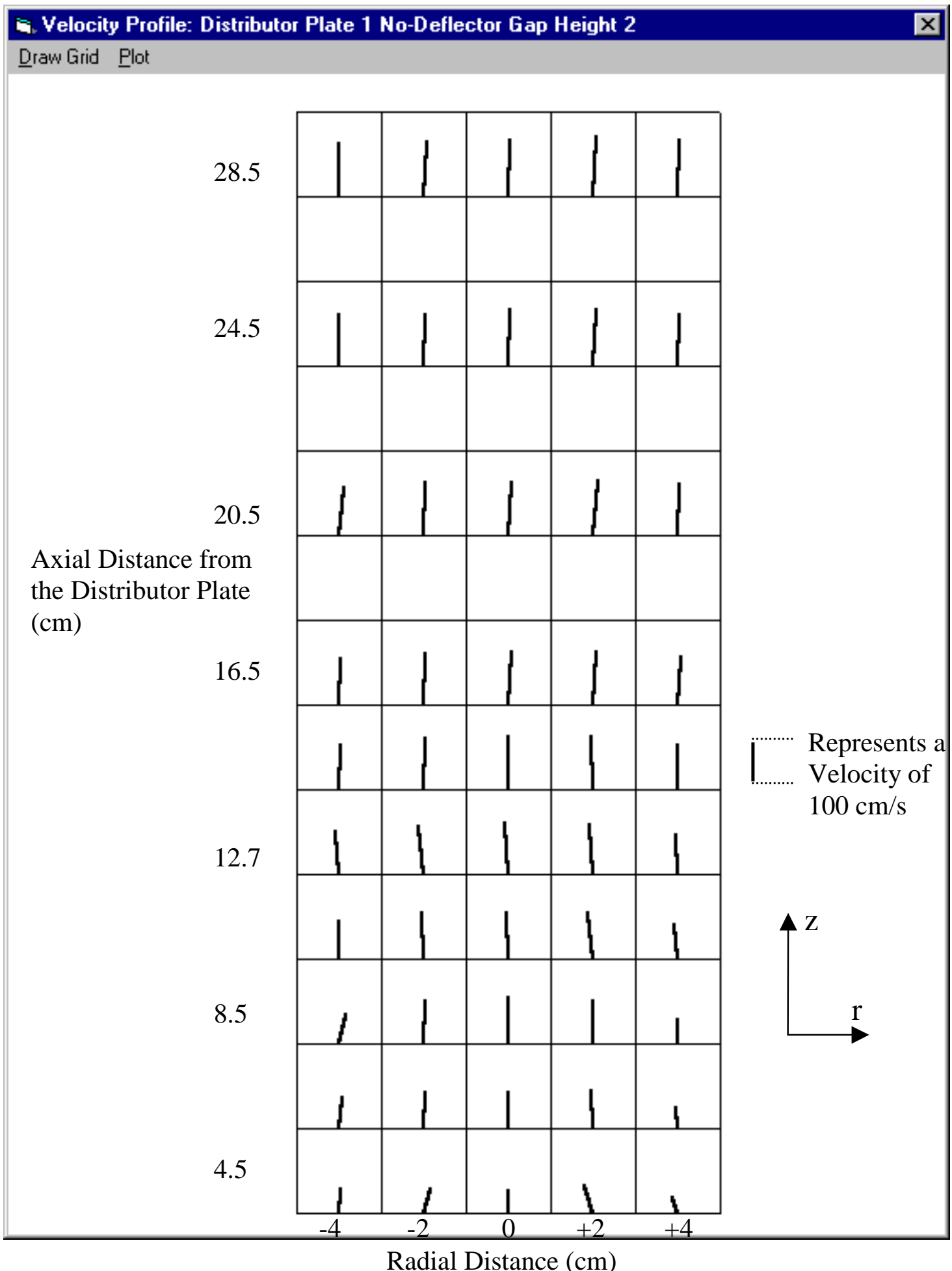

Figure 4-7. Particle velocity map in the draft-tube at different axial locations in the bed with distributor1, no deflector and gap height $7.4 \mathrm{~cm}$. 


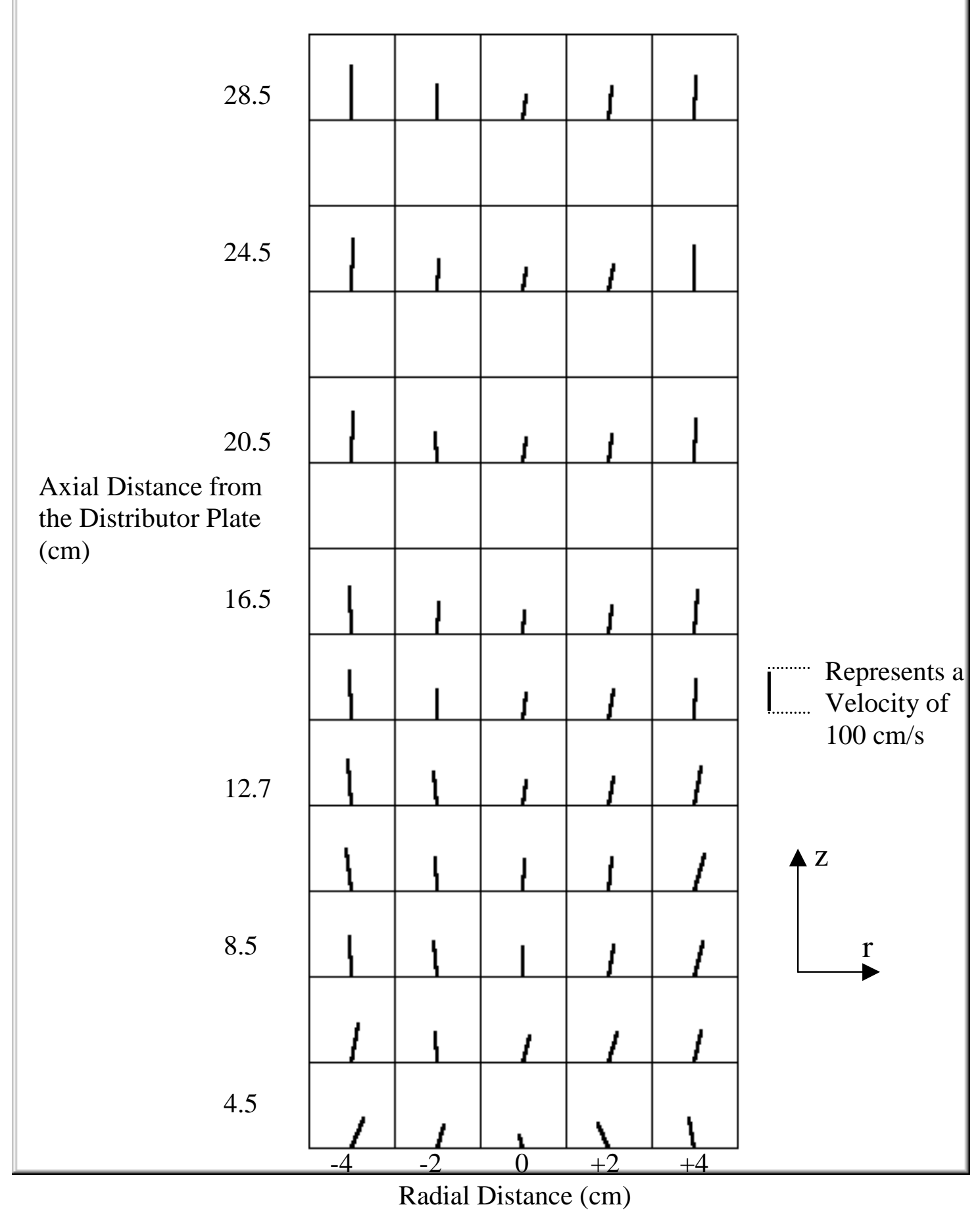

Figure 4-8. Particle velocity map in the draft-tube at different axial locations in the bed with distributor 1, deflector 1 and gap height $2.7 \mathrm{~cm}$. 


\section{Draw Grid Plot}

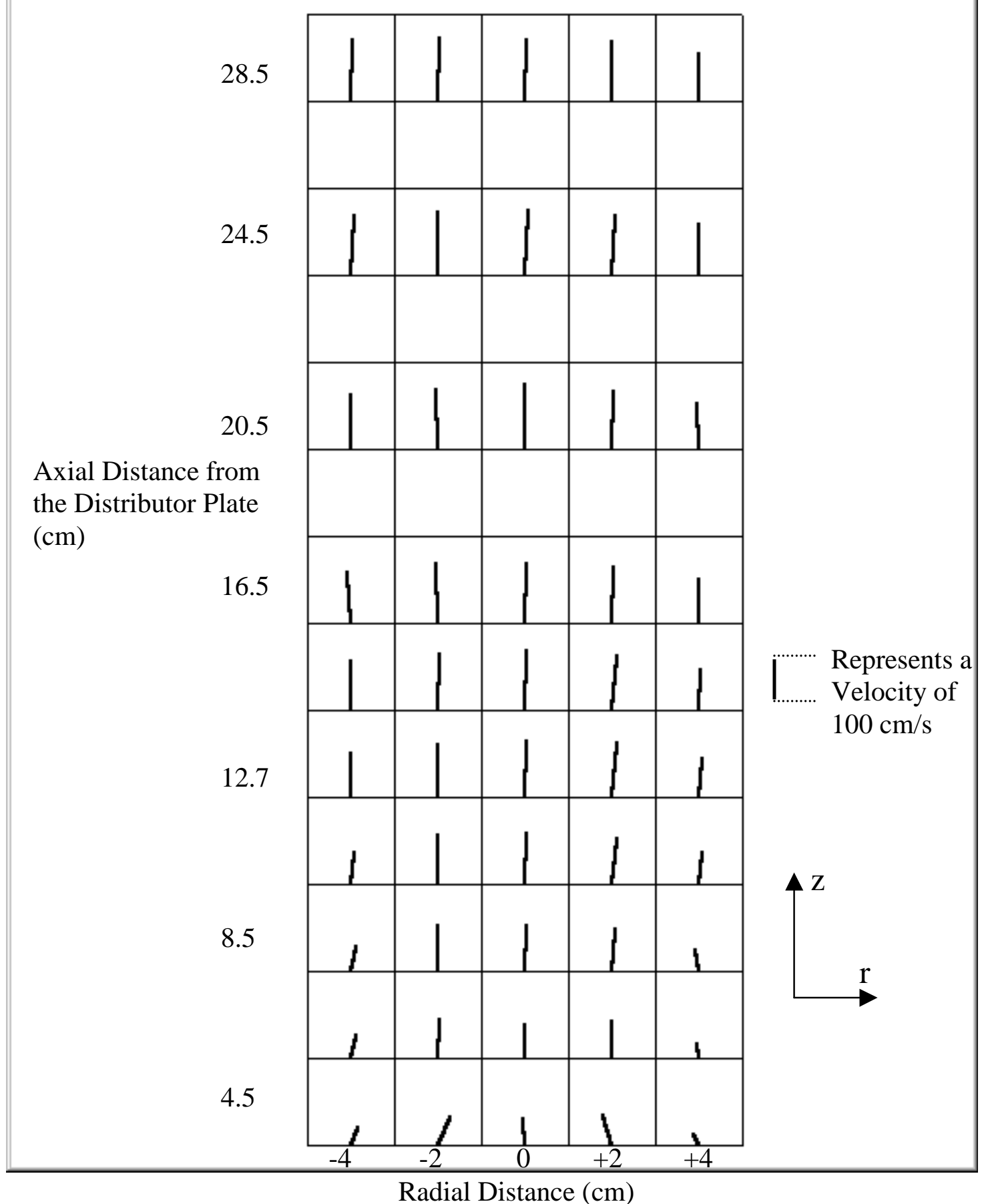

Figure 4-9. Particle velocity map in the draft-tube at different axial locations in the bed with distributor 1, deflector 1 and gap height $7.4 \mathrm{~cm}$. 


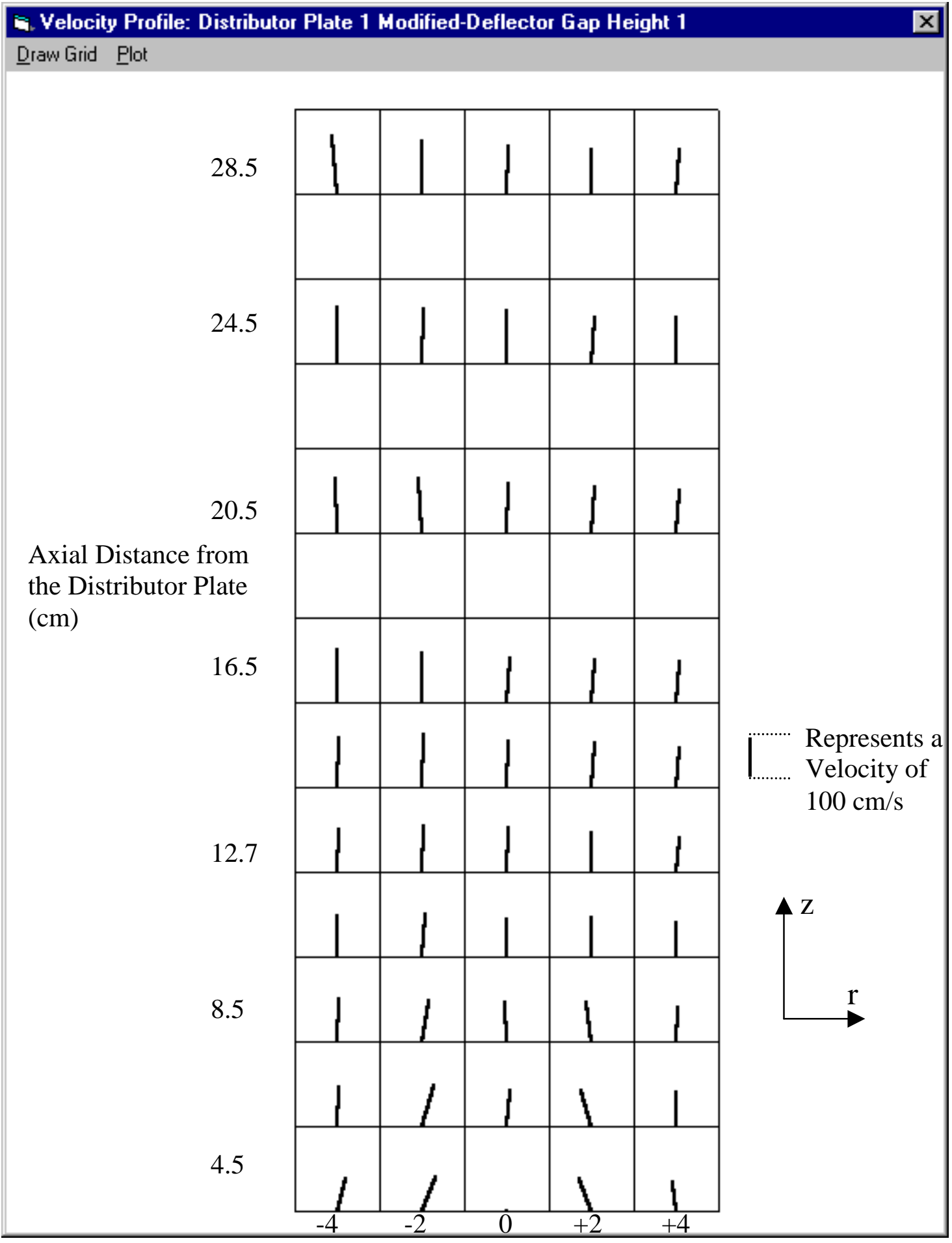

Radial Distance (cm)

Figure 4-10. Particle velocity map in the draft-tube at different axial locations in the bed with distributor 1 , modified deflector 1 and gap height $2.7 \mathrm{~cm}$. 


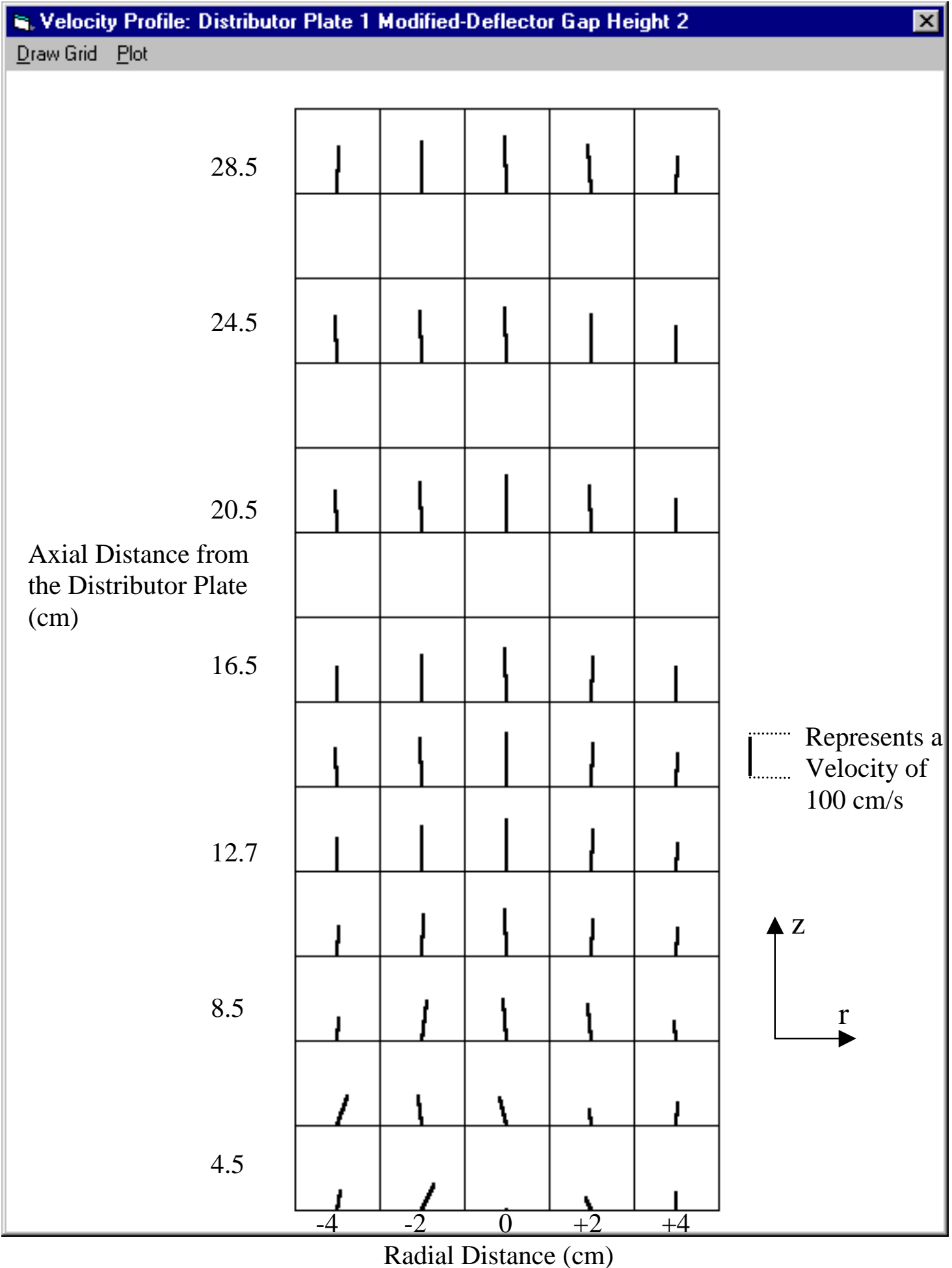

Figure 4-11. Particle velocity map in the draft-tube at different axial locations in the bed with distributor 1 , modified deflector 1 and gap height $7.4 \mathrm{~cm}$. 

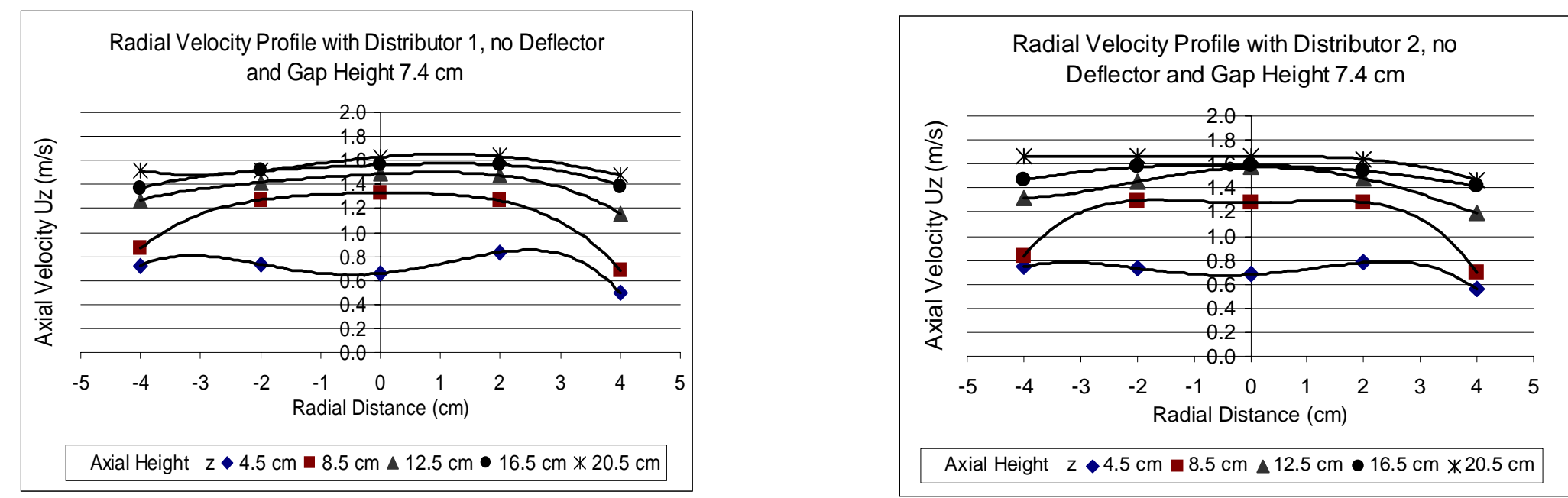

Figure 4-12 a, b. Radial particle velocity profile with height in the draft-tube with no deflector, gap heights $7.4 \mathrm{~cm}$ and with distributor plate 1 and distributor plate 2 respectively.
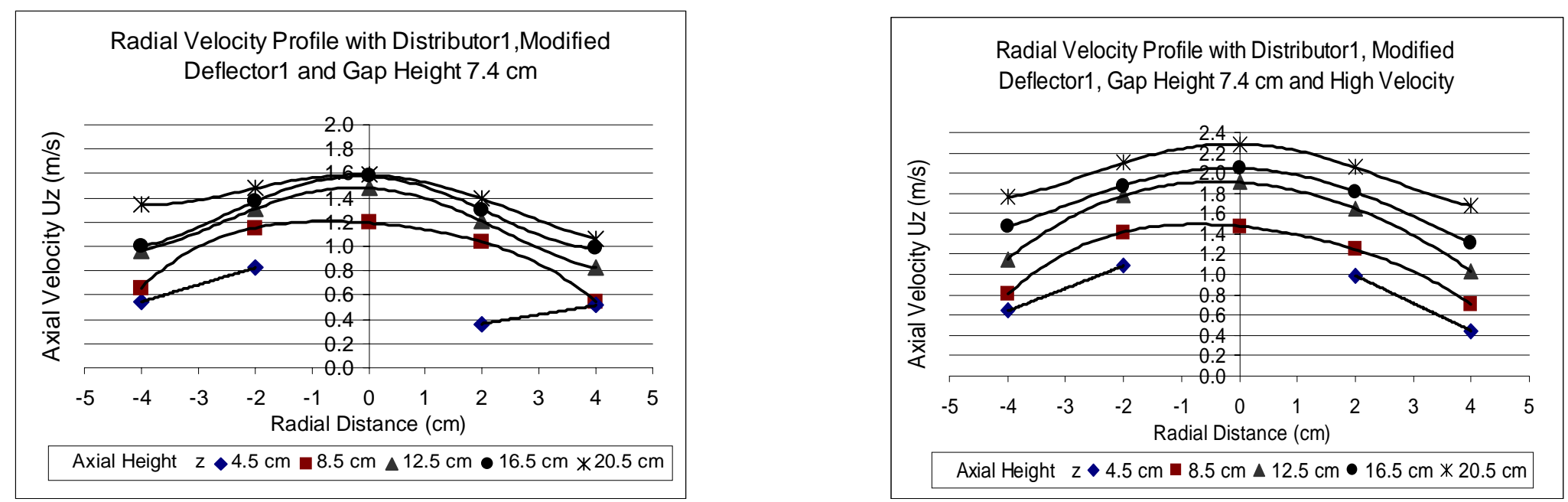

Figure 4-13 a, b. Radial particle velocity profile with height in the draft-tube with modified deflector 1 and gap heights $2.7 \mathrm{~cm}$ and 7.4 $\mathrm{cm}$ respectively. 


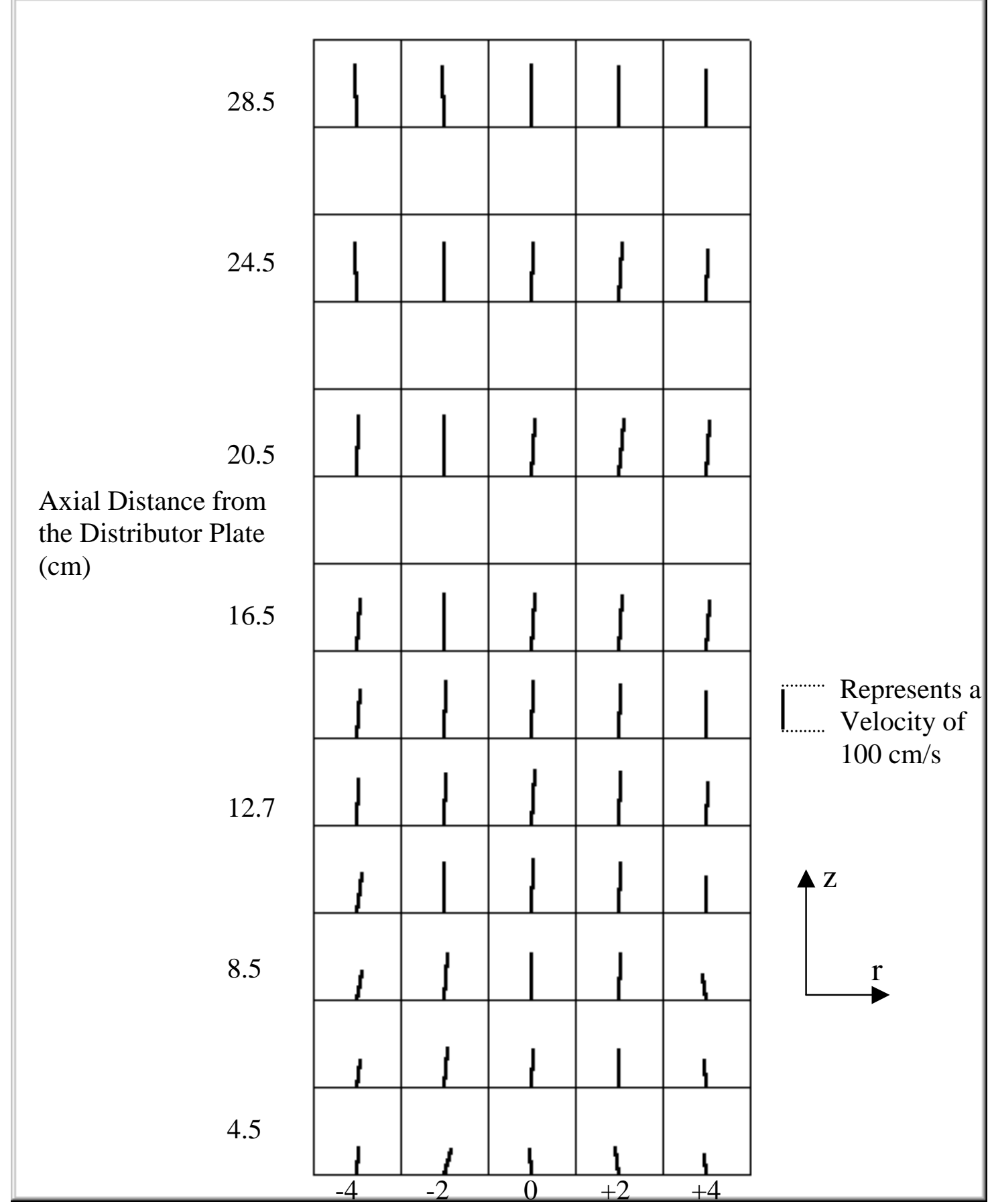

Radial Distance (cm)

Figure 4-14. Particle velocity map in the draft-tube at different axial locations in the bed with distributor 2, no deflector and gap height $7.4 \mathrm{~cm}$. 


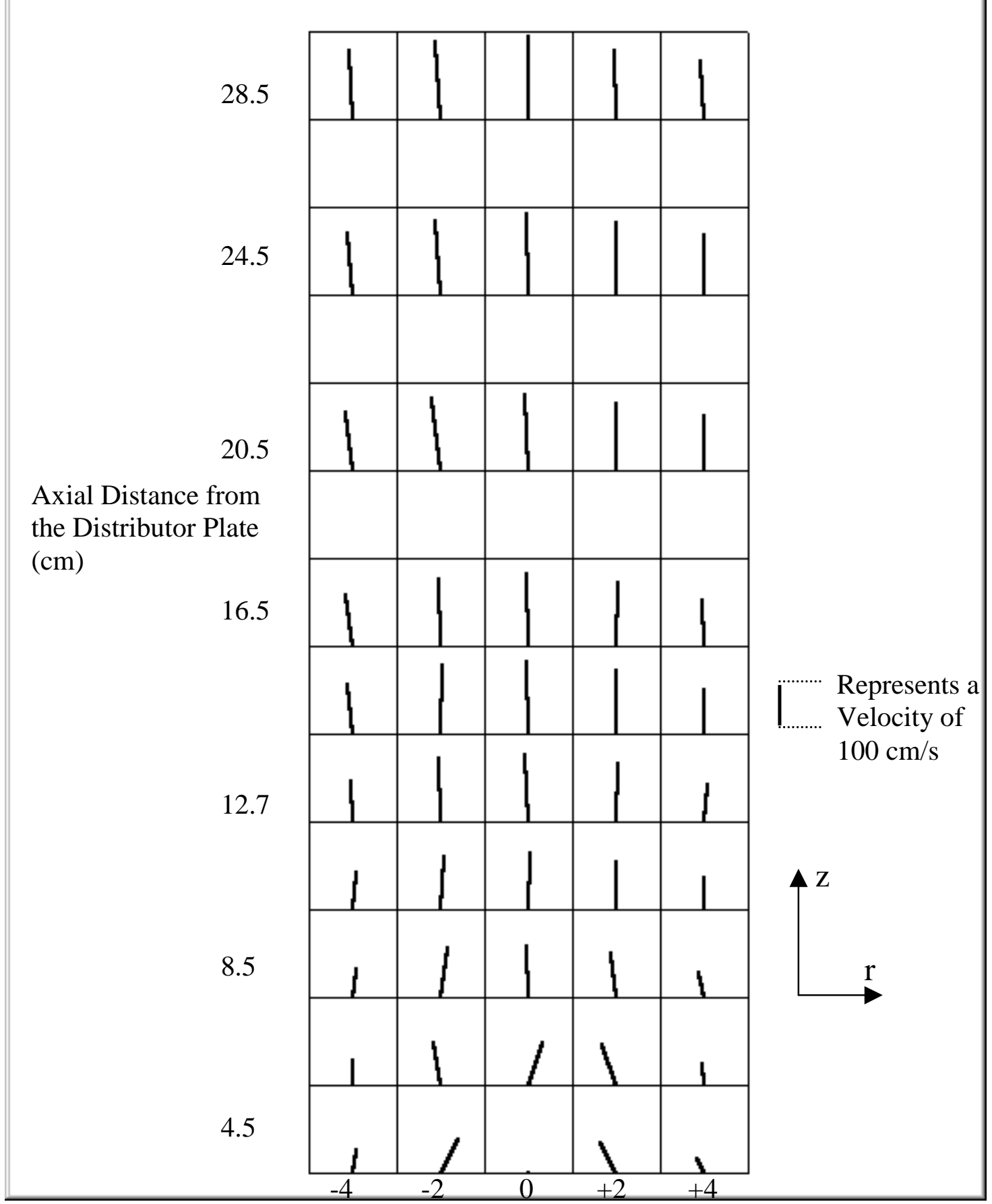

Radial Distance (cm)

Figure 4-15. Particle velocity map in the draft-tube at different axial locations in the bed with distributor 1, modified deflector 1 , gap height $7.4 \mathrm{~cm}$ and high airflow rate. 
almost identical, we can conclude that at these high airflow rates and gap height the variation caused by the distributor plate is not significant

The final experiment in the series for velocity measurement used a higher airflow rate. The airflow rate, maintained at around $0.066 \mathrm{~m}^{3} / \mathrm{s}$ for the other runs, was raised by $16 \%$ to $0.0766 \mathrm{~m}^{3} / \mathrm{s}$ for this experiment. Figure 4-13 shows velocity profiles for the modified deflector 1, gap height $7.4 \mathrm{~cm}$ and these two different air flow rates. We can observe that the profiles look very similar, but that the particle velocities are much higher in case of the high air flow rate. The profile also becomes very symmetric. An increase in the particle attrition was also observed.

\section{4-1.2 Velocity measurements in the Annulus}

The annular velocity of the downward moving tablets was determined using the same method used to determine the velocities in the draft-tube. The cameras were focused on the inner surface of the front glass sheet and the software was used to calculate the distances moved by the particles between the successive fields captured by the cameras with a fixed time lag. The time lag between the cameras was set at $8 \mathrm{~ms}, 3 \mathrm{~ms}$ more than those set for the measurements in the drafttube. This was done so that the particles which move at lower velocities, compared to those in the draft-tube, could travel a significant distance between successive fields grabbed by the two cameras.

Velocities were taken at different radial locations at one particular axial height. The procedure was repeated for the various conditions, with/without the deflector, and with the modified deflector. The experiments were repeated for three different gap heights $2.7 \mathrm{~cm}, 4.8 \mathrm{~cm}$ and $7.4 \mathrm{~cm}$ and the results are shown in Figure 4-16. As seen from this figure, the annular velocity increases as the gap height increases for all the three cases. This is consistent with the result 
described previously. As the gap height increases, there is more space between the distributor plate and draft-tube, which in turn allows more tablets to enter into the draft-tube. This results in higher mass fluxes. The introduction of deflectors around the nozzle resulted in a change in the annular velocities and mass fluxes. In case of deflector 1, the annular velocity increased compared to the one with no deflector. The reverse trend was observed for the case with modified deflector 1 . These observations will be discussed in section 4-3.

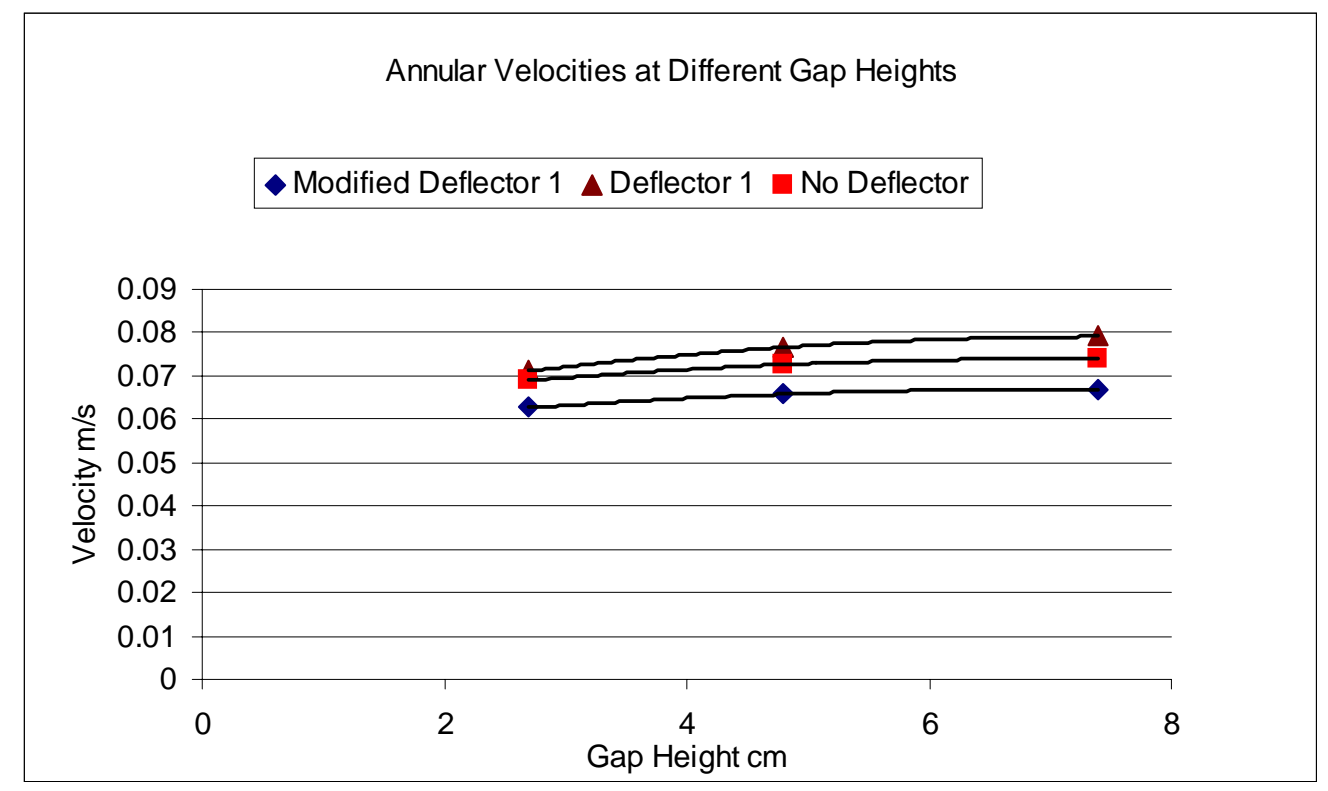

Figure 4.16 Graph showing a plot of annular velocity at different gap heights above the distributor plate for the three cases of with/without deflector and modified deflector 1. 


\section{4-2. Voidage Measurement}

\section{4-2.1 Voidage Measurement in Draft-Tube}

The voidage profiles were determined for all the conditions in the experimental matrix shown in Table 3-1. For the voidage measurements, only one camera was used, as previously explained in the experimental section. The radial voidage profiles at different axial heights are mapped in a similar way to the velocity profiles. The voidage values plotted in the graphs are the average values of the voidage obtained from 50 fields of data over a square box of sides $2 \mathrm{~cm}$, using the same imaginary grid described previously for the velocity measurements. For the pictorial representation, a software program written in Microsoft Visual Basic 6.0 was used. The shading intensity in these voidage maps is proportional to the voidage values. The imaginary boxes of $2 \mathrm{~cm}$ sides were further divided into nine smaller boxes and the box in the center was assigned the value of the voidage for that box and the value of voidage for the surrounding eight boxes were obtained by linear interpolation between the values from the adjacent box. Detailed explanation and sample calculations are given in Appendix XIV. The subdivision of the grid was performed to obtain a smoother transformation in the shades between adjacent boxes.

Figure 4-17 and 4-18 show voidage profiles for the case with and without a deflector, at the two different gap heights of $2.7 \mathrm{~cm}$ and $7.4 \mathrm{~cm}$, respectively. Figure 4-17a and 4-18a look very similar, with lower voidage at the center and increasing voidage towards the draft-tube walls. On closer observation we can see that the voidage value in the box immediately above the spray nozzle $(\mathrm{r}=0, \mathrm{z}=4.5 \mathrm{~cm})$ for the case with deflector is 0.86 which is higher that that for the no-deflector case of 0.80 . This can be explained with the visual observation that the deflector deflects the particle away from the center. Thus, the deflector at the lower gap height is effective in reducing 

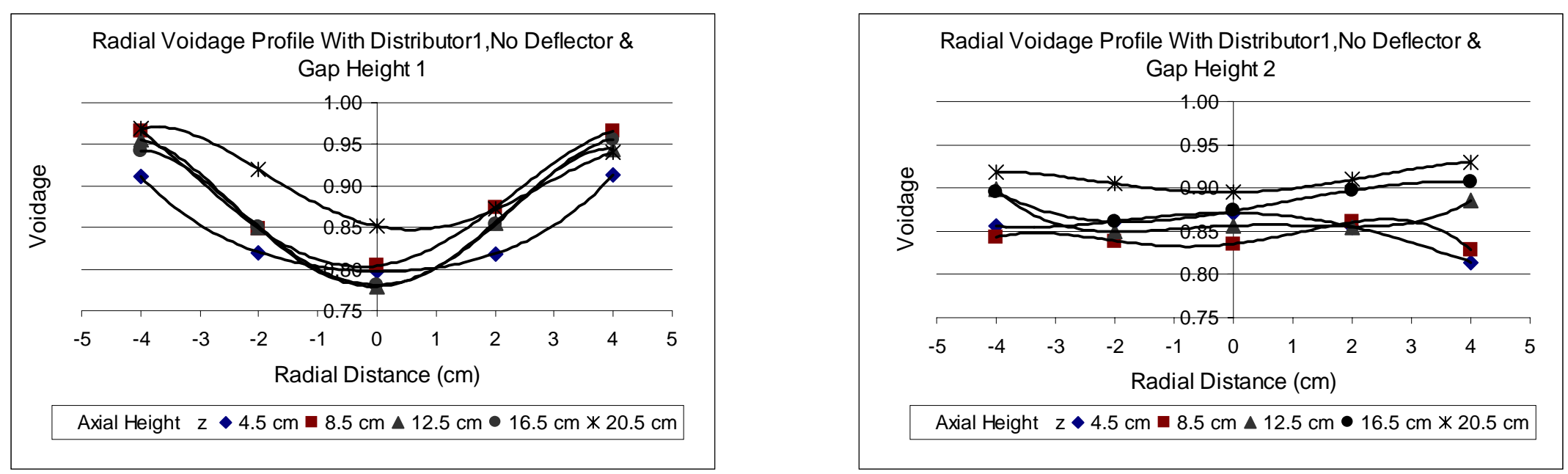

Figure 4-17 a, b. Radial particle voidage profile with height in the draft-tube with no deflector and gap heights $2.7 \mathrm{~cm}$ and $7.4 \mathrm{~cm}$ respectively.
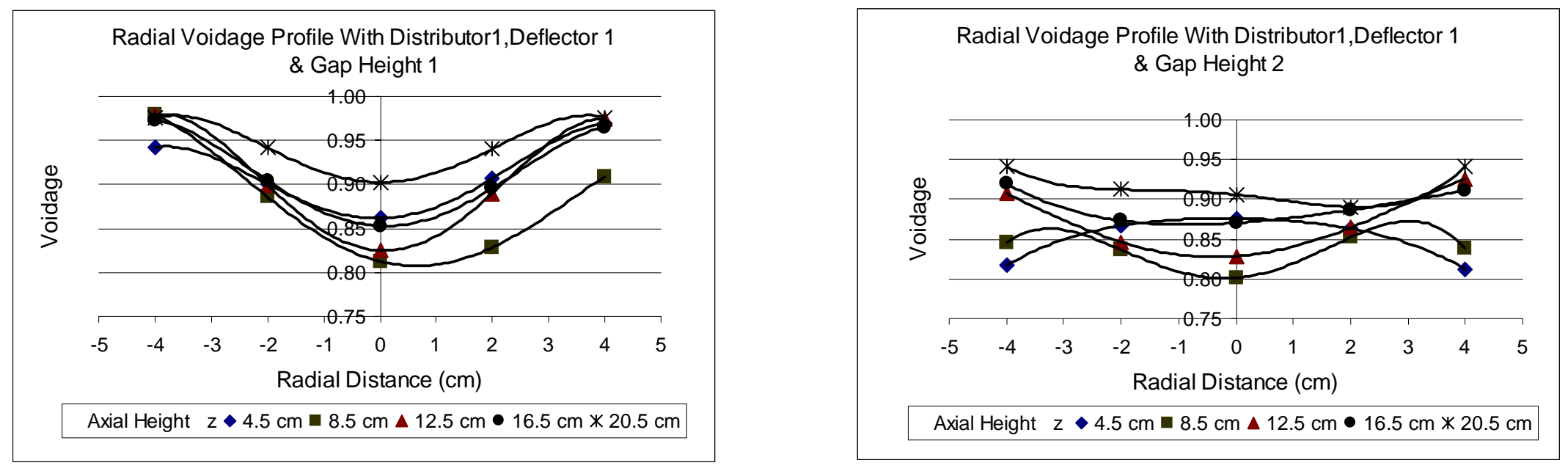

Figure 4-18 a, b. Radial particle voidage profile with height in the draft-tube with deflector 1 and gap heights $2.7 \mathrm{~cm}$ and $7.4 \mathrm{~cm}$ respectively. 
the particle density around the nozzle. The voidage across the bed is also marginally higher for the case with the deflector in comparison with the no-deflector case.

For the case of the higher gap height $(7.4 \mathrm{~cm})$, Figures $4-17 \mathrm{~b}$ and $4-18 \mathrm{~b}$, the voidage profiles still look similar. However, the voidage across the draft-tube varies over a wide range in the presence of deflector 1 ( 0.8 to 0.91$)$ whereas the profile is flat with very little variation ( 0.85 to 0.91$)$ in case of no-deflector. It is very interesting to note that the voidage profile at $\mathrm{z}=4.5$ is almost the same for both these cases. This can explain the similar coating consistency obtained in the above cases detailed in section 4-5. Thus, at the higher gap height deflector 1 is not effective, as it does not increase the voidage significantly around the nozzle and thus does not reduce the sheltering effect in the spray zone.

At the lower gap height, the voidage values at different axial heights are less than the corresponding voidage values for higher gap height for the case with no deflector. This is in contrast to what we might expect. At the lower gap height, the number of particles entering the draft-tube region is low because of the low clearance between the distributor plate and the draft-tube. We might expect this to cause a higher voidage or fewer particles in the draft-tube region. The possible reason for this behavior can be explained as follows. With the lower gap height, the particles face higher resistance to enter the draft-tube region resulting in a very low entry velocity at the bottom of the bed. The air stream in the draft-tube then accelerates the particles, but the acceleration achieved is low resulting in a build-up in the draft-tube and hence higher particle density in the draft-tube. These observations can be confirmed with the velocity profiles, which show that the velocities in case of the lower gap height and no deflector are almost half 

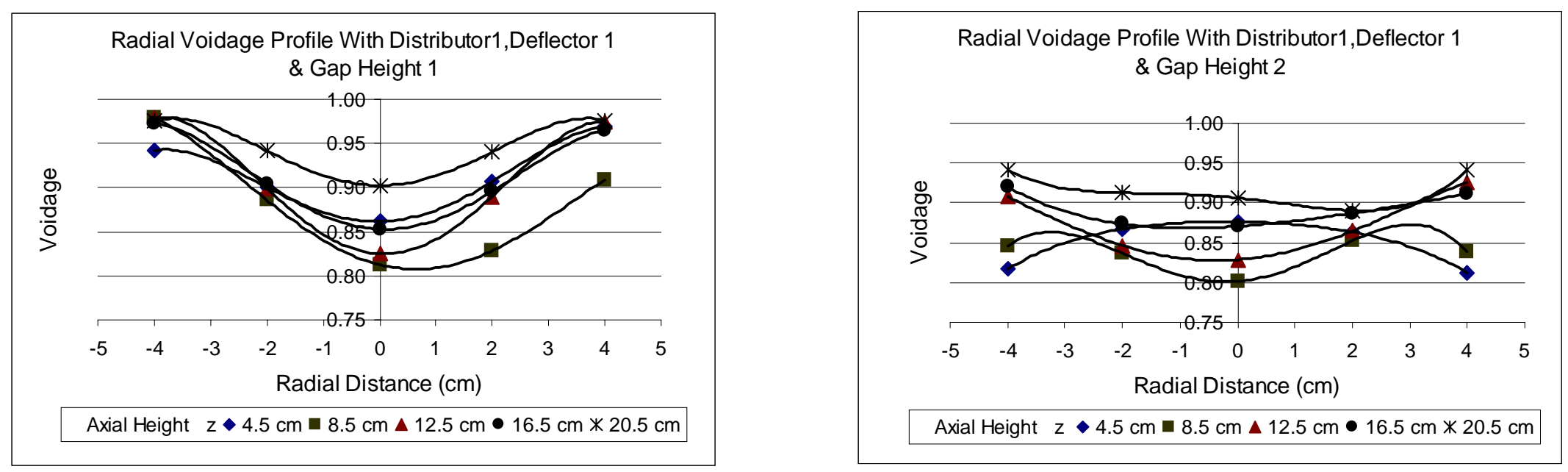

Figure 4-19 a, b. Radial particle voidage profile with height in the draft-tube with deflector 1 and gap heights $2.7 \mathrm{~cm}$ and $7.4 \mathrm{~cm}$ respectively.
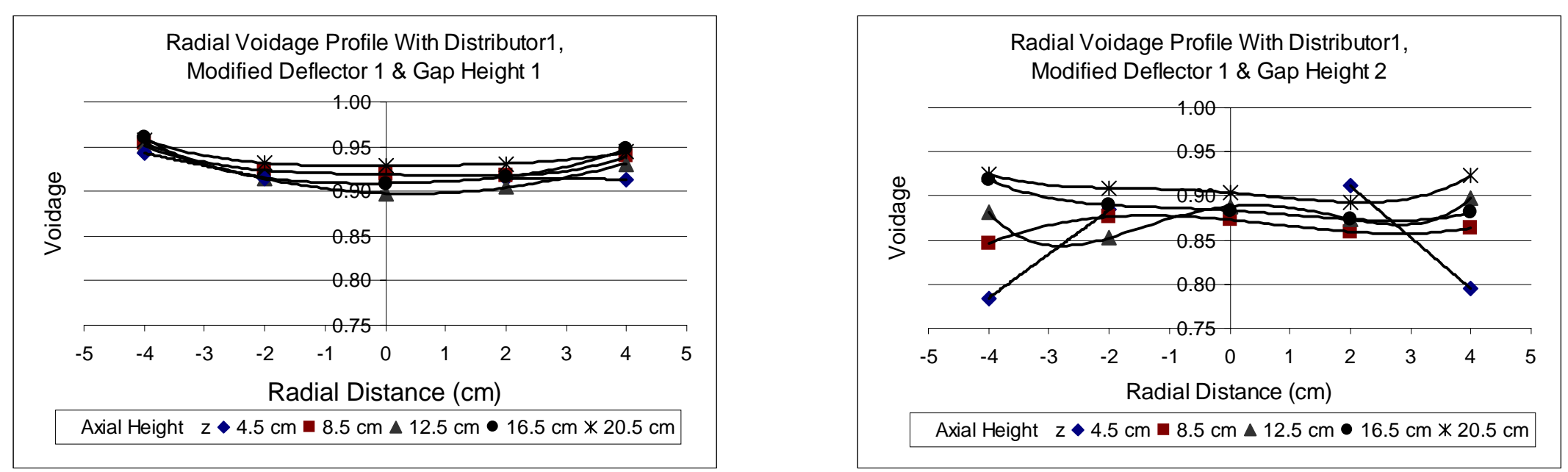

Figure 4-20 a, b. Radial particle voidage profile with height in the draft-tube with modified deflector 1and gap heights $2.7 \mathrm{~cm}$ and 7.4 $\mathrm{cm}$ respectively. 
the velocities for the same case with the higher gap height. With the lower gap height, the particles enter the draft-tube in the horizontal direction and this causes the particles to move to the center of the bed, increasing the particle-particle collision in the center of the draft-tube. This causes further loss of particle momentum, leading to particle accumulation in the center. This can be observed in the voidage profile map in Figure 421 indicated by the darker shade between $\mathrm{r}=-2.7 \mathrm{~cm}$ to $\mathrm{r}=+2.7 \mathrm{~cm}$ and $\mathrm{z}=4.5 \mathrm{~cm}$ to $14.5 \mathrm{~cm}$.

The voidage profiles for the lower gap height with no deflector resemble that of an inverted bell shaped curve, with the lowest voidages at the center of the draft-tube $(r=$ 0 ). The minimum voidage or the maximum particle density for this case is between axial heights $12.7 \mathrm{~cm}$ and $16.5 \mathrm{~cm}$ as shown in Figure 4-17, and the dark areas in the voidage profile map in Figure 4-21. The voidage then increases along the length of the draft-tube as the particles gain velocity. Hence, from the above observations, we can surmise that in the case with no deflector and using a low gap height, the particles enter into the drafttube at very low velocities. This results in a region of low velocity and low voidage in the middle of the draft-tube. Further up, but before the particles leave the draft-tube, a region of high velocity and high voidage is seen. This observation is further confirmed by the mass balance across the draft-tube as discussed in the section 4-3.

In both the above cases, with and without deflectors and the lower gap height, the voidage close to the walls of the draft-tube $(r=-4.5 \mathrm{~cm}$ and $r=+4.5 \mathrm{~cm})$ is higher than that at the center $(r=0)$. This means that there is a general trend for the particles to move to the center of the bed. This is more prominent in the case of deflector 1 and can be seen from the voidage profile maps in Figure 4-22 and 4-25. 
In the case of the modified deflector with the low gap height, Figure 4-20a the voidage profile is very flat and symmetric. The voidage across the entire bed is quite even. The modified deflector reduces the effective gap through which the tablets enter the spray zone and at the same time directs the tablets away from the spray nozzle. The design of the modified deflector enhances the vertical acceleration of the tablets and deflects the tablets towards the draft-tube walls. These tablets are deflected back from the wall into the spout, resulting in a serpentine path in the vertical direction. The maximum measured voidage is at an axial height of $\mathrm{z}=8.5 \mathrm{~cm}$ at $\mathrm{r}=0$. It should be noted that the voidage at $\mathrm{r}=0$ and $\mathrm{z}=4.5 \mathrm{~cm}$ could not be measured as the particles were deflected away from the field of view by the modified deflector 1 . The smooth shading in Figure 423 shows that the voidage distribution in this case is uniform.

At higher gap heights, the tablets get more evenly distributed across the draft-tube, both in the radial and axial direction. Because of the higher gap height, the tablets enter the bed more easily and with greater velocities than in the case of the lower gap heights. At the higher gap height $(7.4 \mathrm{~cm})$, the bottom of the draft-tube is at a height above the top of the nozzle/deflector. This and the $60^{\circ}$ angle at the bottom of the draft-tube, allows a large number of particles to enter into the draft-tube region and flow almost vertically along the wall of the draft-tube, resulting in lower voidage along the walls of the drafttube.

The voidage in the case of the modified deflector at higher gap height is seen to be very even except around the nozzle and the particles are more evenly spread across the entire draft-tube. Figures 4-20 b shows the axial voidage profile for this condition. This voidage profile is unique and is very different from the previous two cases. The 


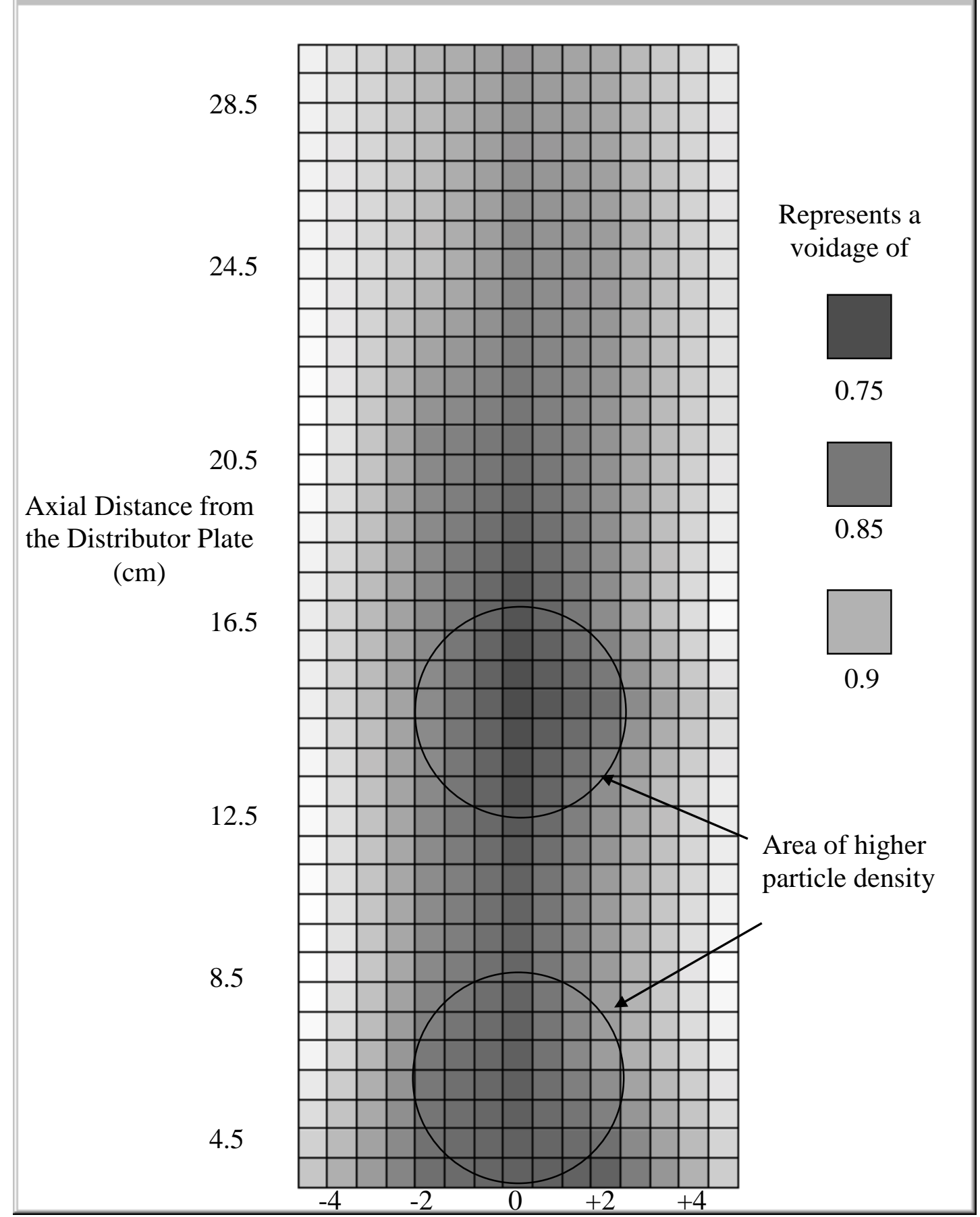

Radial Distance $(\mathrm{cm})$

Figure 4-21. Voidage map in the draft-tube at different axial locations in the bed with distributor 1, no deflector and gap height $2.7 \mathrm{~cm}$. 


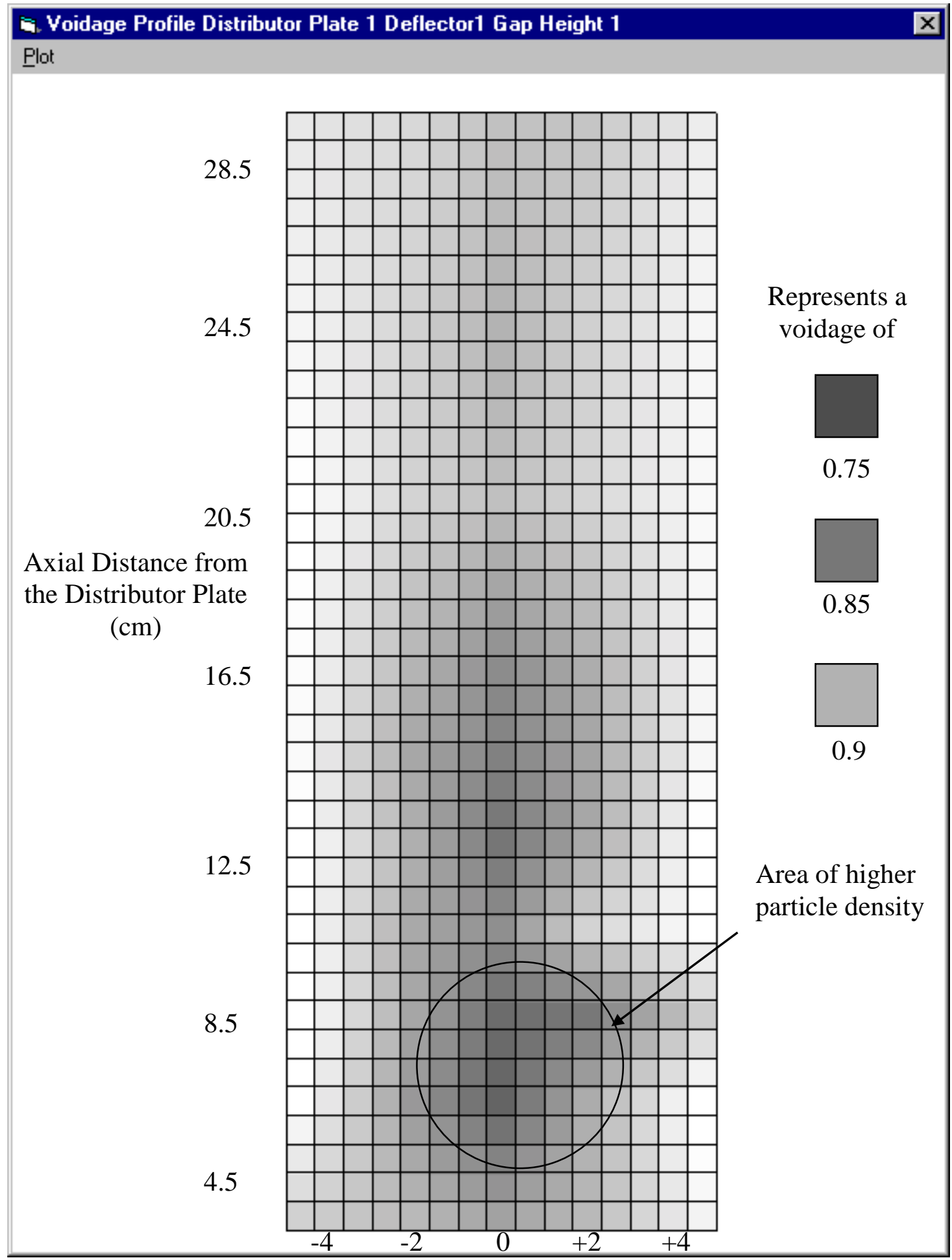

Radial Distances (cm)

Figure 4-22. Voidage map in the draft-tube at different axial locations in the bed with distributor 1, deflector 1 and gap height $2.7 \mathrm{~cm}$. 


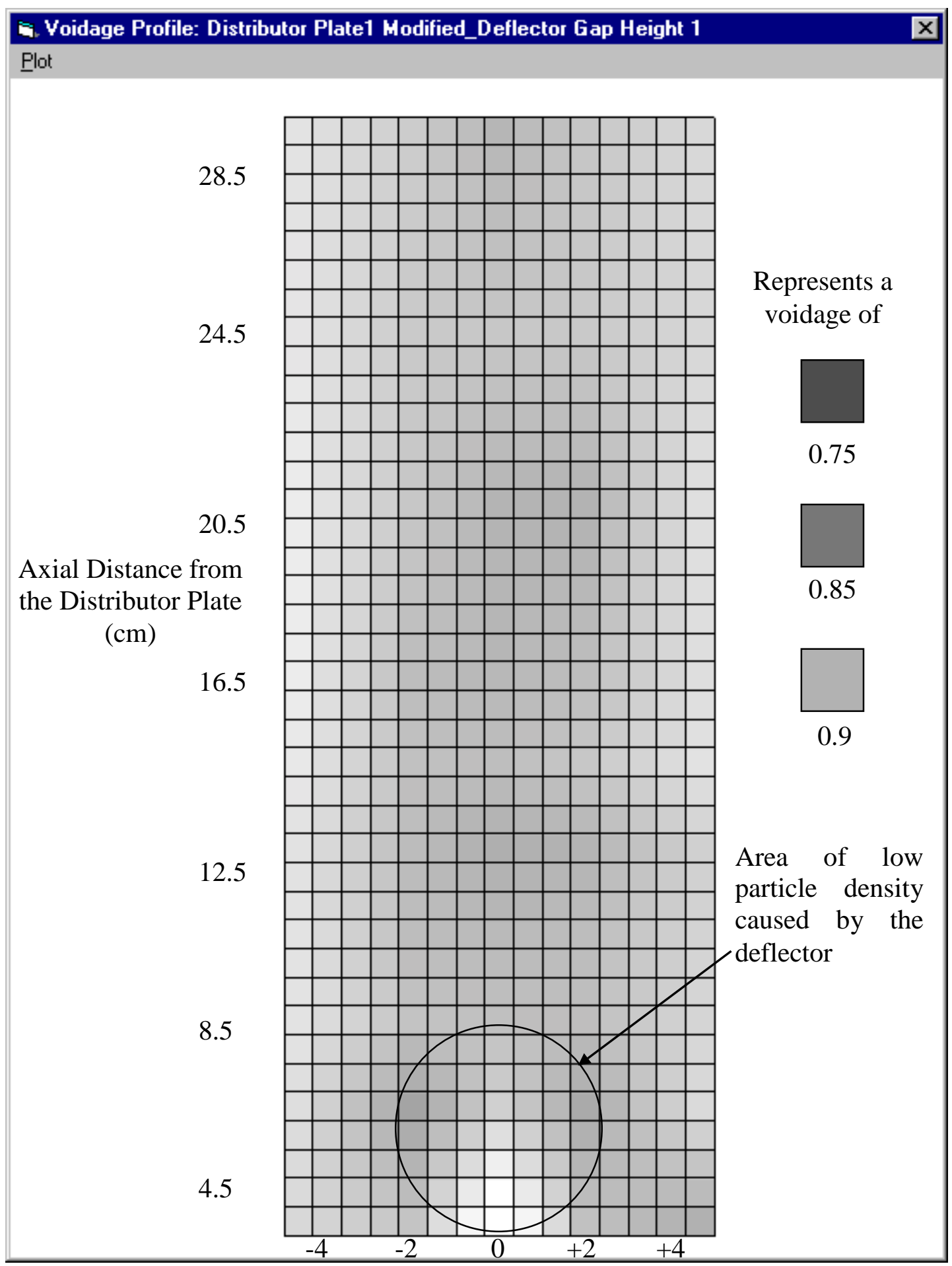

Radial Distances (cm)

Figure 4-23. Voidage map in the draft-tube at different axial locations in the bed with distributor 1, modified deflector 1 and gap height $2.7 \mathrm{~cm}$. 


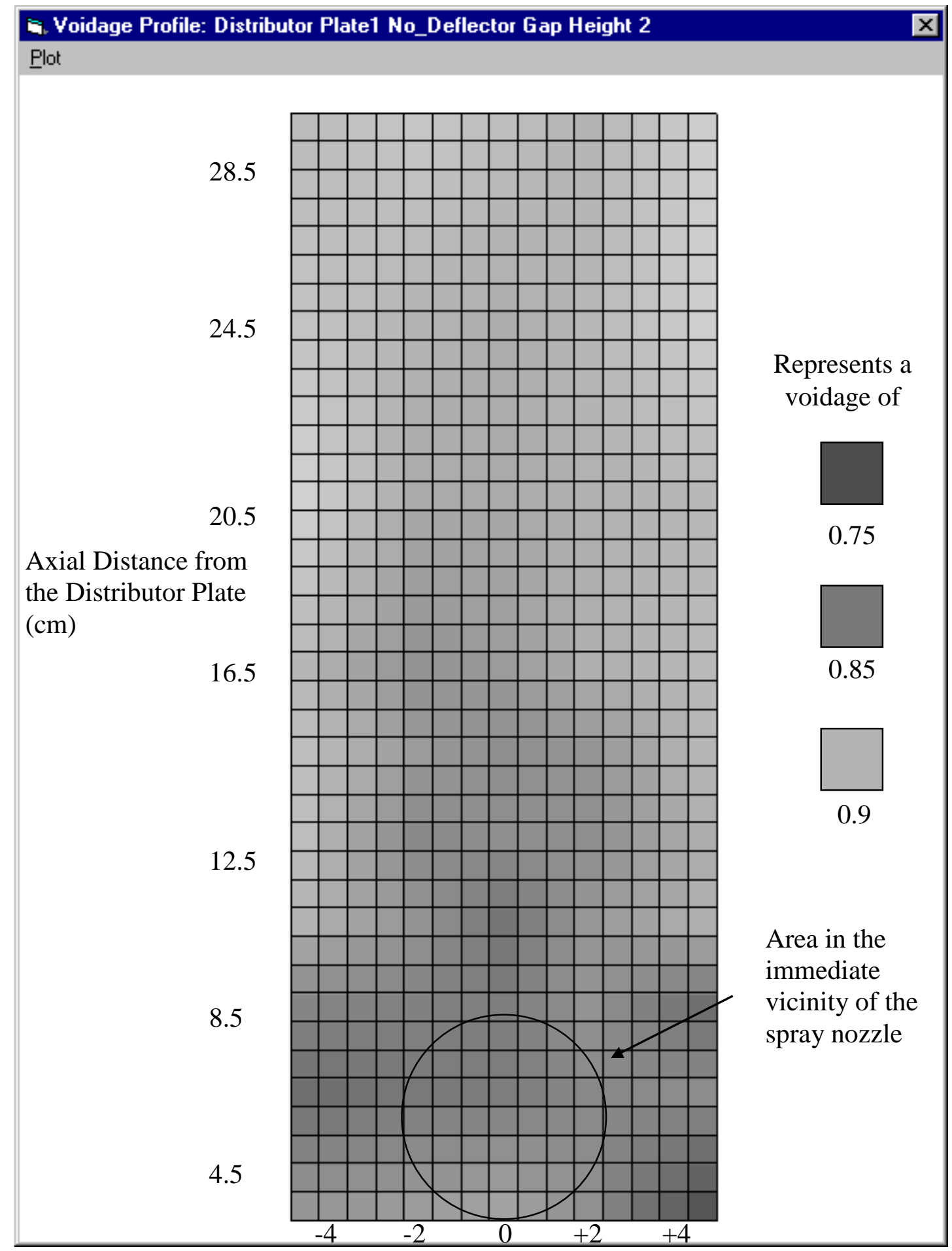

Radial Distances (cm)

Figure 4-24. Voidage map in the draft-tube at different axial locations in the bed with distributor 1, no deflector and gap height $7.4 \mathrm{~cm}$. 


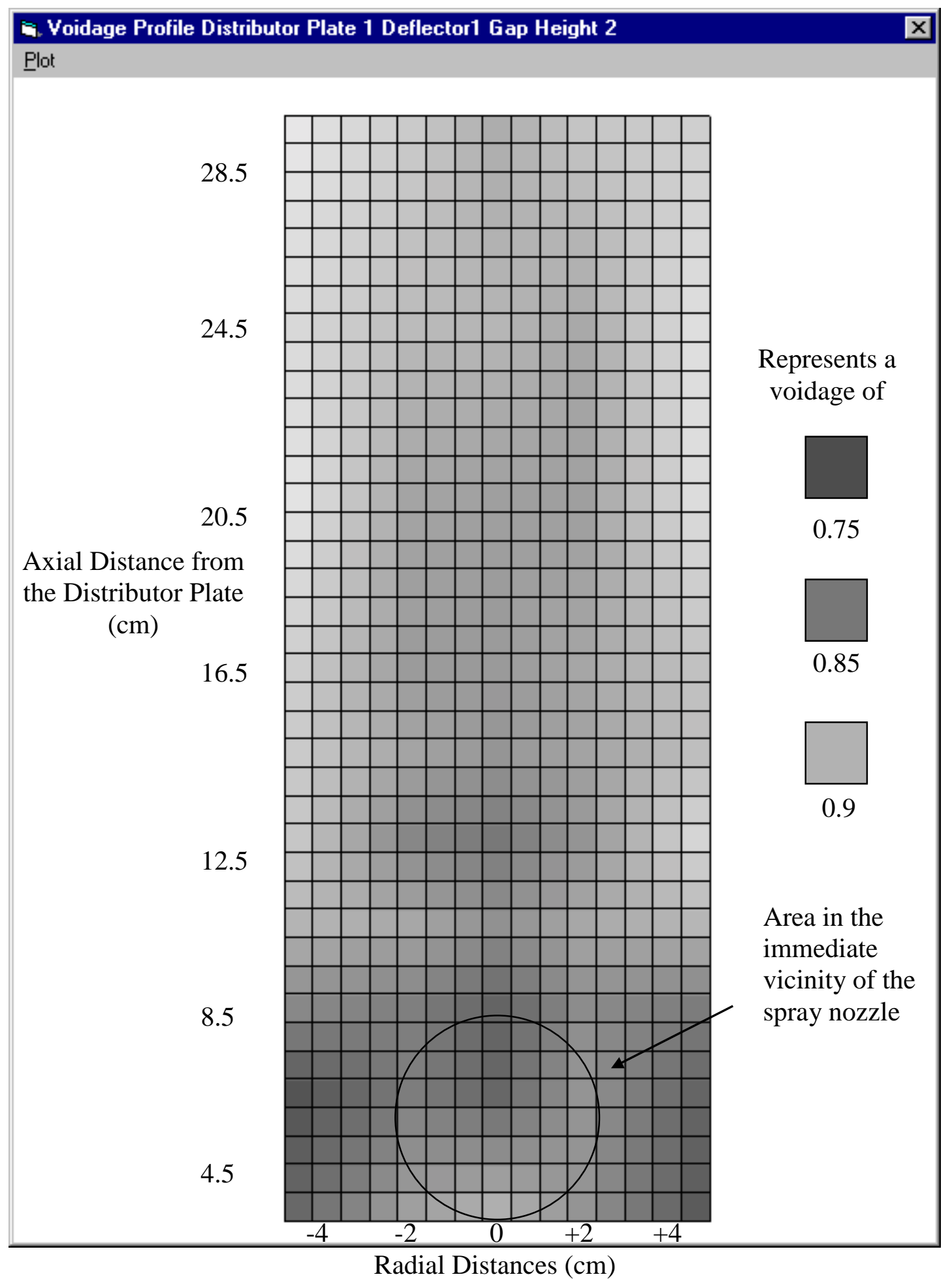

Figure 4-25. Voidage map in the draft-tube at different axial locations in the bed with distributor 1, deflector 1 and gap height $7.4 \mathrm{~cm}$. 


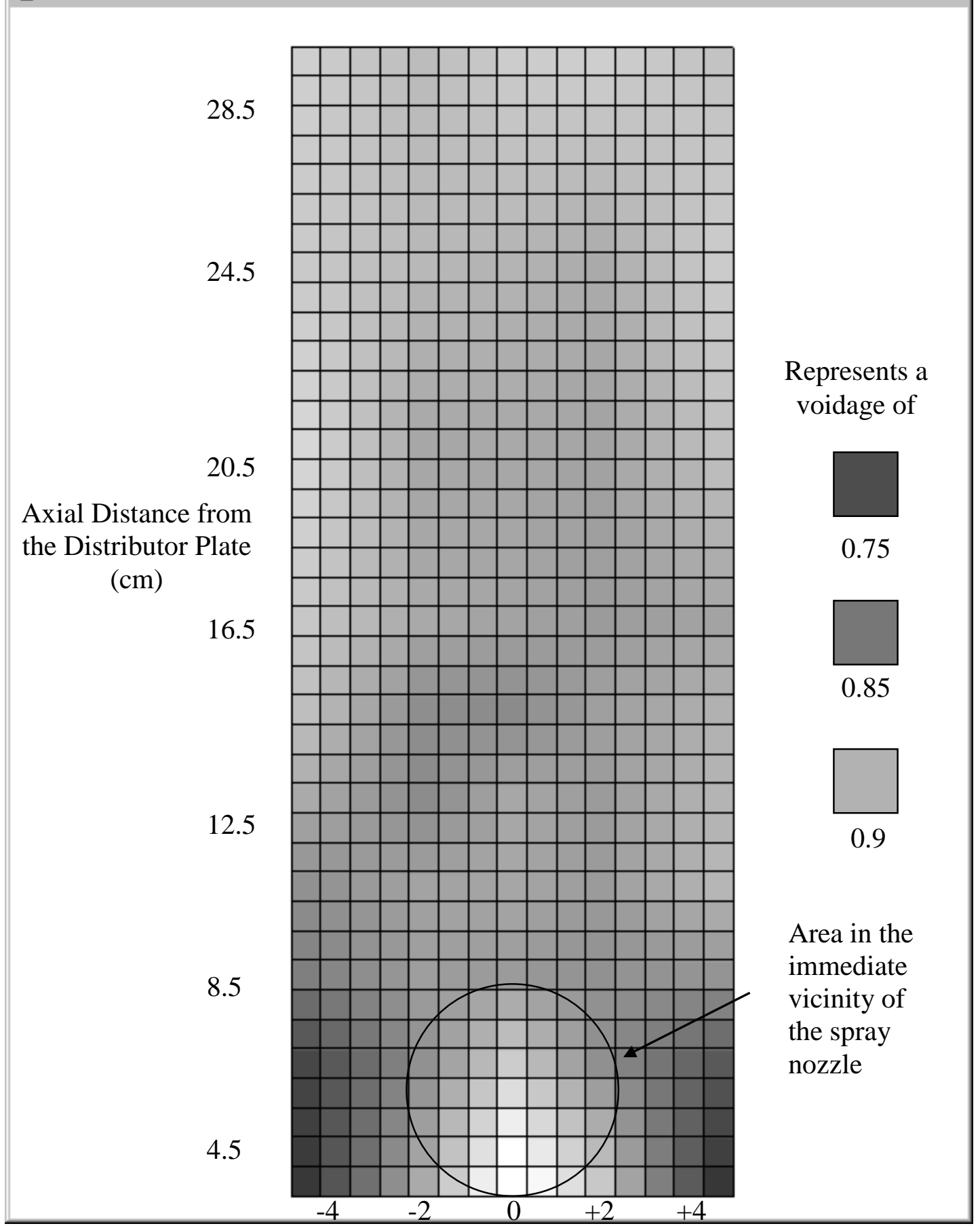

Radial Distances (cm)

Figure 4-26. Voidage map in the draft-tube at different axial locations in the bed with distributor 1, modified deflector 1 and gap height $7.4 \mathrm{~cm}$. 
voidage values are very low at the points where the particles enter the draft-tube $(r=-4.0$ $\mathrm{cm}$ and $\mathrm{r}=+4.0 \mathrm{~cm}$ at $\mathrm{z}=4.5 \mathrm{~cm})$ and increase drastically at $(\mathrm{r}=-2.0 \mathrm{~cm}$ and $\mathrm{r}=+2.0 \mathrm{~cm}$ at $\mathrm{z}=4.5$ ). The inclusion of a ring to the deflector 1 (the modified deflector 1 ), further reduces the gap available for particle entry into the draft-tube. This causes the particles to enter the bed along the wall of the draft-tube. The particles that enter the bed closer to the deflector are deflected away towards the wall of the draft-tube resulting in very high voidage around nozzle area. The modified deflector 1 thus served its purpose of increasing the voidage around the nozzle and giving a very even voidage distribution across the draft-tube, though the inclusion of the modified deflector resulted in reduced mass-flux (reduces particle flow into the draft-tube). However, this difference is small (15.6\% less than no deflector). There was no observed increase in the attrition of the tablets with the use of modified deflector 1.

\section{4-2.2 Voidage measurement in the annulus}

The voidage in the annulus was assumed to be that of a loosely packed bed. The voidage was calculated to be 0.576 from the measured bulk and absolute density. Since there was no separate air supply to the annulus, and the bed was never fluidized, the assumption of packed bed conditions is acceptable. See Appendix II for calculation of bulk and absolute density and voidage calculations in the annulus from these values.

\section{4-3 Mass balance between solid mass flow rate in the spout and annulus}

A mass balance can be made between the mass-flux in the draft-tube and the mass-flux in the downward moving annulus. This serves two purposes: (1) it validates the velocity and 
voidage measurements in the draft-tube, and (2) it acts as a crosscheck for the observed apparent depth of field (ADOF) which is calculated by using the models explained in the experimental section.

Based on the law of conservation of mass, at steady state conditions, the upward solids mass flow at a given cross-section in the spout must equal the downward solids mass flow in the annulus. Figure 4-27 shows the mass-flux plots in the draft-tube and in the annulus, for the eight different sets of conditions shown in the experimental matrix in Table $3-1$. The results show that there is agreement between the solid mass flow rate in the draft-tube and annulus. The solids mass flow rate in the draft-tube and the annulus were calculated using numerical integration of Equations (4-1) and (4-2) respectively, See Appendix XV for details of the calculation.

$$
\begin{aligned}
& \text { Draft-tube } m_{d f t}(z)=\frac{\pi}{2} \rho_{p} \int_{0}^{r_{d_{i}}} u_{d f t, z}\left(1-\varepsilon_{d f t}\right) r d r \\
& \text { Annulus } \quad m_{\text {anul }}(z)=\frac{\pi}{2} \rho_{p} \int_{r_{d_{o}}}^{R} u_{\text {anul, },}\left(1-\varepsilon_{\text {anul }}\right) r d r
\end{aligned}
$$

where $\mathrm{m}_{\mathrm{dft}}$ and $\mathrm{m}_{\mathrm{anul}}$ are the solids mass flow in the draft-tube and annulus, $\mathrm{u}_{\mathrm{dft}}$ and $\mathrm{u}_{\mathrm{anul}}$ are the axial particle velocity in the spout and annulus, $\varepsilon_{\mathrm{dft}}$ and $\varepsilon_{\mathrm{anul}}$ are the voidage in the draft-tube and annulus, and $r_{\mathrm{di}}$ is the radius of the draft-tube to its inner wall, $\mathrm{r}_{\mathrm{do}}$ is the radius of the drafttube plus draft-tube wall thickness, and $\mathrm{R}$ the column radius, respectively. The annular velocities measured were those of the particles in contact with the front glass sheet. However, 
because of the shape, size and smoothness of the tablets the wall friction experienced by the particles was small. It was visually observed that the particles in contact with the smooth glass sheet moved at the same velocity as those particles in the bulk of the annular region.

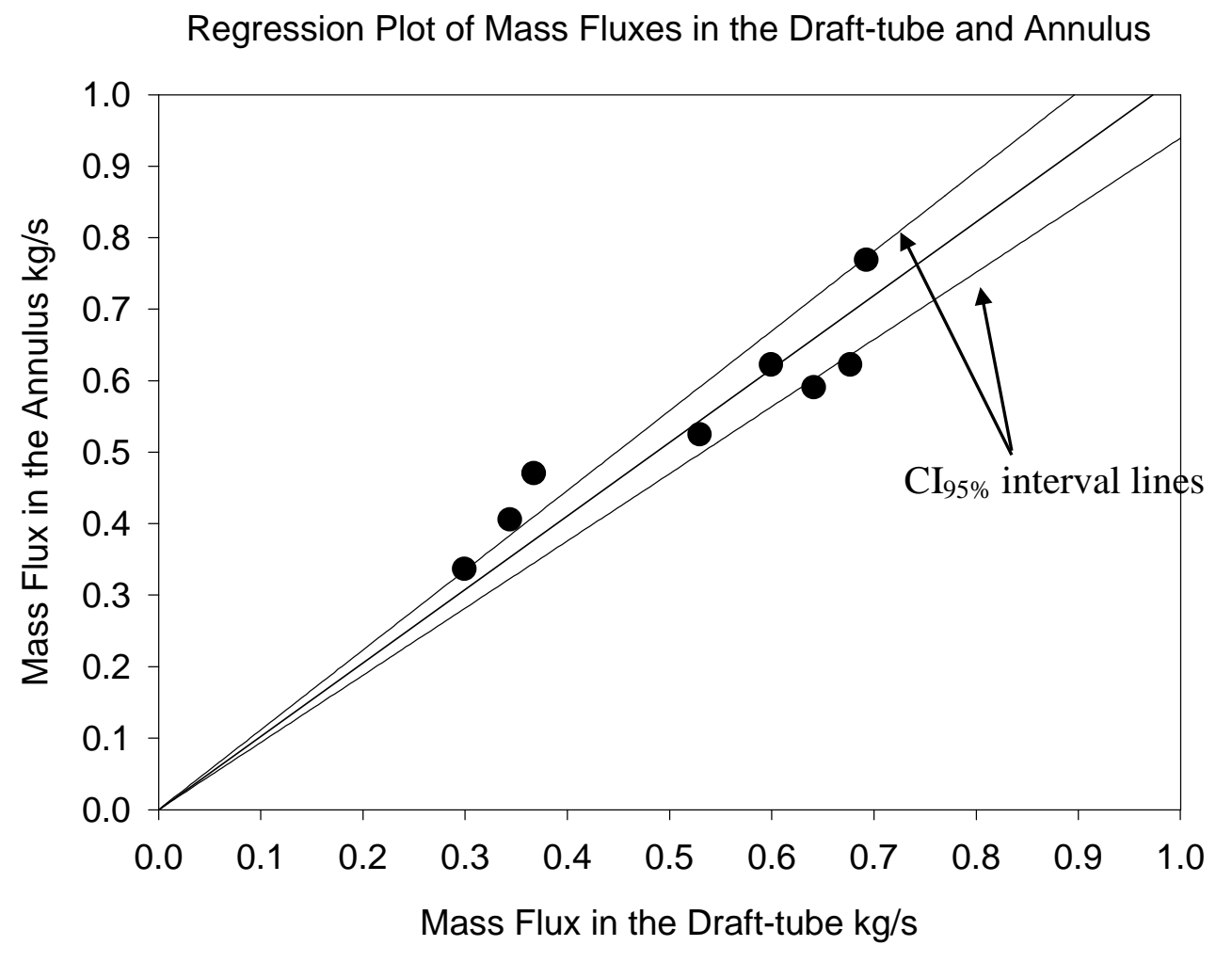

Figure 4-27. Regression plot of mass flux in the draft-tube and annulus for the eight experiments given in Table $3-1$. 


\section{4-4.Sheltering effect and Coating Variation}

The total variation in the amount of coating received by a particle in a fluidized bed coating equipment can be explained or accounted for by two factors: (1) variation in cycle time distribution, and (2) variation in coating received by a particle each time it passes through the spray zone, Cheng and Turton (1993). Cheng (1993) in her dissertation talks extensively about these two factors. She used a phenomenological model to explain the experimental results that she obtained. But the phenomenological model assumed that: (1) the spray pattern was in the form of a hollow cone, (2) all the spray is not coated on the tablets, (3) the spray not captured by the particles is carried upwards by the fluidizing gas, (4) the spray droplets are assumed to follow straight radially directed stream tubes, and (5) most importantly that the particles are distributed uniformly throughout the spray zone with uniform voidage and move vertically upward with a constant velocity.

Figures 4-28 and 4-29 explains the basic process involved in coating and the sheltering effect explained by Cheng. Figure 4-28 explains the continuous renewal theory. The total amount of coating a particle receives at the end of the coating run is an integral amount of the coating the particle receives during each pass through the spray zone. Sheltering effect is explained by Figure 4-29. Particles closer to the spray nozzle receive more coating, and block the spray from reaching the tablets that are away from the nozzle, resulting in those particles getting less coating. The particles closer to the nozzle shelter the particles that are away from the spray nozzle. Mann (1972) derived an expression for the variation in the coating process in terms of the variation in the amount of coating received per pass and the variation in the number of times the tablet passes 


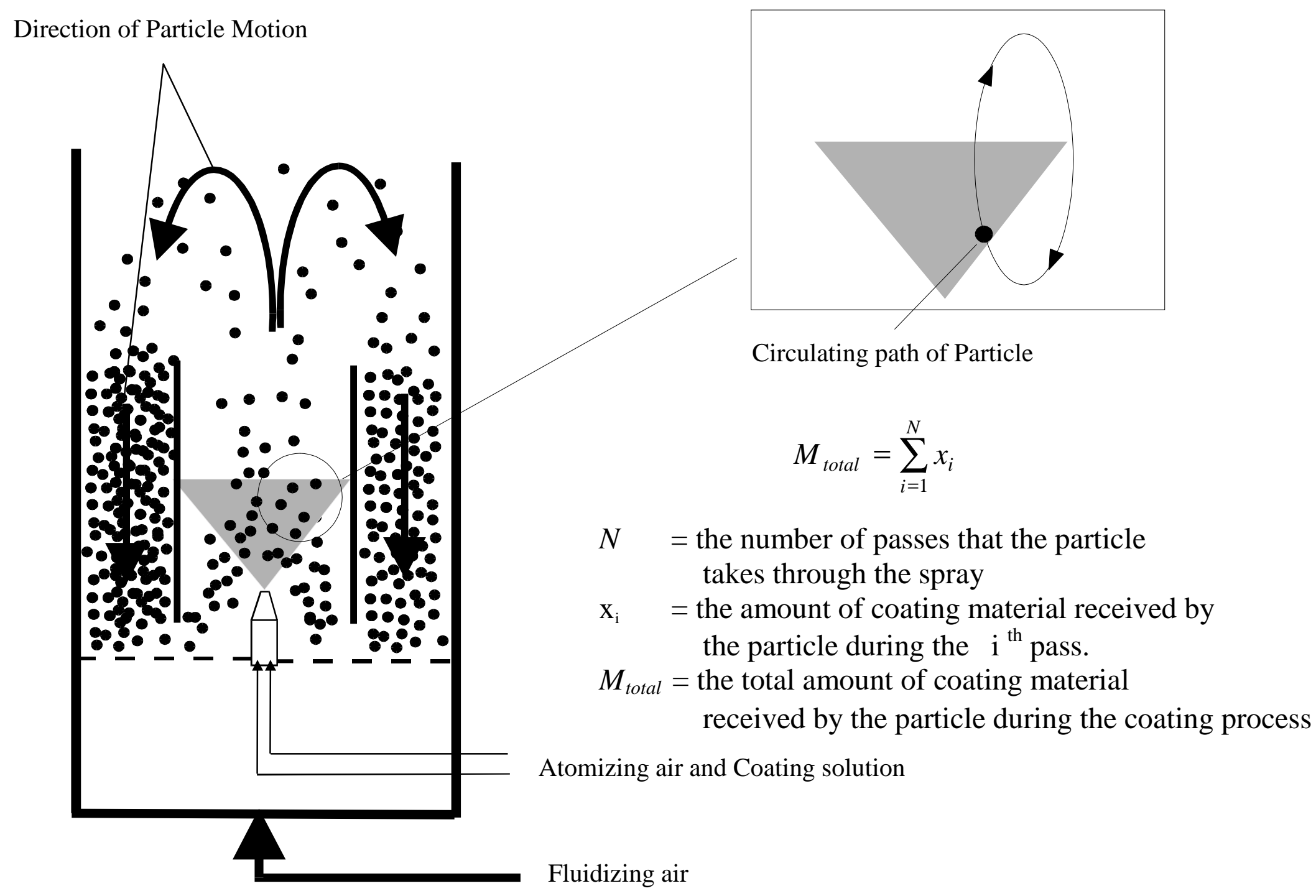

Figure 4-28. The basic process involved during particle coating in a fluidized bed coater. 
Direction of Particle Motion
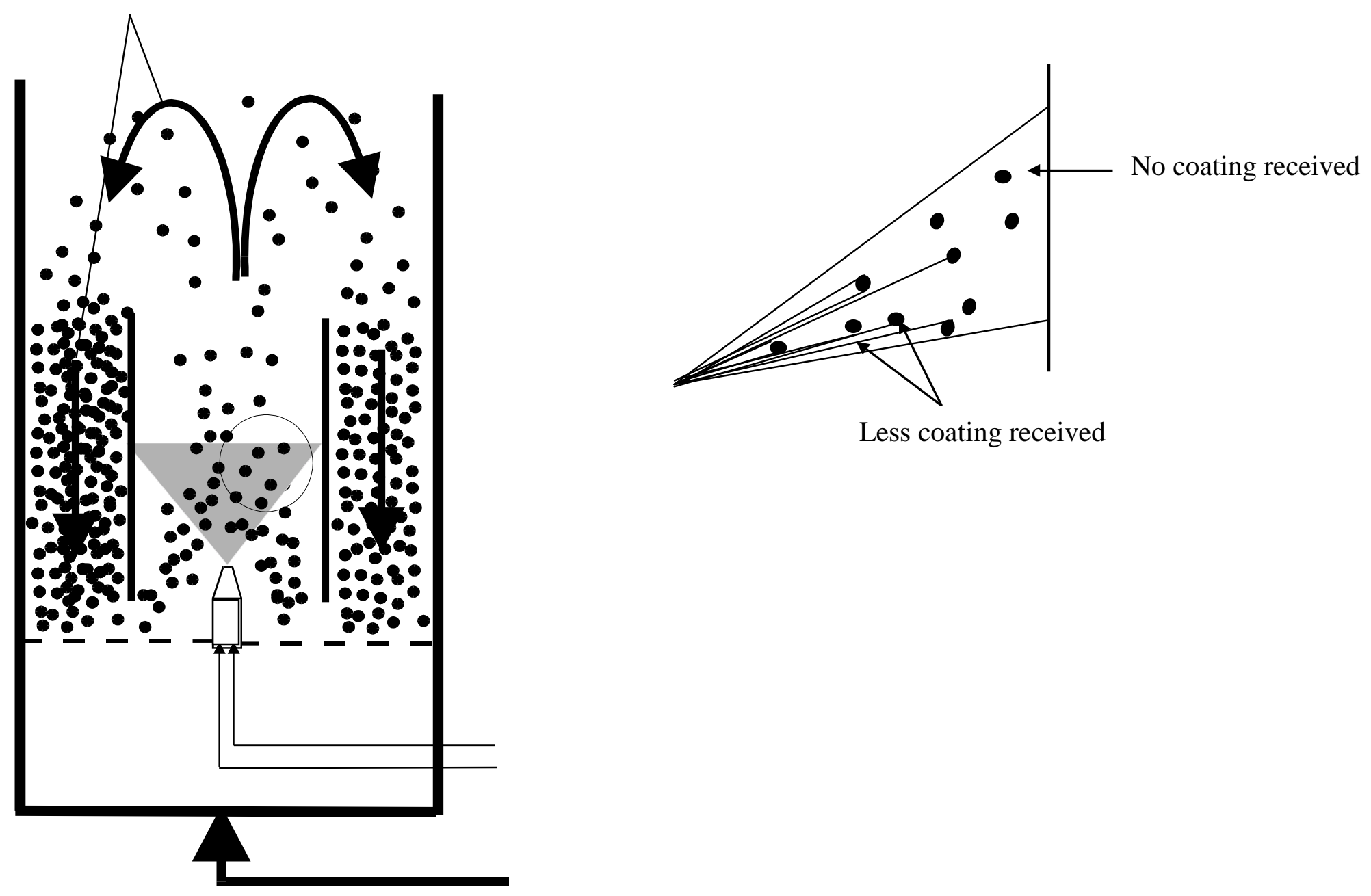

Figure 4-29. A schematic diagram showing the sheltering effect. The tablet closer to the nozzle blocks the coating solution from reaching the tablets that are away from the nozzle. 


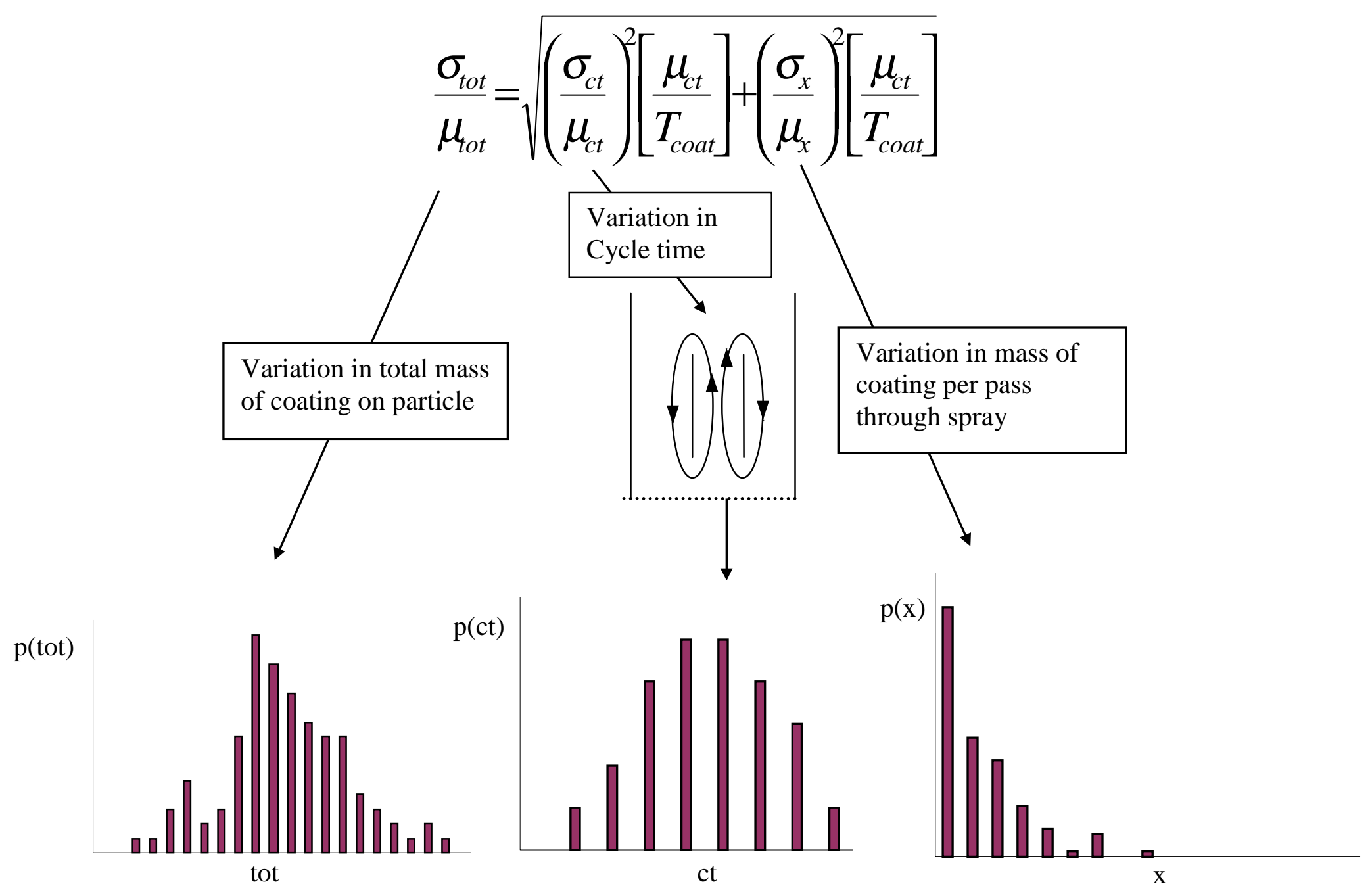

Figure 4-30. Schematic representation of the sources of variation in a fluidized bed coating process and the type of variation obtained for each individual source. 
through the spray zone shown in Figure 4-30. This variation is expressed mathematically in Equation (3-1).

$$
\frac{\sigma_{t o t}}{\mu_{t o t}}=\sqrt{\left(\frac{\sigma_{c t}}{\mu_{c t}}\right)^{2}\left[\frac{\mu_{c t}}{T_{c o a t}}\right]+\left(\frac{\sigma_{x}}{\mu_{x}}\right)^{2}\left[\frac{\mu_{c t}}{T_{c o a t}}\right]}
$$

where $\sigma_{\text {total }}$ is the variance of the coating distribution, $\mu_{\text {total }}$ is the mean of the coating distribution, $\sigma_{\mathrm{ct}}$ and $\mu_{\mathrm{ct}}$ are the standard deviation and mean of the cycle time distribution respectively, and $\mathrm{T}_{\text {coat }}$ is the total coating time. $\sigma_{\mathrm{x}}$ the variance of the coating mass per particle per pass, $\mu_{\mathrm{x}}$ the mean coating mass per particle per pass. Cheng and Turton (1993), and Shelukar, et al. (2000) have shown that the variation in the particle circulation time distribution only accounts for a small percent of the variation of the coated film and that the variation in the coating quality is dominated by the variation associated with the spray zone, as long as the circulation of the particle are reasonably uniform, i.e., there are no dead zones in the bed.

Thus, the second term on the right hand side of equation 3-1 accounts for the major variation and efforts have been made to quantify this and account for the variation in the coating quality. The second term $\sigma_{\mathrm{x}} / \mu_{\mathrm{x}}$ can be determined by conducting pulse tests. In the pulse test, a highly concentrated solution of blue dye is injected such that the blue dye is sprayed for the time duration equivalent to one circulation time. Thus in the ideal case, we would expect all the tablets in the bed to have passed through the spray zone once. Analysis of random samples of tablets, for blue dye content, will give a value for $\sigma_{\mathrm{x}}$ 
(standard deviation of amount of blue dye coated) and $\mu_{\mathrm{x}}$ (mean amount of blue dye coated).

\subsection{Results of the Coating Experimental runs}

As a review, the coating runs can be divided into two categories: (1) the continuous coating runs, and (2) the pulse tests. The continuous coating runs were carried out to determine the total variation in a batch of coated tablets for a given set of experimental conditions. The pulse test were to help determine the variation in coating per-pass and thus verify if this variation accounts for $>70 \%$ of the total variation as observed by earlier researchers. These two sources of variation and the combined variance are shown schematically in Figure 4-30. The continuous coating runs were also used to determine the effectiveness of the various deflectors on the overall coating quality, by reducing the sheltering effect. From the velocity and voidage profiles obtained from the eight different experimental conditions, three conditions were selected for the continuous coating runs: (1) no deflector, (2) deflector 1, and (3) modified deflector 1. Based on the results obtained, three more deflector designs were tried, modified deflector 2, modified deflector 3, and optimum deflector. The experimental matrix for the coating runs is described in Table 3-2.

\section{4-5.1 Continuous coating runs}

For all the continuous coating runs, the process variables such as, fluidizing air velocity and temperature, liquid flow rate and viscosity, gap height, air pressure for atomizing the liquid spray, were held constant. The only variation was the use of different 
deflector designs. The coating runs were typically 60 minutes long with an extra 10 minute period for drying after the coating liquid had been stopped.

After a coating run was completed, the coated tablets were unloaded into a container from which 100 tablets were picked at random and analyzed for their blue dye content. A plot of concentration of blue dye per tablet with the frequency of occurrence gives a frequency plot. The standard deviation and mean of the amount of blue dye coated on the tablets can be determined using commercially available software. Figure 431 shows the frequency plots for the different experimental conditions. A summary of the results is given in Table 4-1. The frequency plot for the case with no deflector shows a wide spread and a large standard deviation $\sigma_{\text {total. }}$. In the absence of a deflector, the particles that enter through the gap accelerate in the diagonal direction resulting in particle-particle collision at the center. The particles thus loose their momentum and redistribute themselves across the radius of the draft-tube. The change in direction of the tablet flow is sudden and hence the tablets at the bottom of the bed move at very low velocity $(r=0, z=4.5, U z=0.66 \mathrm{~m} / \mathrm{s})$. They subsequently gain velocity as they move higher in the draft-tube, but the velocity at an axial height of $4.5 \mathrm{~cm}$, just above the nozzle, is very low. This causes a slight accumulation of tablets at this axial height and hence the sheltering effect of tablets is more pronounced. The voidage profile for this condition is shown in Figure 4-24, it can be observed that the area in the immediate vicinity of the nozzle is dark indicating low voidage or high solids content.

With modified deflector 1 (deflector 1 with a deflecting ring) around the nozzle, the coating consistency showed a marked improvement. The particles entry into the drafttube was smother as some of the downward momentum of the tablets coming from the 

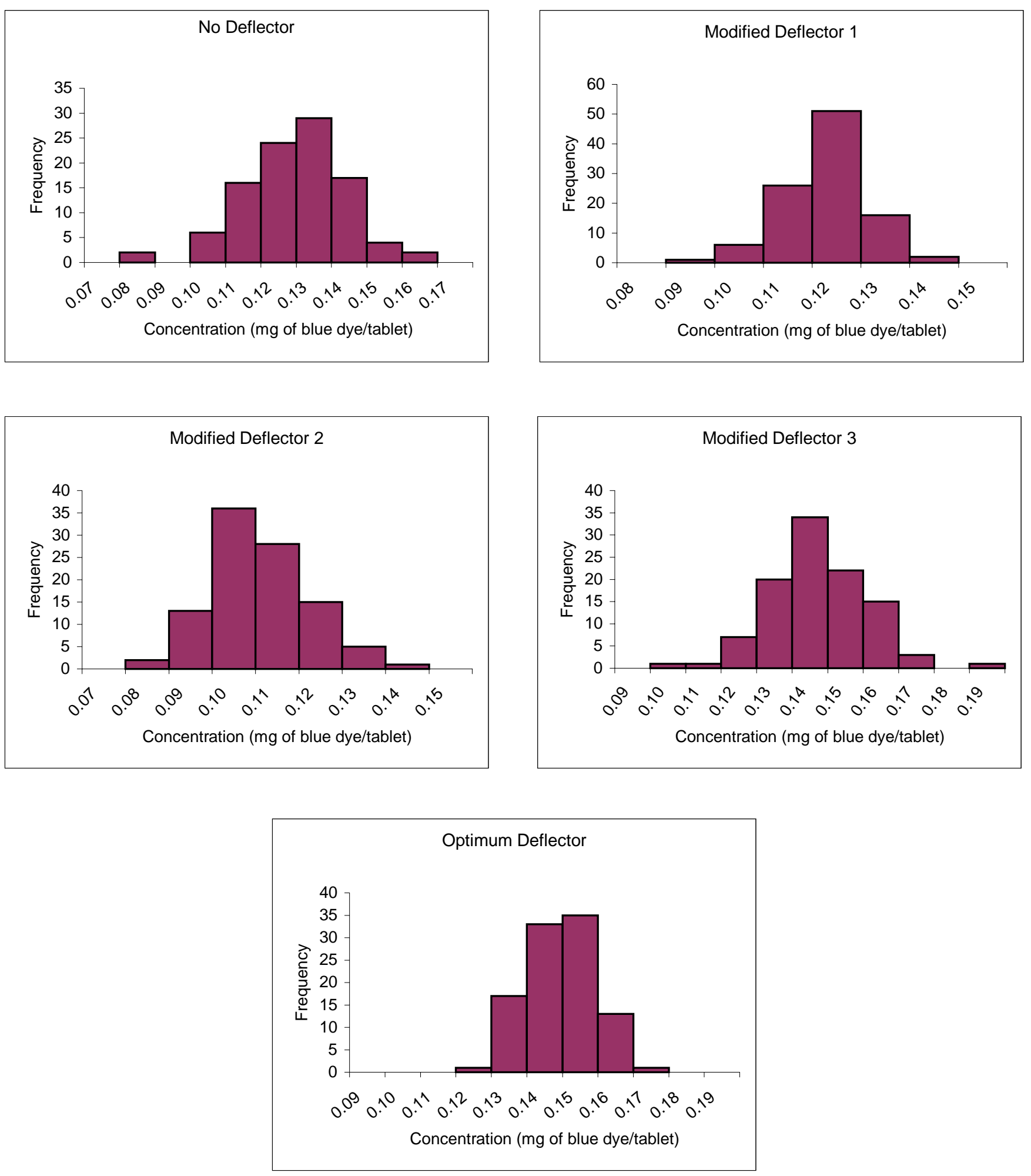

Figure 4-31. Frequency plot of amount of the blue dye coated on tablets during the continuous coating runs with different deflector designs. 
Table 4 -1. STD, Mean ,RSD and \% Efficiency on the amount of coating tablets received with the use of different deflectors

\begin{tabular}{|l|l|l|l|l|}
\hline \multirow{2}{*}{ Deflector Type } & $\begin{array}{l}\text { Standard } \\
\text { Deviation } \\
\sigma_{\text {total }}\end{array}$ & $\begin{array}{l}\text { Mean } \\
\mu_{\text {total }}\end{array}$ & $\begin{array}{c}\mathrm{RSD}_{\text {total }} \\
\sigma_{\text {total }} / \mu_{\text {total }}\end{array}$ & $\begin{array}{l}\% \\
\text { Coating } \\
\text { Efficiency }\end{array}$ \\
\hline No deflector & 0.0136 & 0.121 & 0.113 & 83 \\
\hline $\begin{array}{l}\text { Modified } \\
\text { Deflector 1 }\end{array}$ & 0.0077 & 0.114 & 0.068 & 82 \\
\hline $\begin{array}{l}\text { Modified } \\
\text { Deflector 2 }\end{array}$ & 0.0106 & 0.103 & 0.103 & 80 \\
\hline $\begin{array}{l}\text { Modified } \\
\text { Deflector 3 }\end{array}$ & 0.0132 & 0.137 & 0.096 & 89 \\
\hline $\begin{array}{l}\text { Optimum } \\
\text { deflector }\end{array}$ & 0.0093 & 0.139 & 0.067 & 89 \\
\hline
\end{tabular}


annulus, was transferred smoothly into upward momentum. The deflector also reduced the effective gap between the distributor plate and draft-tube, hence causing a leaner bed. The voidage in the bed is very uniform and the voidage in the immediate vicinity of the nozzle is very high (shown by the circle in the voidage profile map, Figure 4-26).

Modified deflector 1 thus reduces the sheltering effect and the particles are coated more evenly, resulting in improvement in the overall coating consistency. Based on the results obtained with modified deflector 1 , it was decided to try a few other modifications to the deflector. The ring around modified deflector 1 was moved to two different positions as shown in Figure 3-7 and Figure 3-8.

With modified deflector 2, where the ring is moved away from the nozzle, the effective gap for the particles to enter is very low, resulting in the particles entering into the draft-tube at very low velocity. The particles are also deflected away from the nozzle, but since the change in direction of the particles is so drastic, the particles tend to move towards the draft-tube walls and in the process collide with the particles that are entering into the draft-tube. This causes further reduction in velocity resulting in some vortex formation at slightly higher axial heights $(\mathrm{z}=15 \mathrm{~cm}$ to $20 \mathrm{~cm})$. Thus, moving the ring away from the nozzle was counter productive and the coating consistency was worse. The efficiency of coating also went down, as the chances of the liquid spray escaping in the upward draft of air, without coming in contact with the particles, increased. The attrition of tablets was also observed to increase, though no quantitative measurement of this was made. It is believed that the increase in attrition was caused by the increased particleparticle collision and the collision of the particles with the draft-tube walls. 
For modified deflector 3 , the ring was moved higher up the deflecting slope. This caused the deflector to behave more like deflector 1 , which did not have a deflecting ring. This resulted in particles being deflected towards the center resulting in increased particle density above the spray nozzle. Thus this modification of the deflector was not effective in reducing the sheltering effect and the coating consistency obtained was poor compared to that obtained with modified deflector 1 , but was better than that obtained without a deflector.

The optimum deflector was designed based on the observation and results obtained from the previous deflector designs. The best coating consistency obtained with the preliminary designs was with modified deflector 1 and hence the optimum deflector was designed with dimensions very close to this deflector. This deflector was very similar to modified deflector 1 , the only difference being that the former was made of a single piece of Plexiglas ${ }^{\circledR}$ and the slope of the deflector was slightly steeper and the transformation into the vertical section was smother. Hence, the voidage profile obtained for the optimum deflector should be close to that obtained with the modified deflector 1 . Referring back to Figure 4-26, the voidage in the immediate vicinity of the spray nozzle is very high, as seen by the very light shaded region in the circle. This increased voidage in results in reducing the sheltering effect and thus particles acquire a more even amount of spray each time they pass through the spray zone.

The coating efficiencies of the continuous coating runs were calculated based on the average increase in weight of the tablets due to the coating acquired, to that of an ideal case where all the coating solution pumped is coated on the tablets. See Appendix XI for sample calculations. 


\section{4-5.2. Pulse Coating runs}

Researchers in the past, Cheng and Turton (1993), Shelukar, et al. (2000), have found that the major variation in a batch coating process in a fluidized bed can be attributed to the variation in the amount of coating that the particles receive in a single pass. This variation $\sigma_{\mathrm{x}} / \mu_{\mathrm{x}}\left(\mathrm{RSD}_{\text {per-pass }}\right)$, is a measure of the variation of coating per-pass, and can be determined by spraying a pulse of coating solution for a time equal to one cycle time. Coating solution, containing very high blue dye content, was sprayed for a time of 8 to 10 seconds, equivalent to one cycle time. Ideally, all the particles would have passed through the spray zone once. By determining the variation in the amount of coating received by the tablets, we can obtain a coating per pass distribution.

The pulse test was carried out for only two conditions, one with no deflector and the other with the optimum deflector. Figure 4-32 and Table 4-2 show the comparison between the two cases. From the plot, it can be observed that the distribution is not normal and is closer to an exponential distribution. The total number of samples analyzed was 100 .

Table 4-2. Standard Deviation and Mean of $\left(\bar{x} / \mathrm{S}_{\mathrm{x}}\right)$ on the amount of coating tablets received per-pass with No deflector and Optimum deflector.

\begin{tabular}{|c|c|c|}
\hline Statistical Data & No Deflector & Optimum Deflector \\
\hline Std Deviation of $\left(\bar{x} / \mathrm{S}_{\mathrm{x}}\right)$ & 0.3505 & 0.2828 \\
\hline Mean RSD $\left(\bar{x} / \mathrm{S}_{\mathrm{x}}\right)$ & 1.429 & 1.280 \\
\hline $\mathrm{CI}-0.95$ & 1.1479 & 1.078 \\
\hline $\mathrm{CI}+0.95$ & 1.7178 & \pm 0.2024 \\
\hline Range & \pm 0.288 & \\
\hline
\end{tabular}



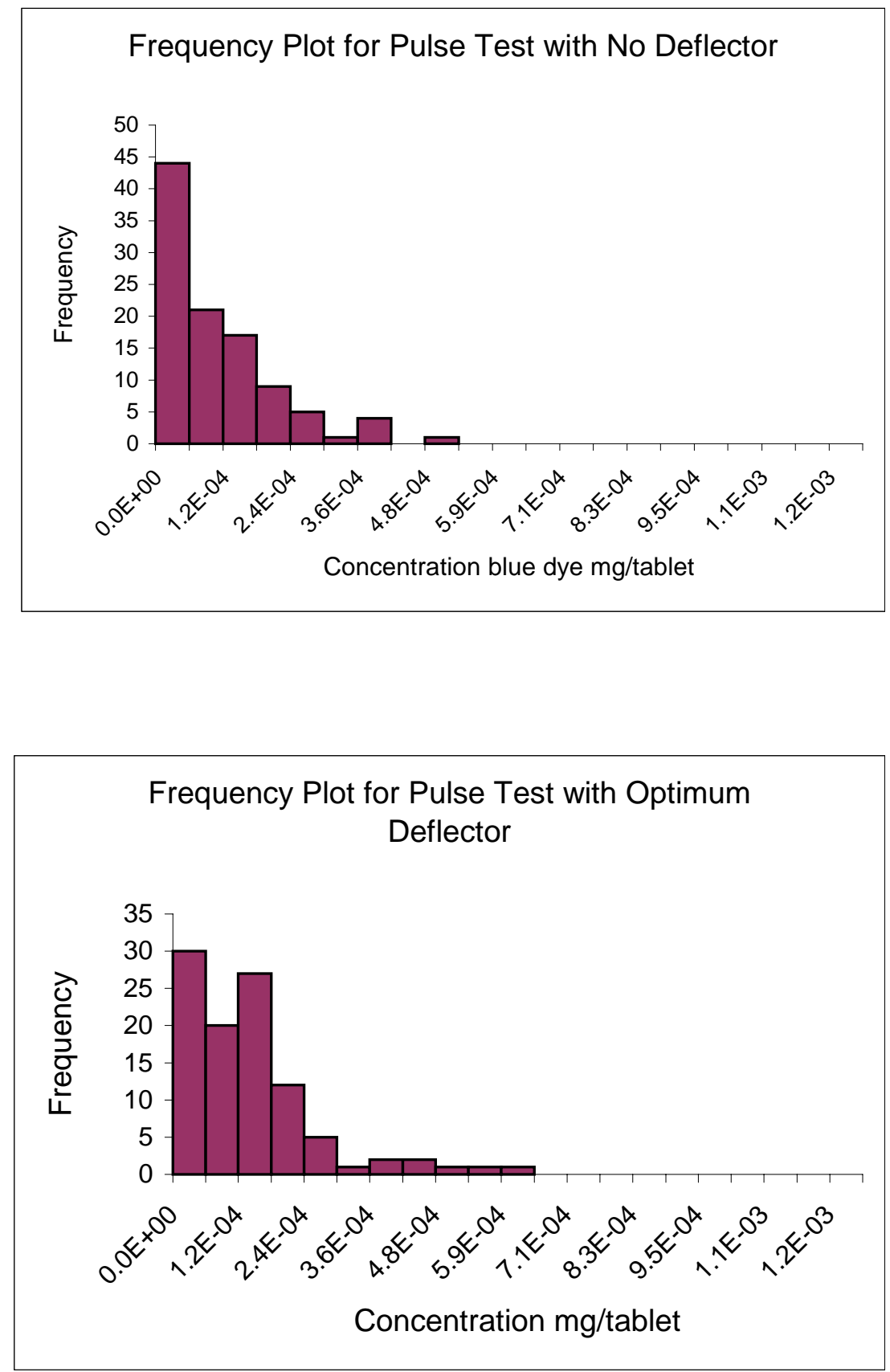

Figure 4-32a, b. Frequency plot for the pulse test, with no deflector and optimum deflector, respectively. 


\section{4-5.3 Statistical Analyses of the Coating Runs}

To check if the total variation in the amount of coating received by a tablet at the end of a continuous coating run can be accounted by the combined variation of the coating per pass variation and cycle time variation the following statistical analysis was made. The 100 samples analyzed for the blue dye content were grouped into groups of 10 without replacement and the mean and standard deviation of these groups were calculated. This was done for both the pulse test and the continuous coating runs. Thus, we have 10 values of mean and 10 values of standard deviation for both continuous and pulse coating experiments and hence 10 values of $\mathrm{RSD}_{\text {total }}$ and 10 values of $\mathrm{RSD}_{\text {per-pass }}$ respectively. Now the mean of these 10 RSD values was determined and a $95 \%$ confidence interval established for the mean. The upper and lower values were then substituted into equation 3-1 and verified if the RHS and LHS values overlapped.

Case I (Optimum Deflector)

The frequency plot of the 10 values of $\mathrm{RSD}_{\text {per-pass }}$ is shown in Figure 4-33 and the values are given in Table 4-3.

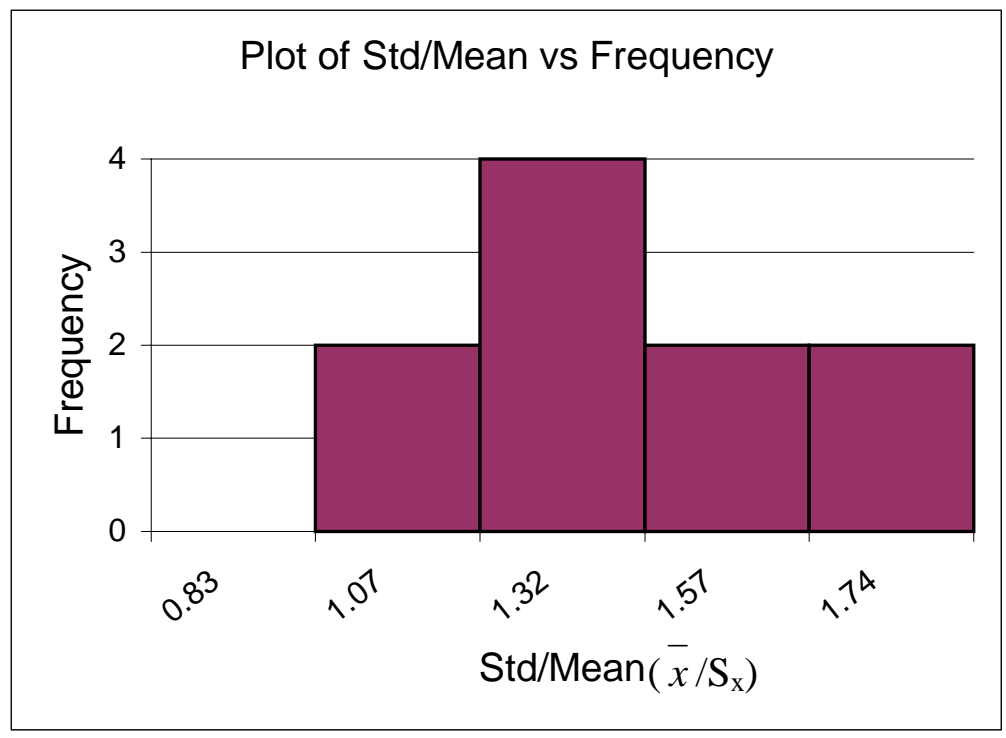

Figure 4-33. Frequency plot of $\left(\bar{x} / S_{\mathrm{x}}\right)$ for the pulse test, with optimum deflector. 
Table 4-3. Average $\mathrm{RSD}_{\text {per-pass }}$ values of the 10 groups formed form the total sample population of 100 for optimum deflector.

\begin{tabular}{|c|c|}
\hline Group & $\bar{x} / \mathrm{S}_{\mathrm{x}}\left(\mathrm{RSD}_{\text {per-pass }}\right)$ \\
\hline 1 & 1.1397 \\
\hline 2 & 1.1490 \\
\hline 3 & 1.5078 \\
\hline 4 & 1.6028 \\
\hline 5 & 1.2569 \\
\hline 6 & 1.6548 \\
\hline 7 & 0.9677 \\
\hline 8 & 0.8284 \\
\hline 9 & 1.1526 \\
\hline 10 & 1.5413 \\
\hline
\end{tabular}

$$
\begin{array}{ll}
\text { Grand Mean of } \bar{x} / \mathrm{S}_{\mathrm{x}}\left(\mathrm{RSD}_{\text {per-pass }}\right) & =1.2801 \\
\text { Grand Standard Deviation of } \bar{x} / \mathrm{S}_{\mathrm{x}}\left(\mathrm{RSD}_{\text {per-pass }}\right) & =0.2828
\end{array}
$$

To obtain a $95 \%$ confidence interval on the mean $\mathrm{RSD}_{\text {per-pass }}$ we can perform the following calculation

$$
C I_{0.95}=\text { GrandMean } \pm t_{0.025, n-1} \times \sqrt{\frac{\text { GrandVariance }}{10}}
$$

From a table of student $\mathrm{t}$ distribution, $\mathrm{t}_{0.025,9}$ is equal to 2.262 , thus equation $16-1$ can be rewritten as:

$$
\begin{aligned}
& C I_{0.95}=\bar{y} \pm 2.262 \sqrt{\frac{\text { GrandVariance }}{10}} \\
& \mathrm{CI}_{0.95}=1.2801 \pm 2.262 \times 0.2828 / \quad 10 \\
& 1.078 \quad \text { Mean RSD } \mathrm{Rer}_{\text {pass }} \quad 1.4824
\end{aligned}
$$


The frequency plot of the 10 values of $\mathrm{RSD}_{\text {total }}$ (continuous coating runs) is shown in Figure 4-34 and the values are given in Table 4-4.

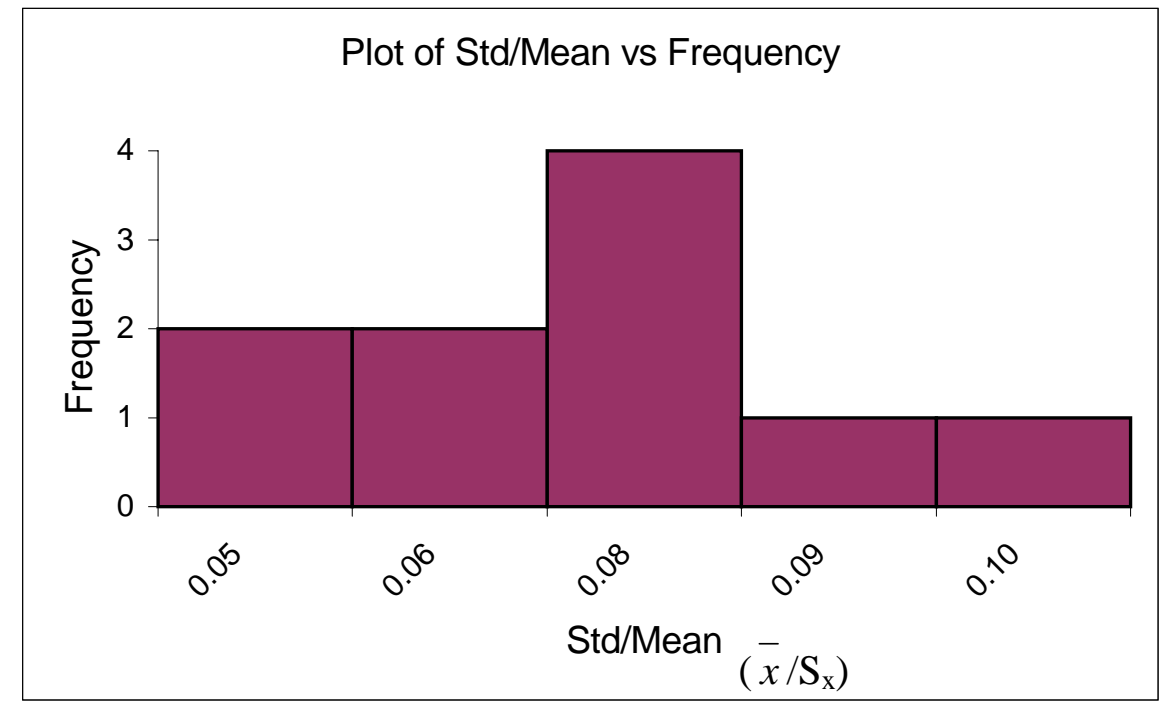

Figure 4-34. Frequency plot of $\left(\bar{x} / S_{\mathrm{x}}\right)$ for the continuous coating experiments, with optimum deflector.

Table 4-4. Average $\mathrm{RSD}_{\text {total }}$ values of the 10 groups formed form the total sample population of 100 for optimum deflector.

\begin{tabular}{|c|c|}
\hline Group & $\bar{x} / \mathrm{S}_{\mathrm{x}}\left(\mathrm{RSD}_{\text {total }}\right)$ \\
\hline 1 & 0.055 \\
\hline 2 & 0.079 \\
\hline 3 & 0.064 \\
\hline 4 & 0.090 \\
\hline 5 & 0.047 \\
\hline 6 & 0.057 \\
\hline 7 & 0.069 \\
\hline 8 & 0.072 \\
\hline 9 & 0.043 \\
\hline 10 & 0.067 \\
\hline
\end{tabular}

Grand Mean of $\bar{x} / \mathrm{S}_{\mathrm{x}}\left(\mathrm{RSD}_{\text {total }}\right) \quad=0.064$

Grand Standard Deviation of $\bar{x} / \mathrm{S}_{\mathrm{x}}\left(\mathrm{RSD}_{\text {total }}\right)=0.014$ 
To obtain a $95 \%$ confidence interval on the mean RSD $_{\text {total }}$ we use equation 4-1.

$$
\begin{aligned}
& C I_{0.95}=\bar{y} \pm 2.262 \sqrt{\frac{\text { GrandVariance }}{10}} \\
& \mathrm{CI}_{0.95}=0.064 \pm 2.262 \times 0.014 / 10 \\
& 0.054 \quad \text { Mean RSD } 10 \text { per-pass } 0.074
\end{aligned}
$$

From the work done by Shelukar et al. (2000) and the correlation derived by Cheng (1993), we can estimate the $\sigma_{\mathrm{ct}}$ with known $\mu_{\mathrm{ct}}$. For a $\mu_{\mathrm{ct}}$ of 9 seconds, the $\sigma_{\mathrm{ct}}$ was estimated to be 4.09. Substituting these values on the Right Hand Side (RHS) of the equation, we can determine if the individual variations caused by these two terms account for the total variation in coating consistency.

$$
\begin{gathered}
\qquad \frac{\sigma_{t o t}}{\mu_{t o t}}=\sqrt{\left(\frac{\sigma_{c t}}{\mu_{c t}}\right)^{2}\left[\frac{\mu_{c t}}{T_{c o a t}}\right]+\left(\frac{\sigma_{x}}{\mu_{x}}\right)^{2}\left[\frac{\mu_{c t}}{T_{c o a t}}\right]} \\
\text { LHS } \quad\left[\frac{\sigma_{t o t}}{\mu_{t o t}}\right] \quad \text { obtained from the continuous runs varies from } 0.054 \text { to } 0.074
\end{gathered}
$$

Substituting the lower (1.078) and upper (1.4824) limit of the Mean RSD ${ }_{\text {per-pass }}$ in the RHS of equation 3-1, we can obtain a range over which the combined variation varies.

RHS $\quad \sqrt{\left(\frac{\sigma_{c t}}{\mu_{c t}}\right)^{2}\left[\frac{\mu_{c t}}{T_{c o a t}}\right]+\left(\frac{\sigma_{x}}{\mu_{x}}\right)^{2}\left[\frac{\mu_{c t}}{T_{c o a t}}\right]}$ 


$$
\sqrt{\left(\frac{4.09}{9}\right)^{2}\left[\frac{9}{60 * 60}\right]+(1.078 \text { to } 1.48)^{2}\left[\frac{9}{60 * 60}\right]}
$$

RHS varies from 0.0585 to 0.078 .

We can see that the RHS and LHS values overlap indicating that the total variation in coating can be accounted by the combined variation of cycle time variation and coating per pass variation and that the second term in the RHS (coating-per-pass variation) is the major contributing term.

\section{Case II (No deflector)}

Samples are grouped at random into groups of 10 similar to the case with optimum deflector. The frequency plot of the 10 values of $\mathrm{RSD}_{\text {per-pass }}$ is shown in Figure 4-35 and the values are given in Table 4-5.

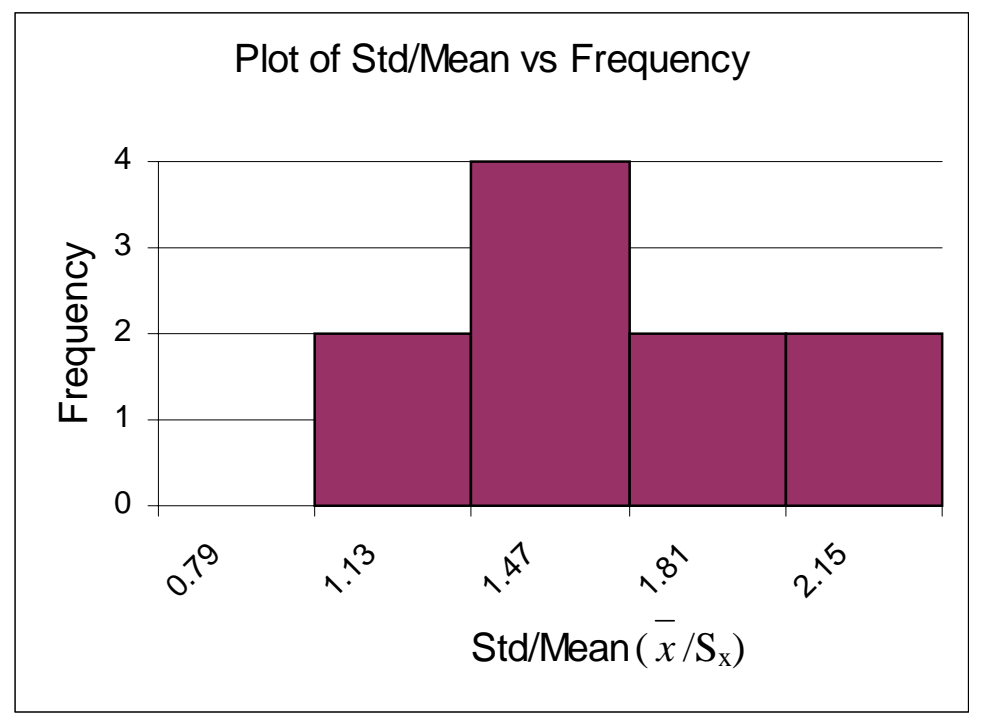

Figure 4-35. Frequency plot of $\left(\bar{x} / S_{\mathrm{x}}\right)$ for the pulse test, with no deflector. 
Table 4-5. Average $\mathrm{RSD}_{\text {per-pass }}$ values of the 10 groups formed form the total sample population of 100 for no deflector.

\begin{tabular}{|c|c|}
\hline Group & $\bar{x} / \mathrm{S}_{\mathrm{x}}\left(\mathrm{RSD}_{\text {per-pass }}\right)$ \\
\hline 1 & 2.0699 \\
\hline 2 & 1.3158 \\
\hline 3 & 1.8415 \\
\hline 4 & 0.9384 \\
\hline 5 & 1.4726 \\
\hline 6 & 1.3980 \\
\hline 7 & 1.4147 \\
\hline 8 & 1.3161 \\
\hline 9 & 0.9555 \\
\hline 10 & 1.6064 \\
\hline
\end{tabular}

$\begin{array}{ll}\text { Grand Mean of } \bar{x} / \mathrm{S}_{\mathrm{x}}\left(\mathrm{RSD}_{\text {per-pass }}\right) & =1.4329 \\ \text { Grand Standard Deviation of } \bar{x} / \mathrm{S}_{\mathrm{x}}\left(\mathrm{RSD}_{\text {per-pass }}\right) & =0.3505\end{array}$

To obtain a $95 \%$ confidence interval on the mean $\mathrm{RSD}_{\text {per-pass }}$ we substitute the appropriate values into equation 4-1.

$$
\begin{gathered}
C I_{0.95}=\text { GrandMean } \pm t_{0.025, n-1} \times \sqrt{\frac{\text { GrandVariance }}{10}} \\
\mathrm{CI}_{0.95}=1.4329 \pm 2.262 \times 0.3505 / 10 \\
1.1822 \quad \text { Mean RSD } \text { per-pass } \quad 1.6836
\end{gathered}
$$


The frequency plot of the 10 values of $\mathrm{RSD}_{\text {total }}$ is shown in Figure 4-36 and the values are shown in Table 4-6.

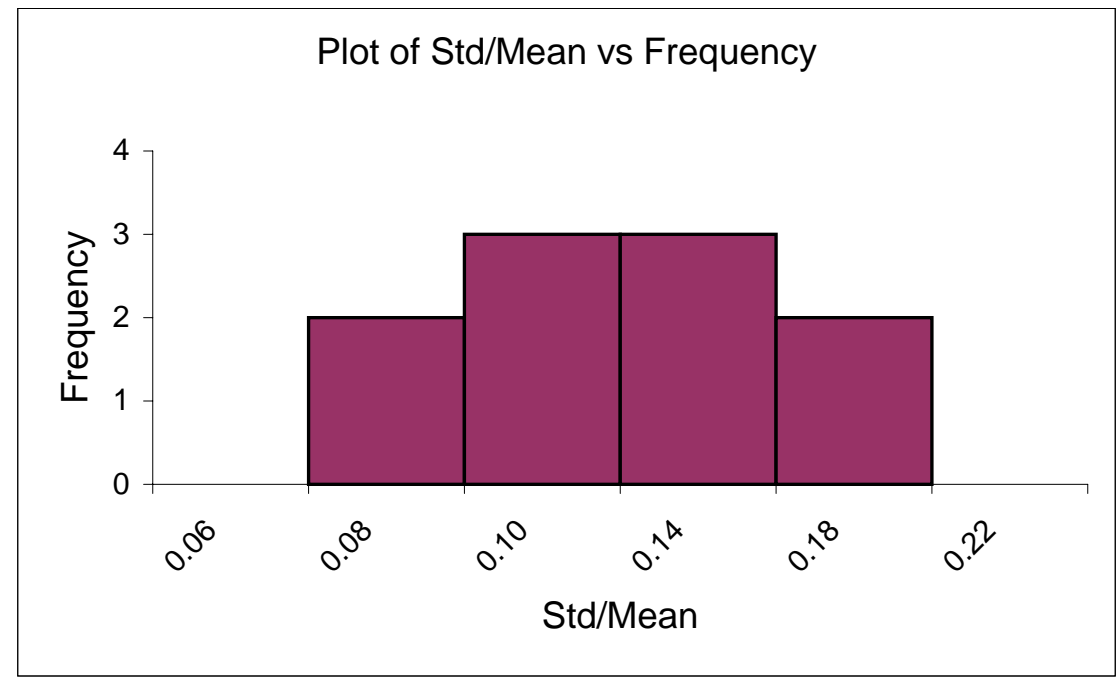

Figure 4-36. Frequency plot of $\left(\bar{x} / S_{\mathrm{x}}\right)$ for the continuous coating run, with no deflector.

Table 4-6. Average RSD $\mathrm{Der}_{\text {pass }}$ values of the 10 groups formed form the total sample population of 100 no deflector.

\begin{tabular}{|c|c|}
\hline Group & $\bar{x} / \mathrm{S}_{\mathrm{x}}\left(\mathrm{RSD}_{\text {per-pass }}\right)$ \\
\hline 1 & 0.078 \\
\hline 2 & 0.118 \\
\hline 3 & 0.112 \\
\hline 4 & 0.083 \\
\hline 5 & 0.168 \\
\hline 6 & 0.112 \\
\hline 7 & 0.177 \\
\hline 8 & 0.097 \\
\hline 9 & 0.075 \\
\hline 10 & 0.084 \\
\hline
\end{tabular}

Grand Mean of $\bar{x} / \mathrm{S}_{\mathrm{x}}\left(\mathrm{RSD}_{\text {total }}\right)$

$=0.11$

Grand Standard Deviation $\bar{x} / \mathrm{S}_{\mathrm{x}}\left(\mathrm{RSD}_{\text {total }}\right)$

$=0.036$ 
To obtain a $95 \%$ confidence interval on the mean $\mathrm{RSD}_{\text {total }}$ we can perform the following calculation

$$
C I_{0.95}=\text { GrandMean } \pm t_{0.025, n-1} \times \sqrt{\frac{\text { Grand Variance }}{10}} \quad 4-1
$$

From a table of values for the student $t$ distribution we get $t_{0.025,9}$ is equal to 2.262 , thus equation 4-1 can be

$$
\begin{aligned}
& C I_{0.95}=\bar{y} \pm 2.262 \sqrt{\frac{\text { Grand Variance }}{10}} \\
& \mathrm{CI}_{0.95}=0.11 \pm 2.262 \times 0.036 / 10 \\
& 0.084 \quad \text { Mean } \mathrm{RSD}_{\text {per-pass }} \quad 0.136
\end{aligned}
$$

The estimated $\sigma_{\mathrm{ct}}$ with known $\mu_{\mathrm{ct}}$. for case with no deflector is 3.8 seconds and 8.5 seconds respectively. By substituting the appropriate values into (RHS) of equation 3-1, we can obtain a range over which the RHS varies.

$$
\begin{gathered}
\frac{\sigma_{t o t}}{\mu_{t o t}}=\sqrt{\left(\frac{\sigma_{c t}}{\mu_{c t}}\right)^{2}\left[\frac{\mu_{c t}}{T_{c o a t}}\right]+\left(\frac{\sigma_{x}}{\mu_{x}}\right)^{2}\left[\frac{\mu_{c t}}{T_{c o a t}}\right]} \quad 3-1 \\
\text { RHS } \quad\left[\frac{\sigma_{t o t}}{\mu_{t o t}}\right] \quad \text { obtained from the continuous runs varies from } 0.084 \text { to } 0.136
\end{gathered}
$$

Substituting the lower (1.1822) and upper (1.6836) limit of the mean $\mathrm{RSD}_{\text {per-pass }}$ in the RHS of equation 3-1, we can obtain a range for the RHS.

RHS

$$
\sqrt{\left(\frac{\sigma_{c t}}{\mu_{c t}}\right)^{2}\left[\frac{\mu_{c t}}{T_{c o a t}}\right]+\left(\frac{\sigma_{x}}{\mu_{x}}\right)^{2}\left[\frac{\mu_{c t}}{T_{c o a t}}\right]}
$$




$$
\sqrt{\left(\frac{3.8}{8.5}\right)^{2}\left[\frac{8.5}{60 * 60}\right]+(1.182 \text { to } 1.684)^{2}\left[\frac{8.5}{60 * 60}\right]}
$$

RHS varies from 0.061 to 0.085 .

We see that the values of RHS and LHS overlap and hence we can conclude that the total variation in coating can be accounted by the combined variation of cycle time and coating per pass variation. Table 4-7 gives the consolidated results.

Table 4-7. Consolidated results of the coating experiments.

\begin{tabular}{|c|c|c|}
\hline Terms in the Equation & No Deflector & Optimum Deflector \\
\hline LHS $\left(\sigma_{\text {total }} / \mu_{\text {total }}\right)$ & 0.084 to 0.0136 & 0.054 to 0.074 \\
\hline$\left[\sigma_{\mathrm{ct}} / \mu_{\mathrm{ct}}\right]^{2}\left[\sigma_{\mathrm{ct}} / \mathrm{T}_{\mathrm{coat}}\right]$ & $4.72 \times 10^{-04}$ & $5.16 \times 10^{-04}$ \\
\hline$\left[\sigma_{\mathrm{x}} / \mu_{\mathrm{x}}\right]^{2}\left[\mu_{\mathrm{ct}} / \mathrm{T}_{\mathrm{coat}}\right]$ & $3.29 \times 10^{-03}$ to $6.69 \times 10^{-03}$ & $2.91 \times 10^{-03}$ to $5.48 \times 10^{-03}$ \\
\hline RHS & 0.061 to 0.085 & 0.0585 to 0.078 \\
\hline
\end{tabular}




\section{CHAPTER V}

\section{CONCLUSIONS}

The hydrodynamics of large particles in the vicinity of the spray zone and in the draft-tube of a semi-circular Wurster fluidized bed coater were investigated using a computer-based video imaging system. The particle velocity profiles and the bed voidage profiles thus obtained were mapped using custom written programs in Microsoft $\subset$ Visual Basic. A large database of velocity and voidage profiles with different operating parameters was also obtained. For the first time, a device for altering the voidage profile in the draft-tube (deflectors) was used and its effect on the hydrodynamics of the bed investigated. Coating studies were carried out to study the variation in the amount of coating received by the particles and to determine the factors that affect the coating consistency. Single-pass coating studies were carried out in an effort to estimate variation in the amount of coating that particles receive per pass and the effect this plays in the total coating variation.

The observations and conclusions that can be made from these experimental investigations are summarized below.

- At the lower gap height, $(2.7 \mathrm{~cm}$ between the distributor plate and draft-tube) the particle velocities at the center were lower than particle velocities closer to the wall of the draft-tube when no deflector was present or deflector 1 was present. This was observed because at the lower gap height, the particles entry is restricted by the low gap height and the particles enter the bed in the horizontal direction. This causes particle-particle interaction at the center resulting in the loss of vertical momentum. In the presence of modified deflector 1 , the velocity at the 
center was marginally less or equal to the velocities near the draft-tube walls. This is because the modified deflector 1 deflects the particles away from the center and thus reduces particle-particle interaction at the center.

- At the higher gap height, $(7.4 \mathrm{~cm}$ between the distributor plate and draft-tube), the particles entered the draft-tube with less restriction, resulting in a denser bed. The particles also showed a tendency to accelerate at higher axial heights and more symmetric velocity profiles were observed. With the higher gap height, deflector 1 became less effective and the profile around the nozzle was not much different. The presence of modified deflector 1 resulted in a very symmetric velocity profile and the velocities at the center were significantly higher than velocities closer to the wall.

- Increasing the fluidizing air velocity did not alter the velocity profile significantly. However, the profile became more symmetric and the particles moved with higher velocities.

- The use of distributor plate 2 with a higher ratio of inner to outer area (11\% more than distributor plate 1) did not result in any significant change in the velocity profile.

- The voidage profiles with the lower gap height are similar for the both the cases of with/without deflector 1 . However, the voidage profile changed significantly in the presence of modified deflector 1 . The voidage across the entire bed became very uniform and the voidage varied over a very narrow range (0.90 to 0.95$)$.

- At the higher gap height, deflector 1 was not effective in increasing the voidage around the spray zone, and the voidage at axial height $\mathrm{z}=4.5$ and $\mathrm{r}=0$ was the 
same for the case with no deflector. With the modified deflector 1 , the voidage in the spray zone increased considerably, and the voidage distribution was even across the draft-tube.

- The continuous coating runs showed that the use of deflectors to alter the voidage around the nozzle resulted in variation in the coating quality. This showed that reducing the sheltering effect results in improved coating consistency. Deflector 1 was not effective in altering the voidage profile around the nozzle and gave a coating consistency close to the no deflector case. However, with modified deflector 1, a marked improvement in coating consistency was achieved.

- An Optimum deflector was designed based on the results obtained with deflector 1, and modified deflectors 1, 2 and 3 . The use of this optimum deflector, gave the best coating consistency although not much improvement was seen from that obtained from modified deflector 1 . The dimensions of the optimum deflector were very close to those of modified deflector 1 .

- The pulse test or the single-pass coat test showed that variation in coating per pass accounted for nearly $80 \%$ of the total coating variation. Hence, the use of these deflectors, which increase the voidage in the spray zone and reduce sheltering effect, resulted in less variation in coating per-pass and a better overall coating consistency.

- The mass balance on flow rate of particles in the draft-tube and annulus, at both dilute (lower gap height), and concentrated (higher gap height) flow conditions, showed good agreement. This favorable agreement is an indication of the 
reliability of the particle velocity and voidage data obtained and the use of computer based video imaging to obtain such data.

The above results indicate that the non-invasive computer-based video imaging technique with custom software can be used effectively to measure particle velocity and voidage profiles in the draft-tube region of a semi-circular Wurster fluidized bed coater. The use of a deflector to guide the particles away from directly passing over the spray nozzle, thus reducing the sheltering effect, resulted in an improvement of the coating consistency of the tablets. As a final check for consistency of data, the particle velocity and voidage data in the draft-tube and annular regions were used to compute a solids mass flow balance using numerical integration. The results show good agreement between the solid mass flow rates in the draft-tube and annulus. 


\section{CHAPTER VI}

\section{RECOMMENDATION FOR FUTURE WORK}

Recommendations and scope for future work:

- Studies in conventional spouted beds (cylindrical), using optical probes and other methods have shown that there are quantitative differences in the velocity and voidage measurements between the semi-cylindrical and cylindrical geometries (this difference is more pronounced with the velocity measurements). Thus obtaining the velocity and voidage measurements in a three-dimensional bed and comparing it with the data obtained in the case of a two dimensional bed of the same dimensions can further validate the data obtained in this study.

- Based on the extensive database of velocity and voidage profiles obtained in this study, simulation and modeling can be done to predict the path that the particles take after entering into the draft-tube region.

- The use of deflectors has shown measurable improvement in the coating consistency in a semi-circular bed. From the observations made, it is clear that these deflectors will be more effective in the case of a three dimensional bed. This can be verified by conducting actual coating runs in a three dimensional bed.

- The optimum deflector design obtained here, proved very effective in improving the coating consistency. However, this deflector's design parameters can be studied further and optimized and can be compared with existing (commercial) designs to give a basis for comparison. 
- The liquid spray nozzle used in this work is of the type hollow inverted cone, and the deflector/guide used was effective in reducing the sheltering effect, which is the cause for variation in coating consistency. Use of these deflectors with a solid cone type spray nozzle and its effectiveness in reducing sheltering effect is an area of interest for future work.

- A modification to the draft-tube, shown in the figure below, has been suggested by Shelukar (2000) and may improve the velocity and voidage profile and will be of interest. The use of these deflectors is expected to prevent tablets from moving along the draft-tube walls, thus forcing every tablet to pass through the spray zone and hence reduce variation in coating per-pass.
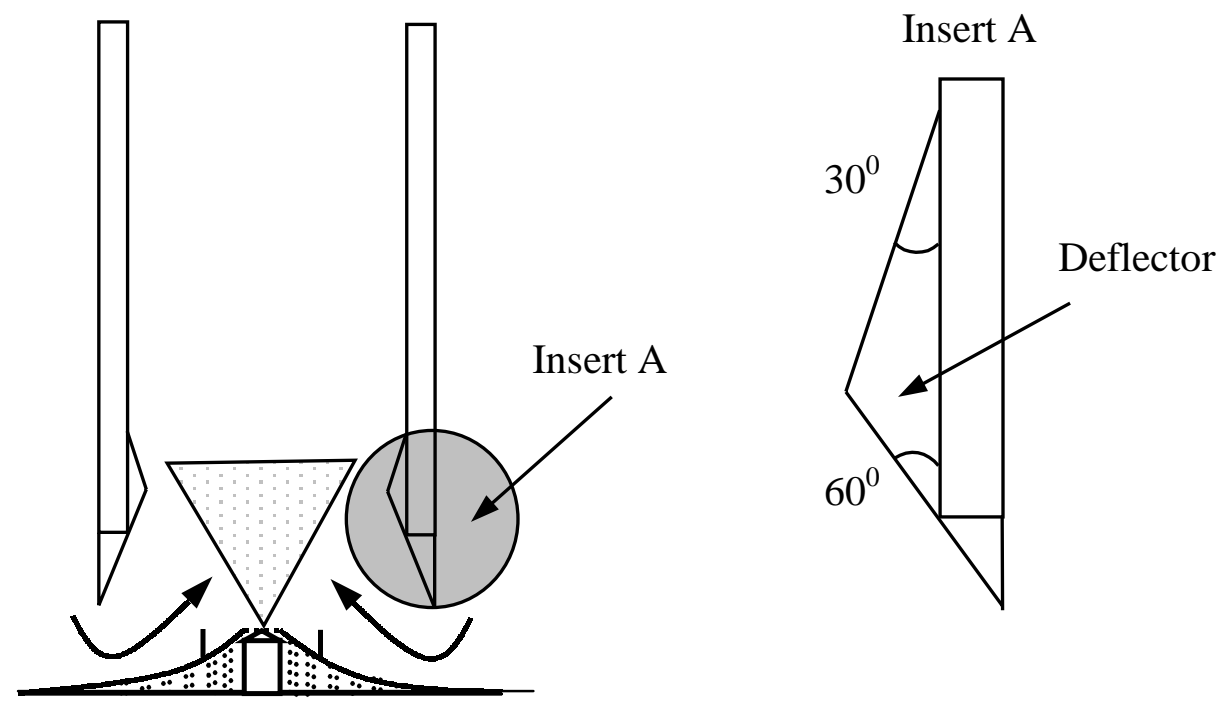

Figure 6-1. Diagram showing alterations made to the draft-tube. 
- The use of the modified/optimum deflector not only showed improvement in the coating consistency but also showed difference in the dissolution rate of the coated blue dye. This observation though not investigated further in this study, is an area of interest for future studies and may hold important answers relating to the morphology of the coating.

- Computer based video imaging technique is limited to measurements at the wall and shallow depths from the wall. As one attempts to penetrate further into the bed, the computer images become more susceptible to the masking effect of foreground particles and changes in the light intensity. Hence, other measurement techniques such as optical probes or $\gamma$-ray emission methods can be used to study particle behavior in these areas of the bed. 


\section{NOMENCLATURE}

$d_{p}$

$\rho_{\mathrm{p}}$

$\rho_{b}$

$r_{d o}$

$\mathrm{r}_{\mathrm{di}}$

$\mathrm{D}_{\mathrm{o}}$

$\mathrm{D}_{\mathrm{i}}$

$\mathrm{u}_{\mathrm{anul}}$

$\mathrm{u}_{\mathrm{dft}}$

$m_{d f t}$

$\mathrm{m}_{\mathrm{anul}}$

$\varepsilon_{\mathrm{dft}}$

$\varepsilon_{\text {anul }}$

$\theta$

$\sigma$

$\mu$

RSD

ADOF

FOV

$\mathrm{CI}_{0.95}$ diameter of the particle, $\mathrm{m}$

absolute density of particles, $\mathrm{kg} / \mathrm{m}^{3}$

bulk density, $\mathrm{kg} / \mathrm{m}^{3}$

inside diameter of draft-tube, $\mathrm{m}$

outside diameter of draft-tube, $\mathrm{m}$

inside diameter of fluidized bed, $\mathrm{m}$

outside diameter of fluidized bed, $\mathrm{m}$

2-D particle velocity in annulus, $\mathrm{m} / \mathrm{s}$

2-D particle velocity in the draft-tube, $\mathrm{m} / \mathrm{s}$

mass flow rate in draft-tube, $\mathrm{kg} / \mathrm{s}$

mass flow rate in the annulus, $\mathrm{kg} / \mathrm{s}$

voidage in the draft-tube

voidage in the annulus

angle of the resultant 2-D velocity vector, relative to the positive $r$ direction

standard deviation

mean

relative standard deviation $(\sigma / \mu)$ also called coefficient of variation

apparent depth of field

field of view

$95 \%$ confidence interval 
$x$

$\mathrm{S}_{\mathrm{x}}$

Std

$\mathrm{T}_{\text {coat }}$ sample standard deviation

sample mean

standard deviation

Total time of coating experiment 


\section{BIBLIOGRAPHY}

Boulos, M.I., and B. Waldie, "High Resolution of Particle Velocities in a Spouted Bed using Laser-Doppler Anemometry," The Canadian Journal of Chemical Engineering, 64, pp. 939-943 (1986).

Brudney, N. and P.Y. Toupin, “Air Suspension Coating," Can.Pharm. J., 94(7), pp. 1819 (1961).

Caldwell, H. C., and E. Rosen, "New Air Suspension Apparatus for Coating Discrete Solids," Journal of Pharm. Sci., 53, pp. 1387-1391 (1964).

Chang, R. K., E. Hsiao, and J. R. Robinson, “ A Review of Aqueous coating Techniques and Prelimenary data on Release from a Theophylline Product," Pharm. Tech., 11(3), pp.56-68 (1987).

Cheng, X.X, "The Study of Uniformity of Particle Coating," Ph.D. Dissertation, West Virginia University (1993).

Cheng, X.X. and R. Turton, "The Uniformity of Coating Occurring in Fluidized Bed," AIChE Symp. Sep. 90 (301), pp. 142-151 (1994).

Choi, M.S. Michael and Meisen Axel "Sulfur Coating of Urea in Shallow Spouted Beds," Chemical engineering Science, 52,pp.1073 (1996).

Davies, W.L., and W.T., Jr., Gloor, "Batch Production of Pharmaceutical Granulations in a Fluidized Bed I: Effects of Process Variables on Physical Properties of Final Granulation,” J. Pharm. Sci., 61, pp. 1869-1874 (1971).

Davies, W.L., and W.T., Jr., Gloor, "Batch Production of Pharmaceutical Granulations in a Fluidized Bed II: Effects of Various Binders and their Concentrations on the Granulations and Compressed Tablets," J. Pharm. Sci., 60, pp. 618-622 (1972).

Ghebre-Sellassie, I., U. Iyer, D. Kubert, and M. B. Fawzi, "Characterization of a New Water-Based Coating for Modified-Release Preparations," Pharm. Tech., 12(9), pp.96106 (1988).

Goldberg, H. and W. J. Joseph, "Using the Web Delivery System to Produce Solid Dosage forms," Pharmaceutical Manufacturing, pp. 21-29, April (1986).

Good, R. W. and Lee, P. I, "Controlle-Release Technology - Pharmaceutical Applications," ACS Sym. Series348, (1987).

Grace, J.R and J. Baeyens, "Gas Fluidization Technology," Chapter 13, ed. D. Geldart, John Wily \& Sons Inc., New York (1986). 
Hattori, H. and K. Takeda, "Slide-outlet Spouted Bed with Inner Draft Tube for Smallsized Solids Particles,” J. Chem. Eng. Japan, 11, pp. 125-129 (1978).

He, Y.L., C.J. Lim, J.R. Grace, J.X.Zhu and S.Z. Qin, "Measurement of Voidage Profiles in Spouted Beds," Can. J. Chem. Eng., 72, pp. 229-234 (1994a).

He, Y.L., C.J. Lim, J.R. Grace, J.X.Zhu and S.Z. Qin, "Particle Velocity Profiles and Solids Flow Patterns in Spouted Beds," Can. J. Chem. Eng., 72, pp. 561- 568 (1994b).

Khoe, G.K. and J. Van Brakel, "Drying Charecteristics of s Draft Tube Spouted Bed," Can. J. Chem. Eng., 61, pp. 411-418 (1983).

Klaflin, J. K. and A. G. Fane, "Spouting with a Porous Draft Tube," Can. J. Chem. Eng., 61, pp. 346-363 (1983).

Kunii, D., O. Levenspiel, "Fluidization Engineering," First Edition, Robert E. Krieger Publishing Company, Inc., Chapter-2, pp. 16 (1969).

Kunii, D., O. Levenspiel, "Fluidization Engineering," Industrial Application of Fluidized Flow, 8 (2), pp. 125-146 (1982).

Kandis Sudsakron, "The Effect of Particle Size on the Amount of coating Received during a Batch Fluidized Bed Coating Operation," Masters Thesis, West Virgina University (1999).

Lee, V. L. and J. R. Robinson, "Controlled Drug Delivery: Fundamentals and Applications," $2^{\text {nd }}$ Ed., Marcel Dekker Inc., (1987).

Lefroy G.A. and J.F. Davidson, "The Mechanics of Spouted Beds," Trans. Instn. Chem. Engrs., 47, pp. T120-T128 (1969).

Lehmann, K. and D. Dreher, "Coating of Tablets and Small Particles with acrylic resins by Fluid bed technology," J. Pharm. Tech \& Prod. Mrf., 2(4) 31-43, (1981).

Li, L. C. and E. G. Peck, "Water Based Silicone Elastomer Controlled Release Tablet Film coating in Process Evaluation," Drug Development and Industrial Pharmacy, 16(3), pp. 415-435 (1990).

Liu, L. X. and J. D. Liter, "Spouted Bed Seed Coating: the Effect of Process Variables on Maximum Coating Rate and Elutration," Powder Tech., 74, pp. 215-230 (1993).

Mann, U., "Coating of Particulate Solids by Air Suspension," Ph.D. Dissertation, University of Wisconsin, Madison (1972). 
Mann, U., E.J. Crosby and M. Rubinovitch, "Number of Cycles Distribution in Circulating Systems," Chem. Eng. Sci., 29, pp. 761-765 (1974).

Massimilla, L., J.W. Westwater, "Photographic Study of Solids-Gas Fluidization," AIChE J., 6(1) pp. 132-138 (1959).

Mathur, K.B., and P.E. Gishler, "A Technique for Contacting Gases with Coarse Solid Particles," AIChE. J., 1, pp. 157-164 (1955).

Rekhi, S.G., W. R. Mendes, S. C. Porter, and S.S. Jamhekar, "Aqueous Polymeric Dispersions for Controlled Drug Delivery - Wurster Process," Pharmaceutical Technology, pp. 112-125, March (1989).

Robinson, M. J., G. M. Grass, and R. J. Lantz, "An Apparatus and Method for the Coating of Solid Particles,” J. Pharm. Sci., 57, pp. 1983-1988, (1968).

Robinson, M. J., "Coating of Pharmaceutical Dosage," Remingtons Pharmaceutical Scinece, $16^{\text {th }}$, pp. 1585-1593 (1980).

Rankell, A. S., M. W. Scott, A. Lieberman, F. S. Chow, and J. V. Battista, "Continuous Production of Tablet Granulations in a Fluidized Bed II. Operation and Performance of Eeuipment," J. Pharm Sci., 53, pp. 320-324 (1964).

Roy, D., F. Larachi, L. Robert, and C. Jamal, "A Study of Solid Behaviour in Spouted Beds Using 3-D Particle Tracking," Can. J. Chem. Eng., 72, pp. 945-952 (1994).

Saadevandi, B. A., and R. Turton, "The Application of Computer-Based Imaging to the Measurements of Particle Velocity and Voidage Profiles in a Fluidized Bed," Powder Technology, 98, pp. 183-189 (1998).

Saadevandi, B. A, "The Use of Imaging Techniques to Study the Hydrodynamics of Particle Motion in a Fluidized Bed Coating Device in the Region of the Liquid Spray," Ph.D Dessertation, West Virginia University (1996).

Shernoy, D. F., "Amodel of Surface Renewal with Application to Fluid Bed Coating of Particles," Chem. Eng. Sci., 36, pp. 845-848 (1981).

Shelukar, S., Jennifer Ho, James Zega, Ed Roland, Norman Yeh, David Quiram, Antony Nole, Ashok Katdare and Scott Reynolds, "Identification and Characterization of Factors Controlling Tables Coating Uniformity in a Wurster Coating Process," Powder Technology, 110, pp. 29-36 (2000).

Singiser, R.E., A.L. Heiser, and E.B. Prilling, "Air-Suspension Tablets Coating," Chem. Eng. Progress, 72 (6), pp. 107-111 (1966). 
Suciu G.C., and M. Patrascu, "Particle Circulation in a Spouted Bed," Powder Technology, 19, pp. 109-114 (1978).

Suciu G.C., and M. Patrascu, "Prediction of Solids Circulation Patterns in a Spouted Bed," Powder Technology, 53, pp. 257-271 (1977).

Todd, D. B., R. H. Overcashier, and D. B. Olney, Motion Picture, "Fluidization Characteristics in a Two-Dimensional Fluid Bed," Shell Development Company, Emeryville, California (1957)

Toomey, R. D., and H.F. Johnstone, Chem. Eng. Progr. Symposium Ser. No 5, 49, 51 (1953).

Van Velzen, D., H.J. Flamm, H. Langenkamp and A. Casile, "Motion of Solids in Spouted Beds," Can. J. Chem. Eng., 52, pp. 156- 161 (1974).

Wan, L. S. C and W. F. Lai, "Factors Affecting Drug Release from Drug-Coated Granules Prepared by Fluidized-Bed Coating," Intl. J. of Pharmaceutics, 72, pp. 14991501 (1980).

Wnukowski, P. and F. Setterwall, "The Coating of Particles in a Fluidized Bed (Residence Time Distribution in a system of Two Coupled Perfect Mixers)," Chem. Eng. Sci., 44(3), pp. 493-505 (1989).

Weiss, P. J. and A. Meisen, "Laboratory Studies on Sulphur-Coating Urea by the Spouted Bed Process," Can. J. of Chem. Eng., 61, pp. 440-447, (1983).

Wurster, D.E., "Means for Applying coating to Tablets or Like," US Patent 2,799,241 (1957).

Wurster, D. E., "U.S. Patent, 2,648,609,” (1953).

Wurster, D.E., Lindlof, and J.Y. Battisita, "Process for Preparing Agglomerates," US Patent 3,207,824 (1965).

Yang, W. C. and D. L. Keairns, "Recirculating Fluidized Bed Reactor Data Utilizing a Two-Dimensional Cold Model," AIChE Symp. Ser., 70 (141), pp. 27-40 (1974).

Yang, W. C. and D. L. Keairns, "Design of Recirculating Fluidized Bed for Commercial Applications," AIChE Symp. Ser., 74(176), pp. 218-227 (1978).

Yang, W. C. and D. L. Keairns, "Studies on the Solid Circulation Rate and Gas Bypassing in a Spouted Fluid-Bed with a Draft Tube," Can. J. Chem. Eng., 61, pp. 349355 (1983). 
$\mathrm{Xu}$ M., "A Theoretical and Experimental Investigation of Spouted Beds With Draft Tube," Ph.D. Dissertation, West Virginia University, (1994).

Zogilo, M. A., W. H. Streng, and J. T. Carstensen, "Diffusion Model for Fluidized Bed Drying," J. Pharm. Sci., 64 pp. 1869-`873 (1975). 


\section{Appendix I}

\section{Orifice plate calibration and flow measurement}

The airflow for fluidizing the bed was supplied by a supply blower (Model VFC904A7W, Fuji Ring Compressor, Fuji Electric Co., LTD., Lincoln Park, NJ). The airflow rate through the orifice plate was calibrated with a Turbine meter (Rockwell No. 4 Meter, Rockwell Manufacturing Company, Pittsburgh, PA), which in turn was first calibrated with a Rotometer (Brooks FullView ${ }^{\mathrm{TM}}$ Model 1100). The pressure drop across the orifice plate was measured using a Magnehelic gauge (scale; 0 to 5 inches water) and is plotted against the flow rate for different upstream pressures. Hence, the pressure reading from the Magnehelic gauge gives the airflow through the bed in scfm directly. This setup is shown in Figure A-1. The calibration curves are given in Figure A-2. From the curves, the volumetric flow rate of air, at different upstream pressures, can be obtained directly.

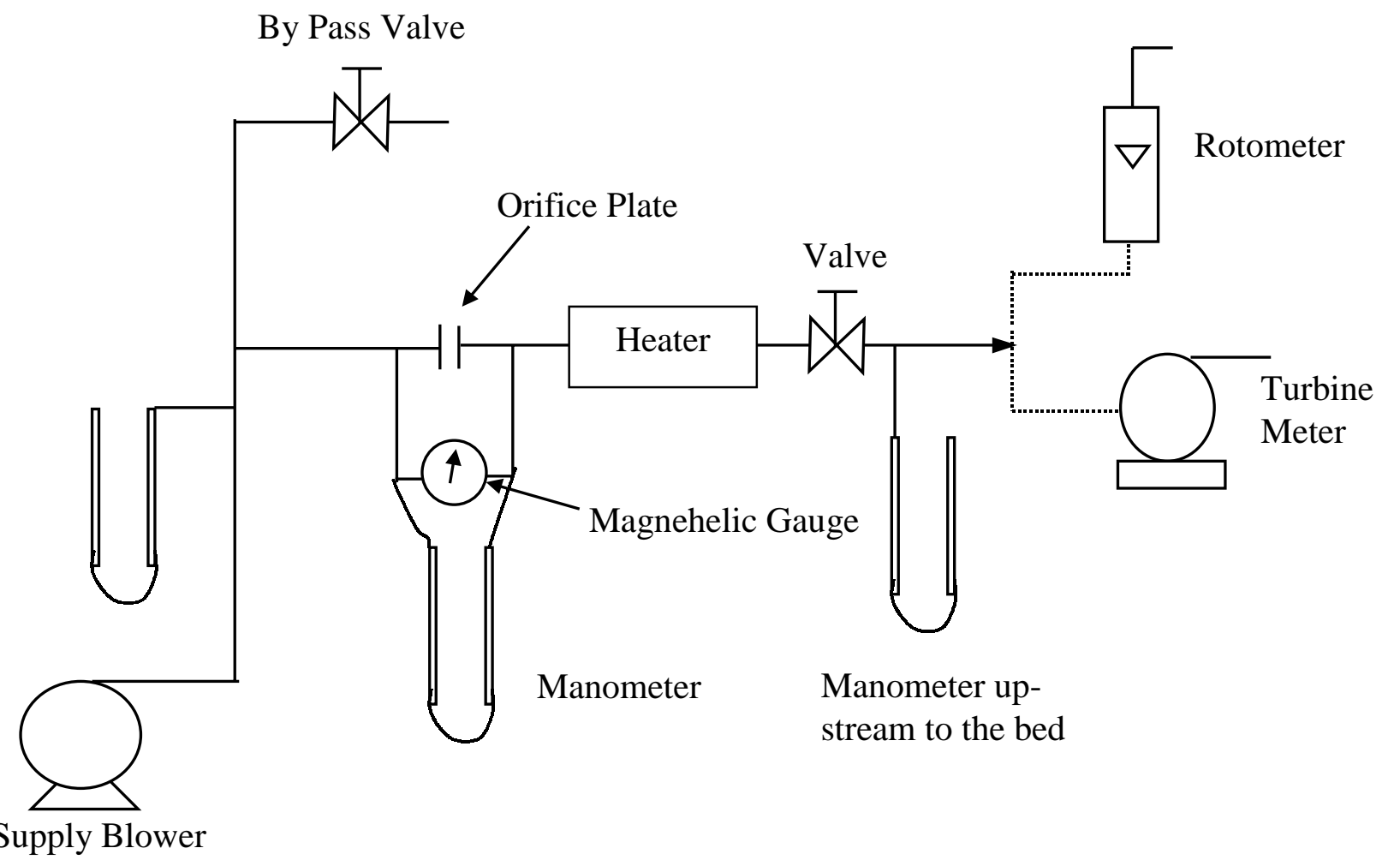

Figure A-1. Figure showing the instrumentation for calibrating the orifice plate in the air supply line. 


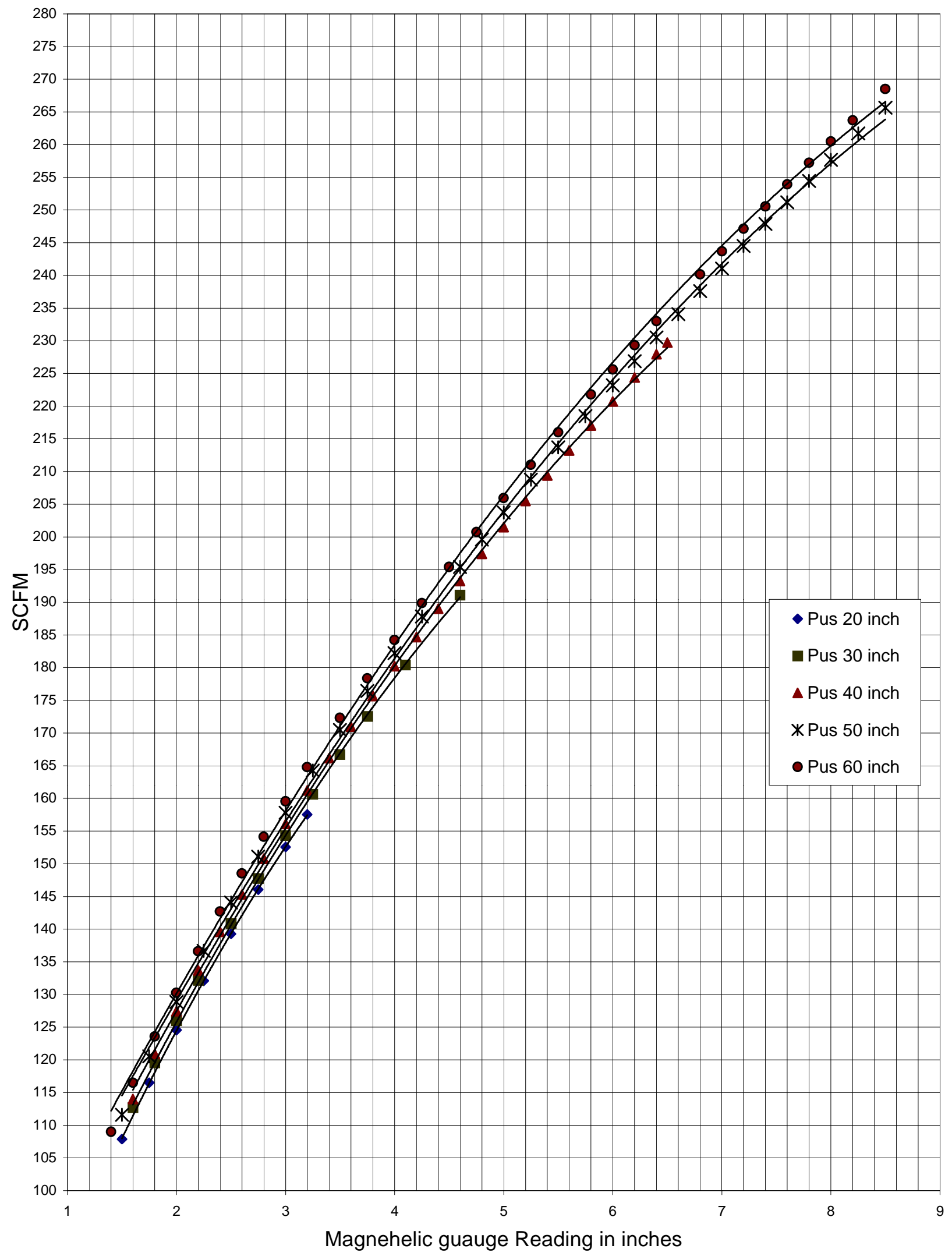

Figure A-2. Calibration curves for the Orifice plate at different upstream pressures $\left(\mathrm{P}_{\mathrm{us}}\right)$ 


\section{Appendix II}

\section{Measurement of voidage in the annulus}

The voidage in the annulus was calculated from the measured absolute and bulk densities. The particles were weighed (electronic balance, model XE-100A, Denver Instruments Company, Arvado, Colorado), in groups of 10 and an average weight of an individual tablet was obtained $(0.205 \mathrm{gm})$. The weight of the tablet, thus determined, confirms that specified by the supplier. The bulk density $\left(0.70813 \mathrm{~kg} / \mathrm{m}^{3}\right)$ of the tablets was determined by the un-tapped volume occupied by tablets poured in a graduated beaker and the absolute

density $\left(1.215 \mathrm{~kg} / \mathrm{m}^{3}\right)$ was measured by the actual volume occupied by a known weight of tablets, the voids being filled by a non-penetrating vegetable oil. The details of the result are given in Table A-1, Table A-2 and Table A-3.

The packed bed voidage was calculated to be 0.42 or $42 \%$ using the following relationship.

$$
\begin{aligned}
& \varepsilon=1-\left(\rho_{\text {bulk }} / \rho_{\text {particle }}\right) \\
& \varepsilon=1-(0.708 / 1.215) \\
& \varepsilon=0.42
\end{aligned}
$$


Table A-2.1. Weight measurement data

\begin{tabular}{|c|c|c|c|}
\hline Trial Number & $\begin{array}{c}\text { Number of } \\
\text { Tablets }\end{array}$ & $\begin{array}{l}\text { Weight of } \\
\text { Tablets gm }\end{array}$ & $\begin{array}{c}\text { Weight of one } \\
\text { Tablet gm }\end{array}$ \\
\hline 1 & 10 & 2.026 & 0.2026 \\
\hline 2 & 10 & 2.055 & 0.2055 \\
\hline 3 & 10 & 2.051 & 0.2051 \\
\hline 4 & 10 & 2.058 & 0.2058 \\
\hline 5 & 10 & 2.048 & 0.2048 \\
\hline 6 & 10 & 2.053 & 0.2053 \\
\hline 7 & 10 & 2.040 & 0.2040 \\
\hline 8 & 10 & 2.059 & 0.2059 \\
\hline 9 & 10 & 2.051 & 0.2051 \\
\hline 10 & 10 & 2.046 & 0.2046 \\
\hline & Average & 0.205 & \\
\hline
\end{tabular}

Average weight of one Tablet $=0.205 \mathrm{gm}$ 
Table A-2.2. Measurement of Bulk density

\begin{tabular}{|c|c|c|c|}
\hline Trial Number & $\begin{array}{l}\text { Weight of } \\
\text { Tablets gm }\end{array}$ & $\begin{array}{c}\text { Volume } \\
\text { occupied ml }\end{array}$ & $\begin{array}{l}\text { Bulk density } \\
\text { gm/ml }\end{array}$ \\
\hline 1 & 260.1 & 362 & 0.718 \\
\hline 2 & 205 & 285 & 0.719 \\
\hline 3 & 328 & 462 & 0.709 \\
\hline 4 & 264.1 & 372 & 0.709 \\
\hline 5 & 409.4 & 585 & 0.699 \\
\hline 6 & 321.4 & 455 & 0.706 \\
\hline 7 & 230.7 & 325 & 0.709 \\
\hline 8 & 277.1 & 392 & 0.706 \\
\hline 9 & 201.7 & 285 & 0.707 \\
\hline 10 & 246.4 & 352 & 0.700 \\
\hline & Average & 0.708 & \\
\hline
\end{tabular}

Average bulk density $\rho_{\text {bulk }}=0.708 \mathrm{~kg} / \mathrm{m}^{3}$ 
Table A-2.3 Measurement of Absolute density

\begin{tabular}{|c|c|c|c|c|}
\hline Trial Number & $\begin{array}{l}\text { Weight of } \\
\text { Tablets gm }\end{array}$ & $\begin{array}{l}\text { Bulk volume } \\
\text { occupied ml }\end{array}$ & $\begin{array}{c}\text { Volume of oil } \\
\text { added ml }\end{array}$ & $\begin{array}{c}\text { Absolute } \\
\text { density gm/ml }\end{array}$ \\
\hline 1 & 68.5 & 105 & 46 & 1.161 \\
\hline 2 & 72 & 110 & 50 & 1.200 \\
\hline 3 & 74 & 112 & 52 & 1.233 \\
\hline 4 & 85 & 130 & 61 & 1.231 \\
\hline 5 & 78 & 120 & 57 & 1.238 \\
\hline 6 & 65 & 95 & 43 & 1.250 \\
\hline 7 & 80 & 125 & 59 & 1.212 \\
\hline 8 & 90 & 138 & 63 & 1.200 \\
\hline 9 & 100 & 148 & 67 & 1.234 \\
\hline 10 & 94 & 144 & 65 & 1.189 \\
\hline
\end{tabular}

Average absolute density $\rho_{\text {absolute }}=1.215 \mathrm{~kg} / \mathrm{m}^{3}$ 
Table A-2.4 Measurement of volume of individual tablets

\begin{tabular}{|c|c|c|c|}
\hline Trial Number & $\begin{array}{c}\text { Number of } \\
\text { Tablets }\end{array}$ & $\begin{array}{l}\text { Volume of oil } \\
\text { displaced ml }\end{array}$ & $\begin{array}{l}\text { Volume of } \\
\text { tablet ml }\end{array}$ \\
\hline 1 & 22 & 4 & 0.182 \\
\hline 2 & 46 & 7 & 0.152 \\
\hline 3 & 24 & 4 & 0.166 \\
\hline 4 & 70 & 11 & 0.157 \\
\hline 5 & 10 & 1.8 & 0.180 \\
\hline 6 & 20 & 3.6 & 0.180 \\
\hline 7 & 25 & 4.5 & 0.180 \\
\hline 8 & 28 & 5.0 & 0.178 \\
\hline 9 & 32 & 5.5 & 0.172 \\
\hline 10 & 15 & 2.3 & 0.153 \\
\hline & & Average & 0.170 \\
\hline
\end{tabular}

Average volume of individual tablet $=0.170 \mathrm{~cm}^{3}$ 


\section{Appendix III}

\section{Calibration of the velocity measurement technique using a rotating disk of known velocity and stroboscope}

The accuracy of the imaging system and software used, to determine the velocity of moving tablets in the fluidized bed, was tested by measuring the velocity of a known source with the imaging system and comparing the results.

The known source was a marked disk mounted on a battery-powered drill as shown in Figure A-3. The cameras were mounted on the stand and the distance between the disk and the cameras were set to be $36.2 \mathrm{~mm}$, the same distance between the cameras and the front glass face of the fluidized bed. The drill was started and the rate of rotation was measured with a stroboscope (Nova-Strobe ${ }^{\circledR}$ DA Digital, AC, Monarch Instrument, Amherst, NH).

The actual velocity of a point on the disk was calculated using the formula, $v=r \omega$ where $\mathrm{v}$ is the velocity, $\mathrm{r}$ is the radial distance from the center and $\omega=2 \pi \mathrm{N}$ ( $\mathrm{N}$ is the rps) and compared to the values obtained by using the software. Figure A-3.1 shows a setup of the drill with a graduated disk and the imaging system. The distance between the cameras and the drill was measured to be the same as the distance between the cameras and the inside surface of the glass sheet. The results are shown in Table A-3.1 and Figure A-3.2. Based on the results, the software captures the true velocity within a $95 \%$ confidence interval. 

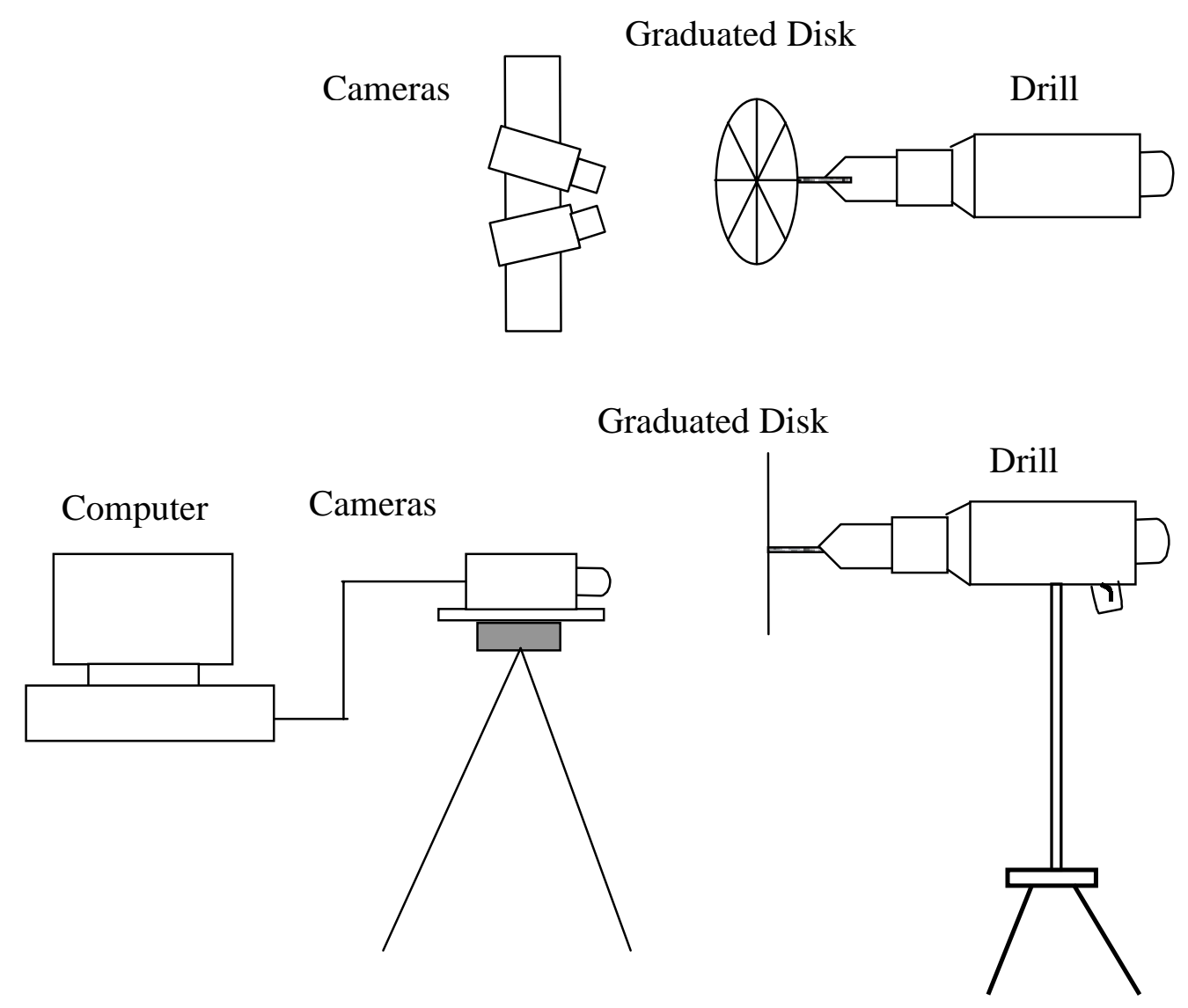

Figure A-3.1. Graduated disk mounted on a battery-powered drill 
Table A-3.1. Velocity measurement values as measured by software and by stroboscope

\begin{tabular}{|c|c|}
\hline Velocity as determined by Software & Velocity as determined by Strobe \\
\hline Mean $=2.61$ & Mean $=2.57$ \\
\hline $\mathrm{CI}_{-0.95}=2.67 \mathrm{~m} / \mathrm{s}$ & $\mathrm{CI}_{-0.95}=2.64 \mathrm{~m} / \mathrm{s}$ \\
$\mathrm{CI}_{+} 0.95=2.54 \mathrm{~m} / \mathrm{s}$ & $\mathrm{CI}_{+0.95}=2.51 \mathrm{~m} / \mathrm{s}$ \\
\hline
\end{tabular}

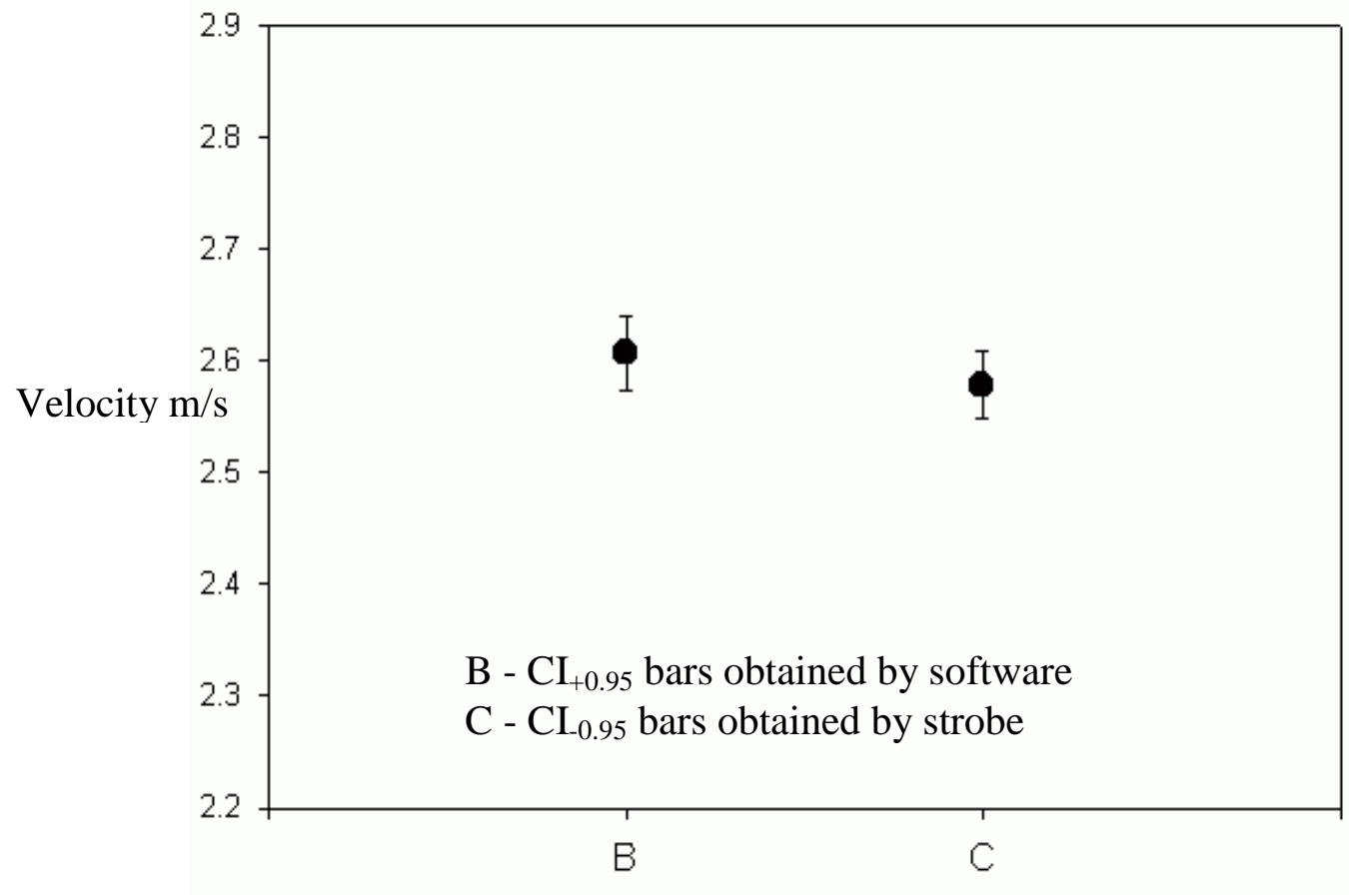

Method of velocity measurement

Figure A-3.2. Plot shows the $\mathrm{CI}_{0.95}$ bars associated with the velocity measurements using the software and the calculated values using the strobe overlap. 


\section{Appendix IV}

\section{Apparent Depth of Field (ADOF) Calibration}

The apparent depth of field is the range of distance over which the camera can record images from the point of focus. The greater the ADOF, the greater is the distance over which the camera can record clear focused images and vice versa. It was necessary to obtain an accurate value of the ADOF, in order that the volume element over which the voidage is to be calculated could be determined. The camera is focused on permanent marks made on the draft-tube so that a fixed reference is always maintained.

The models shown in Figure 3-16, were placed inside the draft tube as shown in Figure A-4.1. The camera was focused on the permanent marks on the draft-tube shown in the figure. The cameras were then moved on the sliding stand to obtain the image of a single model. Each of these models had a different number of tablets with different orientations. The farthest particle recorded by the camera and identified by the software in each of these models was noted and the distance from the front glass sheet was measured. This distance is the calculated ADOF and the average distance was determined to be $1.5 \mathrm{~cm}$. To verify this value of $\mathrm{ADOF}$, the following procedure was carried out. With each model in focus, the routine for determining the voidage, explained in Section 3-5, was carried out. By correlating the number of particles picked up by the camera, and the actual number of particles present within the ADOF $(1.5 \mathrm{~cm})$ from the front glass sheet, we can determine the actual voidage and the voidage obtained using the software. A graph of the actual number of particles vs. the number picked by the software is shown in Figure A- 4.2. 


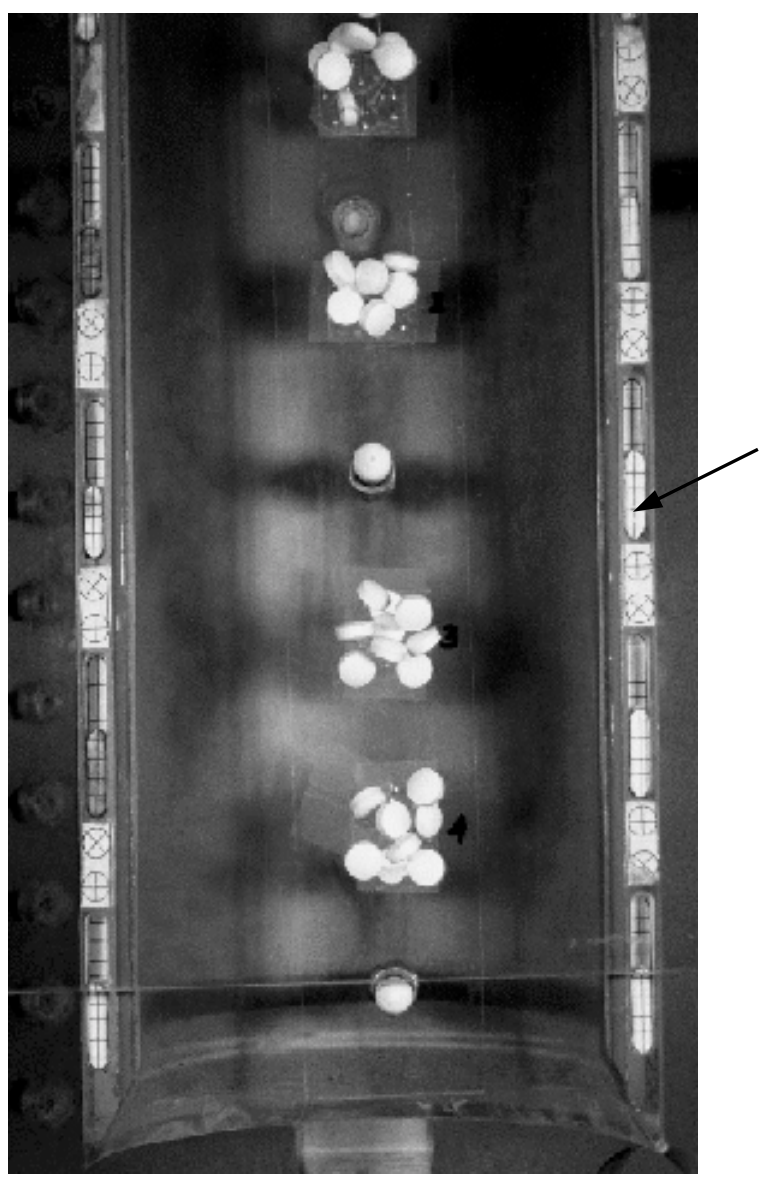

Permanent marks on the draft-tube used as frame of reference

Figure A-4.1. Picture of models placed in the draft-tube.

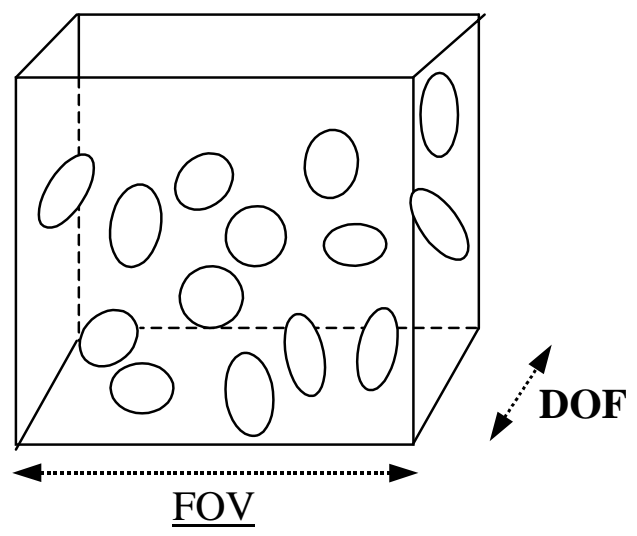

Figure A-4.2. Diagram showing the DOF and FOV. 


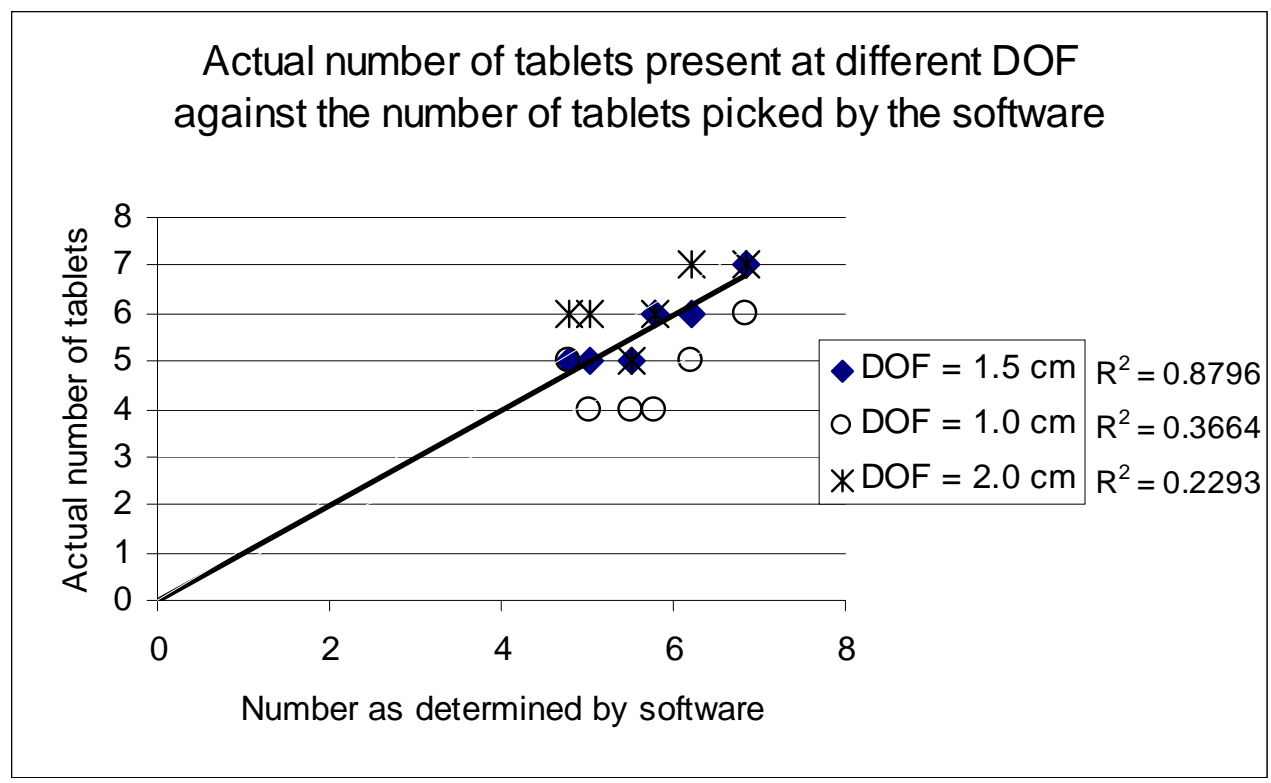

Figure A-6. Regression plot showing the actual number of tablets present at different depth of fields (DOF) against the number of tablets as determined by the software. 


\section{Appendix V}

\section{Alignment of Cameras and Calibration of Pixel Size}

\section{Calibration of Pixel Size}

The imaging system consisted of two CCD cameras (Sony XC - 75 CE CCD Video camera, Sony Inc.,), equipped with Ultrak TV lensess (50 mm and aperture f 1.3) with $8 \mathrm{~mm}$ extension rings, connected to separate frame grabbers (PX610 Precision Frame Grabber, Imagenation Corporation, Beaverton, Oregon). The images acquired by these cameras are viewed on the screen of a computer (486DX, 33 MHZ, Keydata International Inc., S. Plainfield, NJ). The custom software written in Microsoft® Visual Basic used to trigger the frame grabbers and the camera also calibrates the pixel size to actual distance measured by the following routine.

Camera 1 is used as a reference for both pixel calibration and alignment. Camera 1 is focused on an object of known dimensions (a circle with cross hair of known diameter) was used. The dimension of the focused object is entered into the program. After obtaining a focused image, the calibrate pixel command is invoked. The software asks the user to click on the left and right edges of the object. The software now counts the number of pixels between the two edges. With these two values, the actual distance between the two edges and the number of pixels required to measure the distance, the software directly gives the actual distance one pixel represents. This value was determined to be one pixel $=5.825 \times 10^{-2} \mathrm{~m}$, which was maintained constant for all the runs. 


\section{Alignment of cameras}

The alignment of the cameras was a lengthy process and the following sequence of events occurs before the final alignment is made and corrected for parallax error.

\section{1) Positioning the Camera Stand}

The optimum distance between the camera and the front glass sheet of the fluidized bed was first determined. With variation in focusing caused by the camera lens and the extension rings, several distances were tried before the distance between the cameras and the fluidized bed was set. The criteria for this was to obtain a clear focused image and obtain a field of view equal to the imaginary grid boxes of dimension 20 x $20 \mathrm{~mm}$. After finalizing the distance between the cameras and the fluidized bed, permanent marks were made on the floor where the camera stand was placed and this position was used for all the experimental runs.

\section{2) Placing the Cameras on the Sliding Stand Mounted on the Camera Stand}

The two cameras were placed on the sides of a steep isosceles triangle as shown in Figure $3-15$, in order to minimize parallax effects. The greater the angle at the apex, $\theta$, the greater is the difference between the images from the two cameras. Both the cameras were focused on the same object and effort was made to obtain the same FOV in both the cameras. Camera 1 was used as the reference camera. At this point, the calibrate alignment command is invoked in the software. The software prompts the user to click on any particular fixed point (permanent marks made on the draft-tube shown in Figure A-4.1 were used) on the image obtained from camera 1, and then the software prompts the user to click on the same fixed point on the image obtained from camera 2. The 
software determines the relative position of the two points clicked in the two images and offsets the image obtained by camera 2 to match exactly the image obtained from camera 1. After this step, the accuracy of the alignment was verified by focusing the cameras on stationary objects (a packed bed filled with the tablets) and running routines for the velocity measurement. Random tablets are picked and the distance moved by these particles in the time lag between the cameras determined. This value should be zero as the tablets are not in motion. This process of alignment and verifying is repeated until the software returns a value of 0 or close to 0 (maximum error allowed was a value equal to two pixel sizes).

Once these processes of pixel size calibration and camera alignment were completed, the cameras were secured and these positions were marked. The position and alignment of the cameras were closely reproduced for all the experimental runs. 


\section{Appendix VI}

\section{Velocity Vector and Voidage Calculations}

\section{Velocity Vector}

Section 3-5 explains the process of obtaining velocity data. The software returns two values $\mathrm{u}_{\mathrm{x}}$ and $\mathrm{u}_{\mathrm{y}}$ for each velocity measurement. These values are stored in the computer that can later be retrieved using appropriate tools. The Microsoft $($ Excel software package was used to calculate the velocity vector from the data obtained. The values $\mathrm{u}_{\mathrm{x}}$ and $\mathrm{u}_{\mathrm{y}}$ are given in units of meters/second.

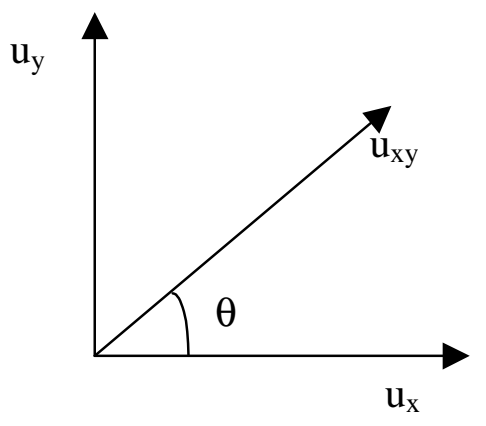

Sample calculation

$$
\begin{gathered}
\mathrm{u}_{\mathrm{x}}=0.627 \mathrm{~m} / \mathrm{s} \quad \mathrm{u}_{\mathrm{y}}=0.905 \mathrm{~m} / \mathrm{s} \\
\mathrm{u}_{\mathrm{xy}}=\left(\mathrm{u}_{\mathrm{x}}^{2}+\mathrm{u}_{\mathrm{y}}^{2}\right)^{1 / 2} \\
\mathrm{u}_{\mathrm{xy}}=\left(0.627^{2}+0.905^{2}\right)^{1 / 2} \\
\mathrm{u}_{\mathrm{xy}}=1.10 \mathrm{~m} / \mathrm{s} \\
\text { Angle } \theta=\operatorname{Tan}^{-1}\left(\mathrm{u}_{\mathrm{y}} / \mathrm{u}_{\mathrm{x}}\right) \\
\theta=55.2^{0}
\end{gathered}
$$

Velocity vector $\mathrm{u}_{\mathrm{xy}}=1.10 \mathrm{~m} / \mathrm{s}$

$$
\text { Angle } \theta=55.2^{0}
$$




\section{Voidage Calculations}

Principles of voidage measurement are explained in section 3-6. For each box in the imaginary grid, the software returns an average number of particles in the FOV and DOF. Thus, we know the volume element of the box over which the camera and software record particles and the number of particles in that volume. Thus, we can obtain a value for voidage, a sample calculation is shown below.

Average number of particles in the volume considered $=7.8$

Volume of the box in which the particles were recorded $=2 \mathrm{~cm} \times 2 \mathrm{~cm} \times 1.5 \mathrm{~cm}$

Volume of one tablet $=0.170 \mathrm{~cm}^{3}$ (from Appendix II, Table A-4)

$$
\begin{aligned}
& \varepsilon=1-\text { volume of particles/volume considered } \\
& \varepsilon=1-7.8 * 0.170 / 2 * 2 * 1.5 \\
& \varepsilon=0.78 \\
& \varepsilon=78 \%
\end{aligned}
$$




\section{Appendix VII}

Scanning spectra of Blue Dye \# 1 in Water.

By using the scanning spectra function from the PECSS software, the maximum absorbance for FD\&C Blue dye \# 1was observed at a wavelength of $629 \mathrm{~nm}$. This spectra is shown below in Figure-7.1.

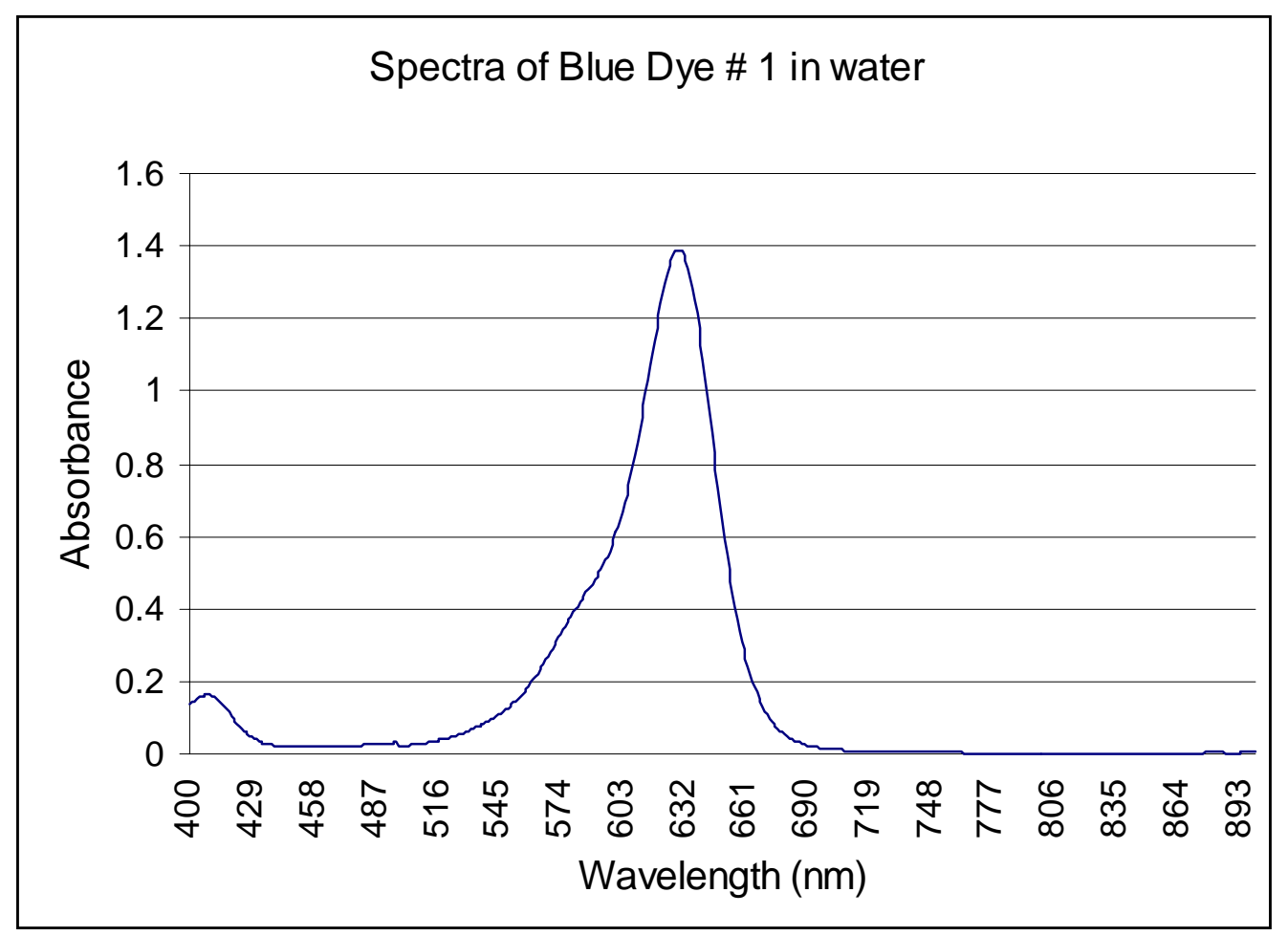

Figure A-7.1 Scanning spectra of Blue Dye \# 1 in Water 


\section{Appendix VIII}

Table A-8.1. Data for calibration of the spectrometer and the calibration curve at normal concentrations

\begin{tabular}{|c|c|}
\hline $\begin{array}{c}\text { Standard Blue Dye } \\
\text { Concentration }(\mathrm{mg} / \mathrm{ml})\end{array}$ & Absorbance Value \\
\hline 0 & 0 \\
\hline 0.0010 & 0.1588 \\
\hline 0.0020 & 0.2731 \\
\hline 0.0050 & 0.6742 \\
\hline 0.0100 & 1.2452 \\
\hline 0.0200 & 2.3845 \\
\hline
\end{tabular}

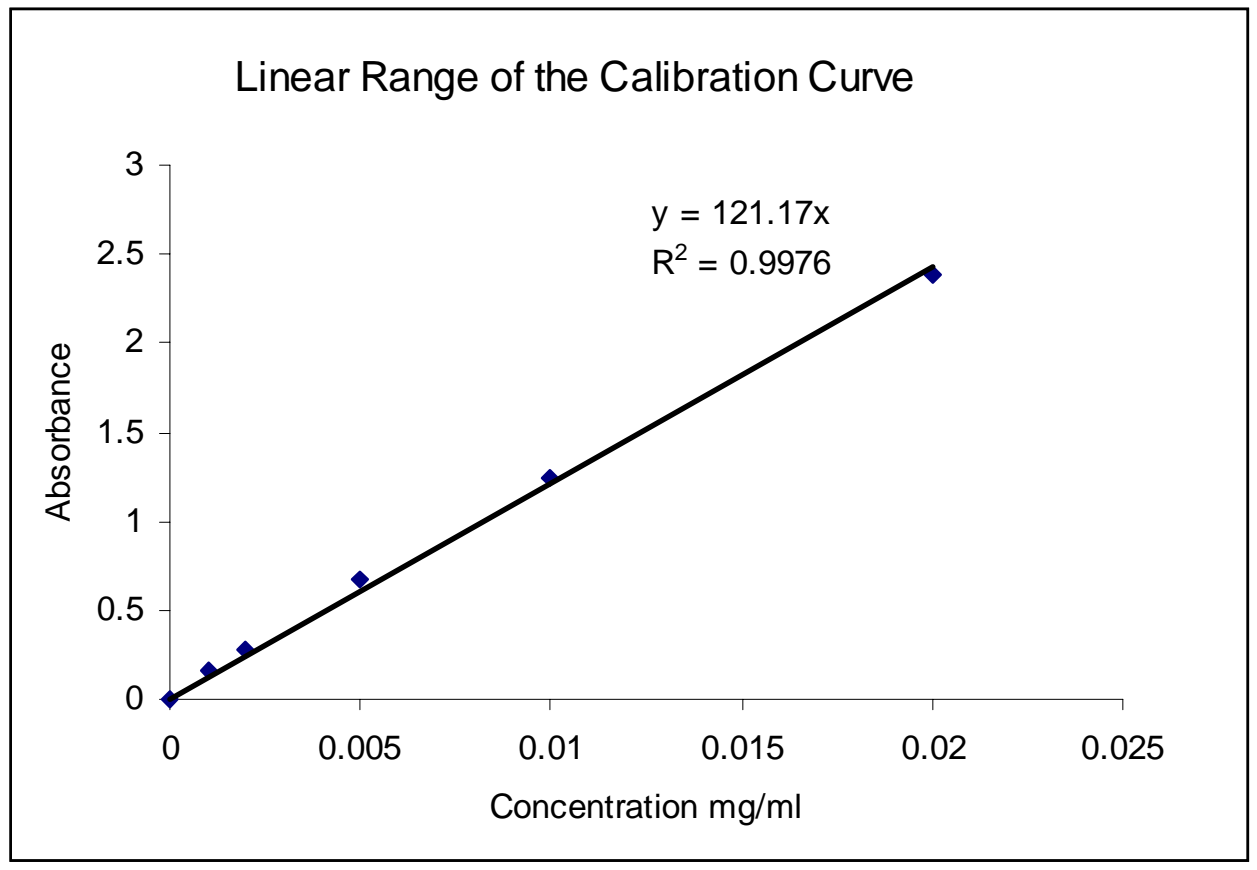

Figure A-8.1 Calibration curve for spectrophotometer at normal concentrations of blue dye 


\section{Appendix IX}

Table A-9.1. Data for the calibration of the spectrophotometer and the calibration curve for low concentrations

\begin{tabular}{|c|c|}
\hline $\begin{array}{c}\text { Standard Blue dye } \\
\text { Concentration }(\mathrm{mg} / \mathrm{ml})\end{array}$ & Absorbance Value \\
\hline 0 & 0.1276 \\
\hline 0.0001 & 0.1198 \\
\hline 0.0001 & 0.1277 \\
\hline 0.0001 & 0.2096 \\
\hline 0.0002 & 0.2148 \\
\hline 0.0002 & 0.2123 \\
\hline 0.0002 & 0.3357 \\
\hline 0.0003 & 0.3378 \\
\hline 0.0003 & 0.2498 \\
\hline 0.0003 & 0.2484 \\
\hline 0.0003 & 0.373 \\
\hline 0.0004 & 0.3828 \\
\hline 0.0004 & 0.4296 \\
\hline 0.0004 & \\
\hline & \\
\hline
\end{tabular}




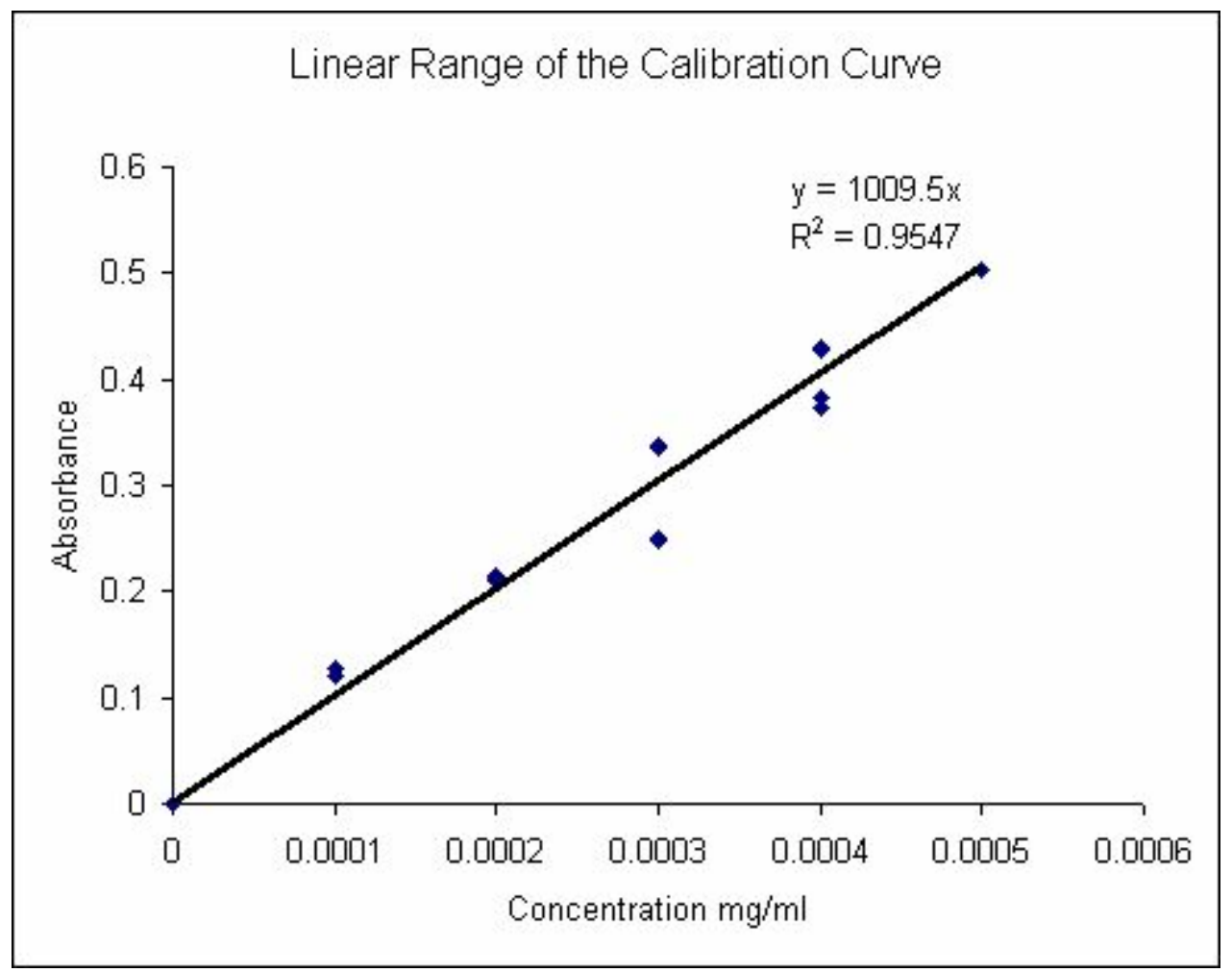

Figure A-9.1 Calibration curve for spectrophotometer at lower concentrations of blue dye 


\section{Appendix X}

\section{Determination of Coating Formula}

$\begin{array}{ll}\text { The flow rate of the coating solution } & =10 \mathrm{ml} / \mathrm{min} . \\ \text { Time to coat } & =60 \mathrm{~min} . \\ \text { Volume of Coating to be used } & =600 \mathrm{ml} \\ \text { Density of the coating media } & =1.00 \mathrm{~g} / \mathrm{ml}, \text { Surelease } \\ \text { Mass of the coating material } & =50550=550 \mathrm{gm} \\ \text { Amount of water added } & =2.5 \mathrm{gm} \\ \text { Amount of Blue dye added } & =552.5 \mathrm{gm} \\ \text { Total weight of coating mixture } & =0.205 \mathrm{gm} \\ \text { Total weight of the particles to be coated } & =3.675 \mathrm{~kg} \\ \text { Average weight of each particle } & =17.93 * 10^{3} \\ \text { Average number of particle in the bed } & =2.5 / 17.93 * 10^{3}=1.4 * 10^{-4} \mathrm{gm} \\ \text { Average wt of blue dye/particle } & \end{array}$

$15 \mathrm{ml}$ of water was used to dissolve the blue dye from the tablet, thus the blue

dye concentration will be

$$
\begin{aligned}
& =0.14 \mathrm{mg} / 15 \mathrm{ml} \\
& =0.009 \mathrm{mg} / \mathrm{ml}
\end{aligned}
$$

The calculations above are based on $100 \%$ efficiency. Considering an efficiency rage of $70 \%$ to $80 \%$, the concentration of blue dye/tablet will fall in the range of $0.0063 \mathrm{mg} / \mathrm{ml}$ to $0.0072 \mathrm{mg} / \mathrm{ml}$. The optimum concentration required to obtain a good absorbance value was in the rage of $0.006 \mathrm{mg} / \mathrm{ml}$ to $0.009 \mathrm{mg} / \mathrm{ml}$. 


\section{Coating Efficiency Calculations}

\section{Appendix XI}

Example 1: Coating efficiency calculation for the case with modified deflector 1

Amount of Blue dye used $\quad=2.5 \mathrm{gm}$

Total weight of the particles to be coated $=3.675 \mathrm{~kg}$

Average weight of each particle $\quad=0.205 \mathrm{gm}$

Average number of particle in the bed $=3.675 * 10^{3} / 0.205=17.93 * 10^{3}$

Average amount of blue dye coated on tablet (obtained from the 100 samples

analyzed for blue dye content $\quad=0.1137 \mathrm{mg}$

Total amount of blue dye accounted for $=17.93 * 10^{3} * 0.1137$

$=2038.3 \mathrm{mg}$

$\%$ coating efficiency $\quad=(2038.3 / 2500) * 100$

$=82 \%$

Example 2: Coating efficiency calculation for the case with no deflector

Amount of Blue dye used

$=2.5 \mathrm{gm}$

Total weight of the particles to be coated $=3.285 \mathrm{~kg}$

Average weight of each particle $\quad=0.205 \mathrm{gm}$

Average number of particle in the bed $=3.505 * 10^{3} / 0.205=17.09 * 10^{3}$

Average amount of blue dye coated on tablet (obtained from the 100 samples

analyzed for blue dye content $\quad=0.1212 \mathrm{mg}$

Total amount of blue dye accounted for $=17.09 * 10^{3} * 0.1212$

$=2072.2 \mathrm{mg}$

$\%$ coating efficiency

$=(2072.2 / 2500) * 100$

$=82.8 \%$ 


\section{Appendix XII}

Calibration of the peristaltic pump used for pumping the coating solution

Table-11.1 Calibration data for the peristaltic pump.

\begin{tabular}{|c|c|}
\hline Pump Reading & Pumping Rate lit/min \\
\hline 1.0 & 0.0370 \\
\hline 1.0 & 0.0370 \\
\hline 1.0 & 0.0370 \\
\hline 0.75 & 0.0279 \\
\hline 0.75 & 0.0279 \\
\hline 0.75 & 0.0278 \\
\hline 0.5 & 0.0186 \\
\hline 0.5 & 0.0186 \\
\hline 0.5 & 0.0186 \\
\hline 0.25 & 0.0094 \\
\hline 0.25 & 0.0091 \\
\hline 0.25 & 0.0092 \\
\hline 0.15 & 0.0050 \\
\hline
\end{tabular}




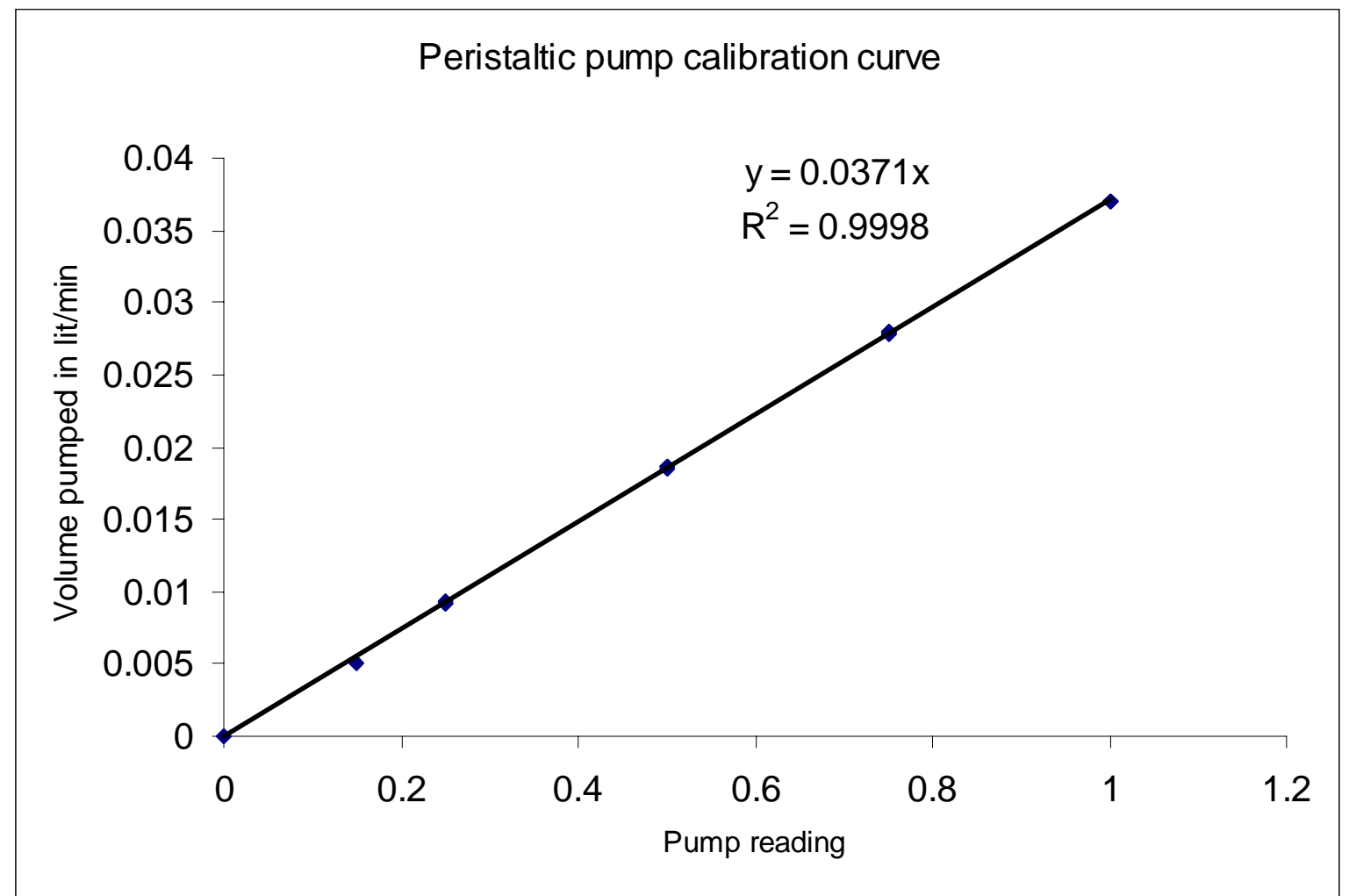

Figure A-11.1 Calibration curve for peristaltic pump 


\section{Appendix XIII}

\section{Calculation of Amount of Blue Dye Coated during the Pulse Test}

During the pulse test, the tablets pass through the spray zone only once and the amount of blue dye coated on them is very small, making it difficult to measure. To obtain blue dye concentrations in the detectable range the solution used for pulse tests was saturated with blue dye and the amount of water used to dissolve the blue off the tablets was kept at the lowest possible amount. Even so, the blue dye content fell in the lower part of the detectable range of the spectrophotometer and a low concentration calibration curve shown in Appendix IX had to be used. The software, PECSS version 4.0, used with the spectrometer could calculate values only up to the fourth decimal value and hence when values less than that were calculated, they were rounded off to 0. Hence, even though the spectrometer detected different values of absorbance for the samples, the software sometimes gave the same (zero) concentration values. Therefore, for the pulse tests the value of blue dye concentration was calculated by substituting the value of absorbance in a linear equation that related absorbance to blue dye concentration shown in the Appendix IX rather than using the results from the PECCS software.

Equation relating the absorbance to concentration obtained from the graph is

Concentration $\mathrm{mg} / \mathrm{ml}=$ Absorbance $/ 1009.5$........From Graph A-9.1

For example:

If the absorbance value obtained was $=0.0015$

Concentration

$=0.0015 / 1009.5=1.48588 \mathrm{E}-06 \mathrm{mg} / \mathrm{ml}$

Amount of blue dye mg/tablet (when dissolved in $\mathrm{ml}$ of water) $=(3) * 1.48588 \mathrm{E}-06$

$$
=4.45765 \mathrm{E}-06 \mathrm{mg} / \mathrm{tablet}
$$




\section{Appendix XIV}

\section{Obtaining Values for Voidage by Linear Interpolation}

The voidage values obtained from the runs were the average voidage data for a box of FOV $20 \mathrm{~mm}$ x $20 \mathrm{~mm}$ as explained in section 3-6. By representing these values on a voidage map, using shades of gray with the intensity proportional to the voidage in the region, it was observed that the transition between the boxes was very abrupt. To overcome this and to make a pictorial representation that would show a smooth transformation between boxes, the box of $20 \mathrm{~mm}$ x $20 \mathrm{~mm}$ was divided into 9 boxes of equal size and the box in the center was assigned the measured value for the original box as shown in Figure A-13.1. The voidage values for the surrounding 8 boxes were obtained by linear interpolation between the adjacent boxes.

\begin{tabular}{|l|l|}
\hline 0.85 & 0.95 \\
& \\
\hline
\end{tabular}

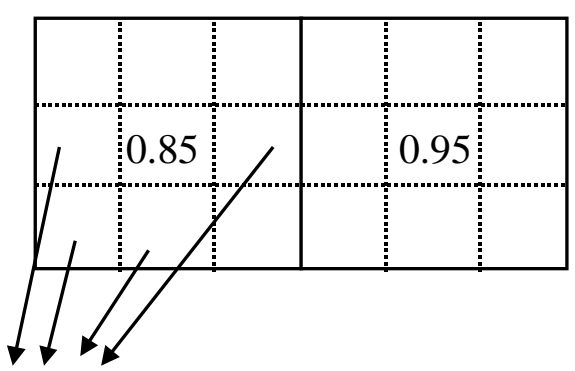

Data obtained by interpolation

Figure A-13.1. Schematic diagram showing how the values are assigned to the box in the center. Values for all the other boxes are obtained by linear interpolation. 
As an example, the calculation to determine the voidage value for the shaded box, from the values in the adjacent boxes, is shown below.

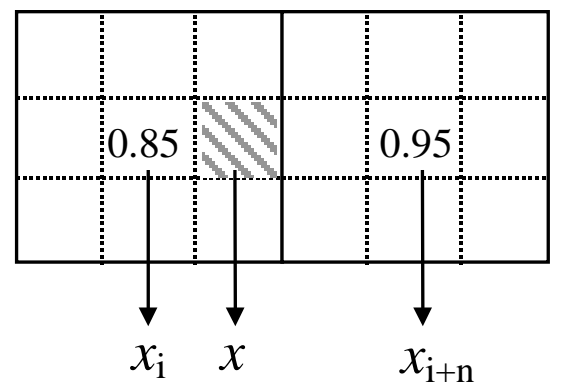

The equation used for this interpolation is shown below

$$
\frac{x-x_{i}}{x_{i+n}-x_{i}}=\frac{\varepsilon_{x}-\varepsilon_{x_{i}}}{\varepsilon_{x_{i+n}}-\varepsilon_{x_{i}}}
$$

A similar form of this equation is used to interpolate in the vertical direction. For boxes lying around the edge of the bed, linear extrapolation is used. 


\section{Appendix XV}

\section{Solids Mass Flow Calculations in the Draft-Tube and Annulus}

\section{Mass flow calculations in the spout (Draft-tube)}

Solids mass flow rate in the draft-tube and the annulus were calculated using numerical integration. The semicircular draft-tube was divided into two and the mass flow in one half was determined by numerical integration and multiplied by two to obtain the mass flow through the draft-tube.

Volumetric flow rate through a half-cylinder can be obtained by the equation A.1

Volume flow $\quad v_{d f t}(z)=\frac{\pi}{2} \int_{0}^{r_{d_{i}}} u_{d f t, z}\left(1-\varepsilon_{d f t}\right) r d r$

Mass flow

$$
\mathrm{m}_{\mathrm{dft}}=\mathrm{v}_{\mathrm{dft}} * \rho_{\mathrm{particcle}}
$$

A plot of $\pi / 2 * u_{\mathrm{dft}}\left(1-\varepsilon_{\mathrm{dft}}\right) \mathrm{r}$ vs. $\mathrm{r}$ is made and the area under the curve (gives the volumetric flow rate) is numerically approximated using Simpson's $1 / 3^{\text {rd }}$ rule.

$$
\begin{aligned}
& \mathrm{I}=\int_{a}^{b} f(x) d x \cong \frac{h}{3}\left[f\left(x_{0}\right)+4 f\left(x_{1}\right)+f\left(x_{2}\right)\right] \\
& \mathrm{h}=(\mathrm{b}-\mathrm{a}) / 2 \\
& \mathrm{~h}-\text { Step size }
\end{aligned}
$$

$\mathrm{a}, \mathrm{b}-$ are the lower and upper limits of the integration 
Simpson's $1 / 3^{\text {rd }}$ rule was used because of its simplicity and having sufficient number of subintervals for good accuracy.

Example Calculation of Solid Mass Flow Rate in the Spout Region using Microsoft Excel The values of $/ 2 * u_{\text {dft }}(1-\varepsilon) r$ and $r$ is plotted and a graph similar to the one shown in Figure A-14 is obtained. The function $y=f(x)$ is obtained using the software.

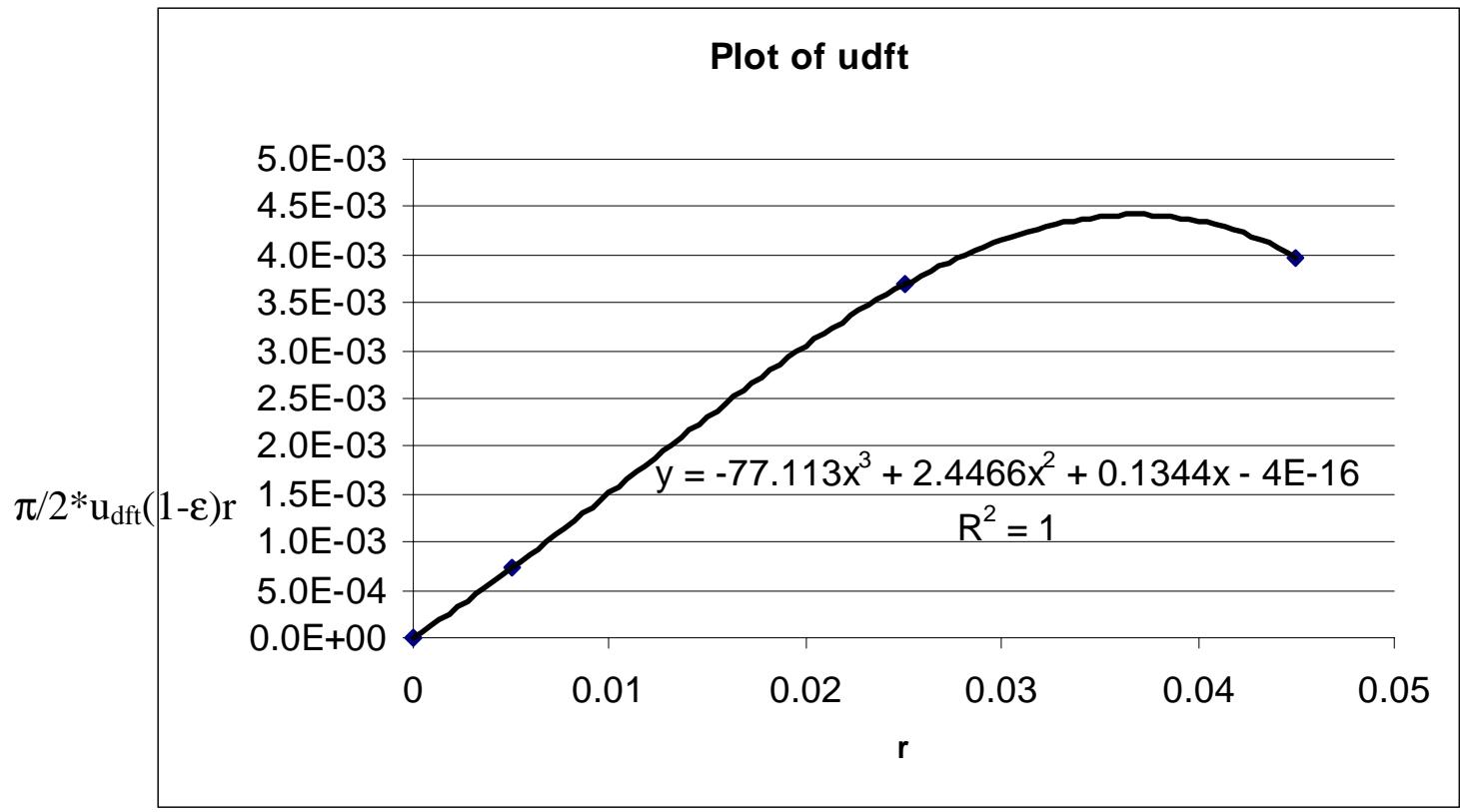

Figure A-14. Plot of $\pi / 2 * \mathrm{u}_{\mathrm{dft}}(1-\varepsilon) \mathrm{r}$ and $\mathrm{r}$ at a height of $14 \mathrm{~cm}$ from the distributor plate

$$
f(x)=-77.113 x^{3}+2.446 x^{2}+0.1344 x-4 e^{-16}
$$

Now equation A.4 is substituted into equation A-3. and the value of I is computed.

$$
=\frac{h}{3}\left[f\left(x_{0}\right)+4 f\left(x_{1}\right)+f\left(x_{2}\right)\right]
$$




$$
\begin{array}{lcl}
\mathrm{x}_{0}=0.005 \quad \mathrm{x}_{1}=0.025 & \mathrm{x}_{2}=0.045 \\
\mathrm{~h}=(0.045-0.005) / 2=0.02 &
\end{array}
$$

Substituting the values into equation A.5 the value of I is determined.

$$
\begin{aligned}
& \mathrm{I}=0.000129573 \\
& \mathrm{v}_{\mathrm{dft}}=2 *(0.000129573)=2.59 \times 10^{-4} \mathrm{~m}^{3} / \mathrm{s}
\end{aligned}
$$

$$
\begin{aligned}
& \text { Mass flow }=\mathrm{v}_{\mathrm{dft}} * \rho_{\text {particle }} \\
& \text { Mass flow }=2.59 \times 10^{-4} * 1.215 * 10^{3}\left(\mathrm{~m}^{3} / \mathrm{s}\right)\left(\mathrm{kg} / \mathrm{m}^{3}\right) \\
& \text { Mass flow }=0.32 \mathrm{~kg} / \mathrm{s}
\end{aligned}
$$

The mass flux at different heights from the distributor plate is calculated in a similar fashion and then they are averaged to obtain the average mass flux in the draft-tube.

\section{Mass flow calculations in the annulus.}

The voidage in the annulus was assumed to be equal to the packed bed voidage was also assumed a constant. The downward velocity of the particles in the annulus was assumed the same across the annulus and assumed a constant. With the above assumptions of constant voidage and velocity across the annulus the equation A.1 can be written as

Volume flow $\quad v_{\text {anul }}(z)=\frac{\pi}{2} u_{\text {anul, } z}\left(1-\varepsilon_{\text {anul }}\right) \int_{r_{d_{o}}}^{R} r d r$

This equation can now be integrated directly and the mass flow rate can be determined by multiplying the value obtained with the particle density. 
Mass flow $\quad \mathrm{m}_{\mathrm{anul}}=\mathrm{v}_{\mathrm{anul}} * \rho_{\text {particcle }} \quad$ A.7

Substituting values into equation A.6

$$
\begin{aligned}
& \mathrm{v}_{\text {anul }}=\pi / 2(0.054 \mathrm{~m} / \mathrm{s})^{*}(1-0.42) \int_{6.35}^{11.45} r d r \\
& \mathrm{v}_{\text {anul }}=\pi / 2(0.054 \mathrm{~m} / \mathrm{s})^{*}(1-0.42) *\left\{\left[(0.1145)^{\wedge} 2-(0.0635)^{\wedge} 2\right] / 2\right\} \\
& \text { Mass flow }=2.23 \times 10^{-4} \mathrm{~m}^{3} / \mathrm{s} * 1.215 \times 10^{3} \mathrm{~kg} / \mathrm{m}^{3}
\end{aligned}
$$

$$
\text { Mass Flow }=0.273 \mathrm{~kg} / \mathrm{s}
$$




\section{Appendix XVI}

\section{Photographs of the Fluidized Bed}

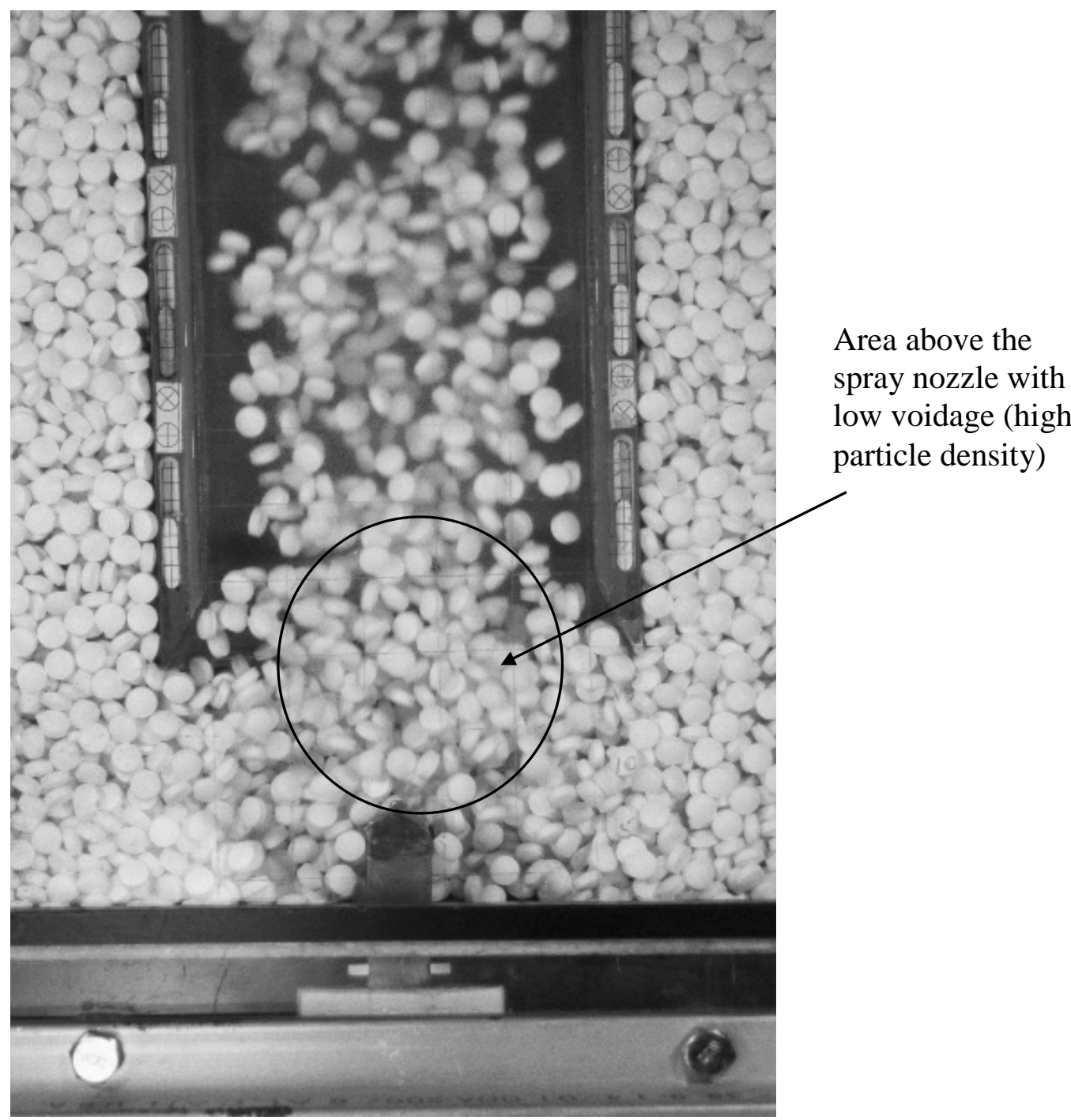

Figure A-17.1 Photograph of the fluidized bed at high gap height $(7.4 \mathrm{~cm})$ and no deflector. 


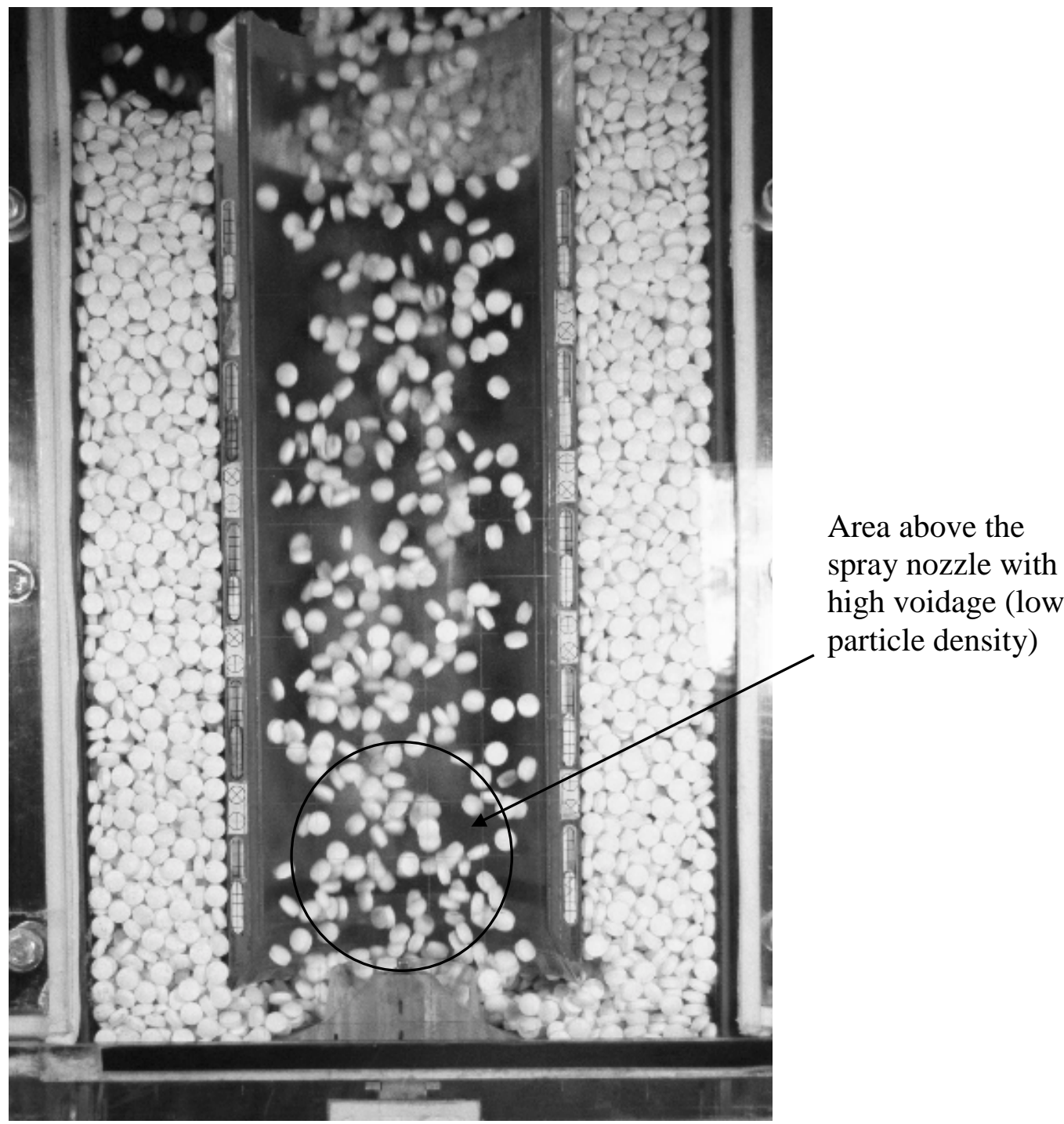

Figure A-17.2 Photograph of the fluidized bed at low gap height $(2.7 \mathrm{~cm})$ and modified deflector 1 . 


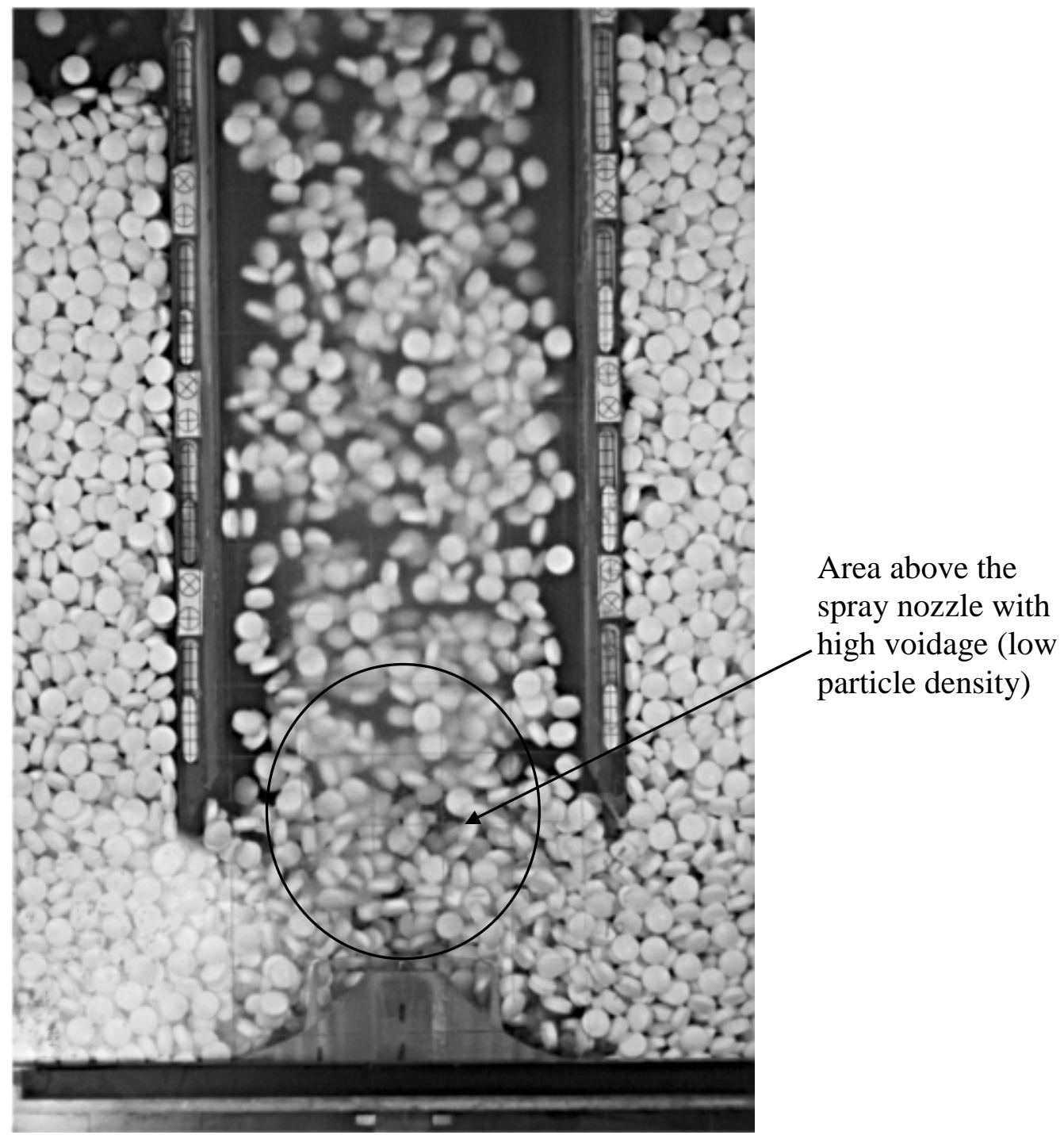

Figure A-17.3 Photograph of the fluidized bed at high gap height $(7.4 \mathrm{~cm})$ and modified deflector 1 . 


\section{Appendix XVII}

\section{Photographs of the two Distributor plates used}
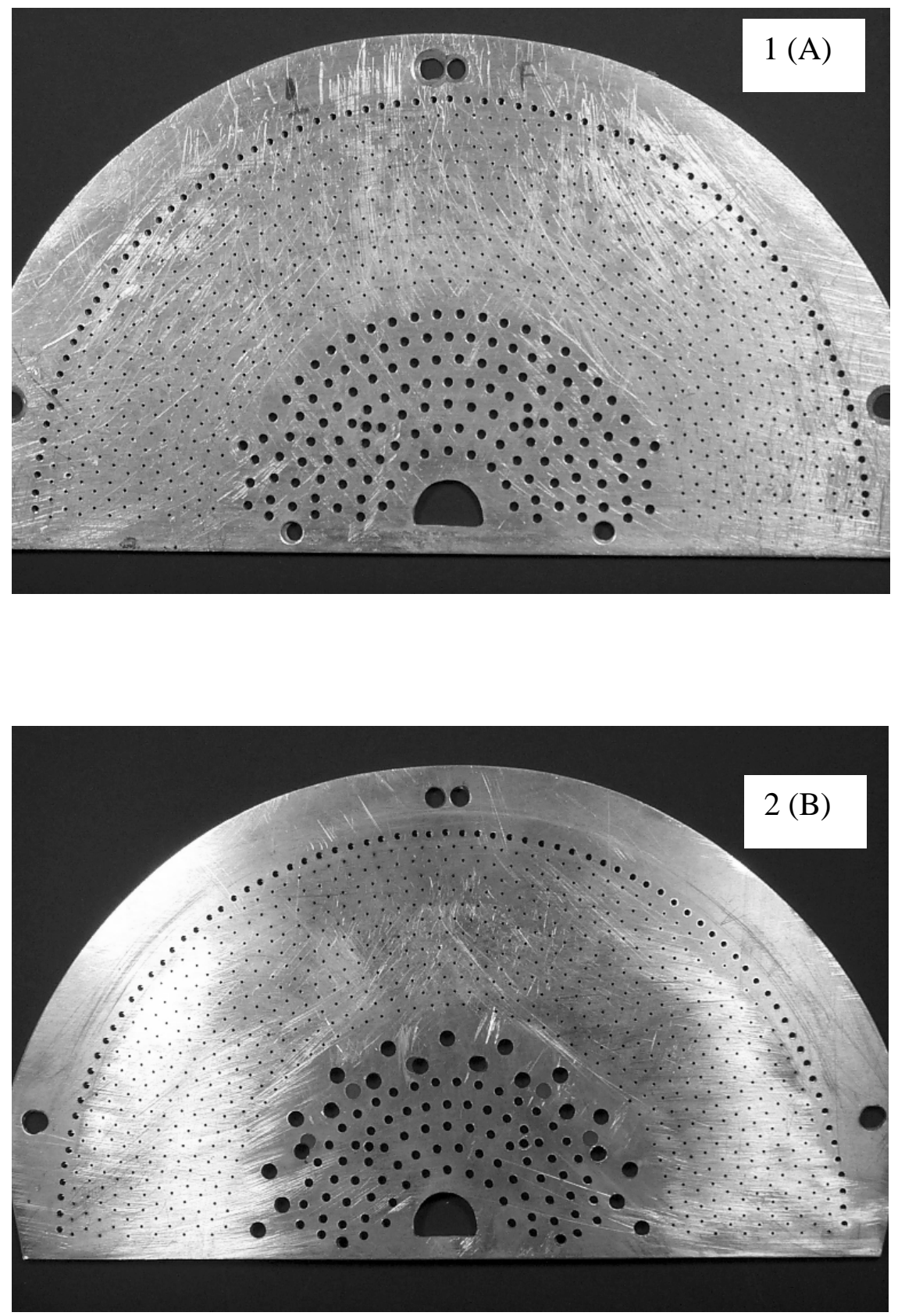

Figure 18-1. Photographs of Distributor plate 1 and Distributor plate 2 , respectively.

Distributor Plate 1(A): Ratio of inner to outer area $=0.83$

Distributor Plate 2(B): Ratio of inner to outer area $=0.92$ 